\title{
Las Prácticas Corporales, un Camino a la Prevención
}

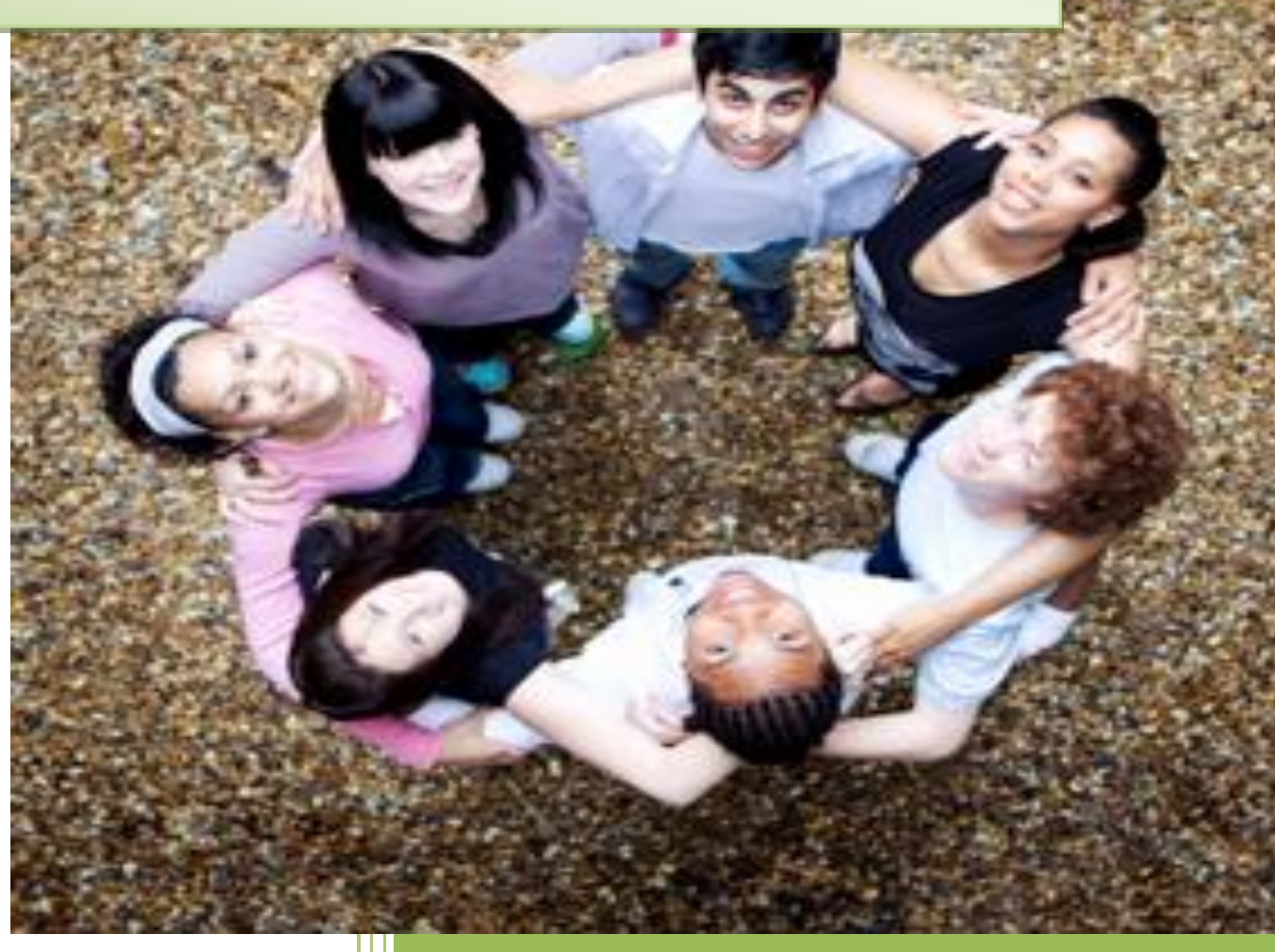

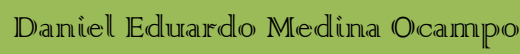

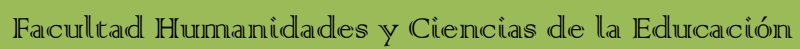

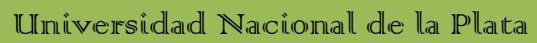
Alburill dee 20onll 


\section{LAS PRÁCTICAS CORPORALES, UN CAMIJNO $\mathcal{A} \mathcal{L} \mathcal{A}$ PREVEJVIÓN}

\&l Dresente trabajo de Tesis, fue elaborado por el estudiante Daniel \&uAuardo Crectina Ocampo como último ejercicio académico, previo a la obtención del título de CKagister en \&uducación Porporal. Sse reatizó en la ciudad de @bagué, en Polombia; se encuentra abiento a todos aquellos que de manera incansable trabajan para prevenir las conductas drogodependientes, ofreciendo a la \&ducación Porporal como un camino para lograrlo. 


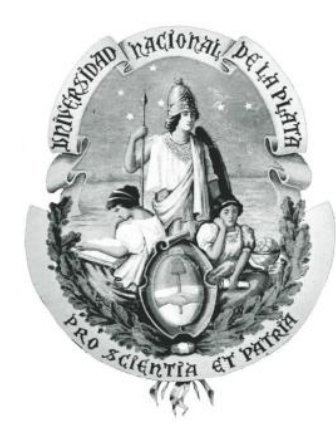

\title{
Zeniversidad Wacional de la Dlata
}

Facultad de OHumanidades y Fiencias de la E ducación

Craestría en Exducación Porporal

\author{
Director de la Craestría \\ RICARDO LUIS CRISORIO
}

\author{
Pomité Asesor

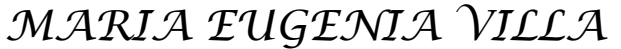

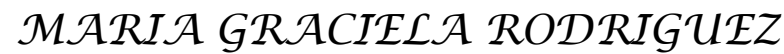

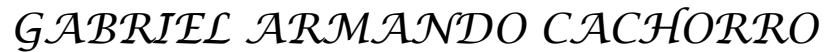 \\ $\mathcal{E D U} \mathcal{A R D O} \mathcal{L} \mathcal{A} U \mathcal{T} \mathcal{A} \mathcal{R O} G \mathcal{A} \mathcal{L} \mathcal{A} \mathcal{K}$ \\ Director Tesis \\ $G \mathcal{E R} \mathcal{M} \mathcal{A} \mathcal{N} C \mathcal{A} \mathcal{R} D O \mathcal{N} \mathcal{A} G \mathcal{A R C I \mathcal { A }}$
}

Podirectora Tesis

$\mathcal{A} \mathcal{N} \mathcal{A} C \mathcal{A} \mathcal{N D} \mathcal{R E} \mathcal{V} \mathcal{A}$

Alutor

$\mathcal{D A} \mathcal{N} I \mathcal{L} \mathcal{E} \mathcal{D} U \mathcal{A} \mathcal{R} D O \mathcal{M E D} I \mathcal{N} \mathcal{A} O C \mathcal{A} \mathcal{M} \mathcal{P O}$ 


\section{CONTENIDO}

pág.

AGRADECIMIENTOS VIII

PROLOGO IX

$\begin{array}{ll}\text { PRESENTACION } & 1\end{array}$

CAPÍTULO 1. DE LOS ORIGENES A LA PROHIBICION 3

$\begin{array}{ll}\text { Drogadicción } & 11\end{array}$

$\begin{array}{ll}\text { Drogodependencia } & 13\end{array}$

$\begin{array}{ll}\text { Prevención } & 20\end{array}$

Problemas relacionados con la prevención de drogodependencias 21

$\begin{array}{ll}\text { Factores conexos } & 26\end{array}$

CAPÍTULO 2. DIAGNOSTICO 28

Ibagué y su cultura entorno al consumo 29

Variables del Consumo - Encuesta RUMBOS 40

CAPÍTULO 3. LAS ACCIONES PREVENTIVAS 51

Problema y Línea Base $\quad 54$

$\begin{array}{ll}\text { Propuesta de Intervención } & 55\end{array}$

Objetivo de los Cuatro Años $\quad 55$

Acciones Plan Operativo PAB - 2004

Acciones Plan Operativo PAB - $2005 \quad 56$ 
Acciones Plan Operativo PAB - $2006 \quad 56$

Acciones Plan Operativo PAB - $2007 \quad 57$

Mecanismos de Evaluación $\quad 58$

$\begin{array}{ll}\text { Resultados } & 59\end{array}$

CAPITULO 4. CONSIDERACIONES FINALES 66

El Cuerpo en las acciones preventivas $\quad 68$

Qué se espera de las Prácticas Corporales en un Dispositivo de Prevención?

Qué aportes se esperan en la Escuela?

Factores de riesgo y de protección a tener en cuenta 73

$\begin{array}{ll}\text { BIBLIOGRAFIA } & 77\end{array}$

$\begin{array}{ll}\text { GLOSARIO } & 81\end{array}$

$\begin{array}{ll}\text { ANEXOS } & 86\end{array}$

$\begin{array}{ll}\text { Acuerdo Concejo Municipal } & 87\end{array}$

Circular PAB - Ministerio de la Protección Social 91

$\begin{array}{ll}\text { Formato VESPA } & 97\end{array}$ 


\section{LISTA DE TABLAS}

Tabla 1.

pág.

Población por Rangos de Edad y Sexo. 2.003

37

Tabla 2.

Población por grandes Grupos de Edad. Estimada a Junio 30

38

$2.003-2.004$

Tabla 3.

Distribución de la Población Encuestada. 2.001

Tabla 4.

Descripción del Consumo de Alcohol. 2.001

Tabla 5.

Descripción del Consumo de Cigarrillo. 2.001

Tabla 6.

Descripción del Consumo de Marihuana. 2.001

Tabla 7.

Descripción del Consumo de Cocaína. 2.001

Tabla 8.

Porcentaje de Incidencia del Maltrato según Factores de Riesgo del Agresor. 2.002

Tabla 9.

Eventos referidos vs. Frecuencia de mención 


\section{LISTA DE FIGURAS}

pág.

Figura. 1. Mapa de Ibagué

Figura. 2 Casos notificados de consumo de SPA según droga de inicio. Ibagué $2.004-2.007$

Figura. 3 Porcentaje de casos notificados por VESPA en el consumo de SPA según género. Ibagué $2.004-2.007$

Figura. 4 Casos notificados de consumo de SPA por grupos etáreos. Ibagué $2.004-2.007$

Figura. 5 Casos notificados por el VESPA según tipo de SPA consumida en lbagué $2.004-2.007$

Figura. 6 Casos Notificados de Consumo de SPA según el nivel educativolbagué $2004-2007$ 


\section{AGRADECIMIENTOS}

El sentimiento más noble de un ser humano no está antecedido con manifestaciones físicas; tan solo el prevalecer de la memoria es el reconocimiento a la diligencia y el desprendimiento con el cual las personas e instituciones que contribuyeron en este estudio generaron, además, un espacio en el corazón llamado gratitud.

De esta manera se extiende un agradecimiento muy especial a la Doctora Ana Candreva y al médico Germán Cardona, cuya sabiduría y experiencia actuaron como Faro y son guía frente a la iniciativa y estructura que soporta el presente estudio; de igual manera se extiende un agradecimiento al equipo técnico de la Secretaría de Salud de lbagué por brindar la información de su accionar; a la comunidad por su honestidad y por haber asistido a la construcción de los diagnósticos situacionales que dieron argumentos a las acciones ejecutadas.

Por otra parte, los fundamentos teóricos, académicos y experimentales representan el sentido de ser de este estudio y desde luego, la justificación a la construcción intelectual, aporte social que espero poder materializar y que por lo anterior me incentivo a extender un reconocimiento de gratitud a todo el equipo docente de la Maestría en Educación Corporal de la Universidad Nacional de la Plata, por crear en mí los fundamentos de un mejor ser humano, desde todas las perspectivas.

Por último y no menos importante, agradezco a mi familia por su amor, por su apoyo sin condiciones, por su dedicación y contribución a todos mis sueños, que por gracia de Dios he empezado a compartir con mi Esposa, a quien también agradezco el caminar de su mano y el que hoy, comparta conmigo tan inefable alegría.

A todas y todos, muchas Gracias. 


\section{PRÓLOGO}

En las últimas décadas se ha venido insistiendo sobre la prevención como la estrategia más eficaz frente a las problemáticas generadas por los denominados "consumos abusivos" y las dependencias a las drogas; en Colombia son varias las instituciones de carácter privado, público y mixto que se han dedicado a la prevención desde diversas intencionalidades: unas desde lo investigativo, otras desde lo formativo y en su mayoría desde la intervención. La magnitud, la relevancia política y socioeconómica del fenómeno y las presiones internacionales hacia Colombia han creado varios intereses y, por consiguiente, grupos de personas que aun viven alrededor de la droga ya sea en su producción, consumo o tráfico. Muchas de las acciones se han desarrollado de manera desarticulada, marcando un problema estructural y no sólo coyuntural entre lo público y lo privado.

En Colombia ha faltado una mayor claridad y consenso sobre los modelos teóricos que orientan las acciones preventivas. Algunas instituciones se dedican exclusivamente a programas de prevención y otras por su lado, realizan procesos formativos e investigativos, pero no se observa una retroalimentación permanente entre los dos. Ello se puede deber, a que en los primeros predomina un cierto empirismo y en los segundos una tendencia hacia el teoricismo, sin que ello derive en acciones prácticas.

En este orden de ideas, muchas de las acciones de prevención responden a la formación de las personas que las lideran, por consiguiente, se fundamentan desde perspectivas como: psicológica, clínico terapéutica, pedagógica, religiosa y desde la salud pública, así como por diferentes concepciones con las que se ha abordado el problema de la drogodependencia y la prevención. Algunas propuestas se han orientado a identificar factores de riesgo y plantear como alternativa la identificación de factores de protección, otras han optado por la formación individual y social de los seres en las diferentes esferas con el fin de tener una mayor capacidad de resistencia de los sujetos hacia el consumo de las drogas, aparece por otro lado perspectivas más de tipo comunitario tendientes a fortalecer las diferentes estructuras de la comunidad: salud, educación, vivienda, mostrando así una prevención más inespecífica, ya no desde el individuo sino desde la comunidad. 
El presente estudio no tiene precedentes en Colombia, se realizó con el ánimo de conocer qué aspectos tuvo en cuenta la Secretaría de salud de la ciudad de lbagué para realizar prevención en drogodependencia desde el año 2004 hasta el año 2007 y cuáles fueron los resultados o fallas, como también conocer el concepto de cuerpo que estructuró el proceder analizado; esto constituye una razón fuerte e interesante como futura base en pro de la orientación de acciones preventivas a través de la educación, del conocimiento del propio yo, del conocimiento del cuerpo y de su entorno.

Se recopilaron los datos (geográficos, demográficos y situacionales) que sirvieron como base a la construcción de las acciones preventivas, así como sus posteriores resultados, de igual manera se efectuaron algunas entrevistas en las que personal a cargo de la ejecución de PAB, relataron la forma y principales características a la hora de "hacer prevención" y como, existiendo algunas hipótesis, estas (las acciones preventivas) no fueron partícipes de las retroalimentaciones a que dieron lugar las acciones antecesoras.

El cuerpo, fundamento principal del actual análisis, se presentó de manera "tímida" en cada uno de los procederes señalados, como también fue evidente la carencia de un sustento teórico que le permitiera singularizarse; razón que consolida aun más las conclusiones del presente estudio y aprueba diferentes puntos de partida en la que el cuerpo sea el actor principal, no solo para efectuar o implantar mecanismos de prevención hacia la drogodependencia, sino para re-visionar la percepción del mismo. 


\section{PRESENTACIÓN}

La drogadicción es un tema manejado desde muchos flancos, principalmente en su aspecto de rehabilitación, seguido muy de cerca por los múltiples intentos fallidos para prevenirla (siendo la prevención la única estrategia adecuada para enfrentarla y sin embargo carece de importancia).

El presente tema ostenta un lugar muy elevado en su trato, manejo y forma por cuanto se indaga en el, de ahí que cualquier información del mismo existe y actualmente se trabaja; por consiguiente, las formas de hacer prevención abundan aunque con directrices no unificadas; por esta razón es que surge la forma comparativa de metodologías y las posibilidades de acercamiento hacia la excelencia en los procesos preventivos a emplearse cualquiera que sea el lugar, la población y las condiciones. Inmerso en el tema, se encuentra un grupo de factores susceptibles de ser analizados en el desarrollo de cualquier investigación, siendo estos el ámbito social, familiar y escolar; para luego dar paso al ámbito bio - psico social y cultural, construyendo así un enfoque integral y ubicando el cuerpo como eje central de este proceso y como su conservación, desarrollo y potencialización dependen de su acción preventiva en general y en particular con relación al uso indebido de drogas.

Por otra parte, es pertinente resaltar que las estrategias que se emplean actualmente para prevenir la drogodependencia en la ciudad de lbagué Colombia, se pueden caracterizar por múltiples factores con 0 sin intervención ciudadana, (es posible que exista exclusión de la familia y del ámbito escolar, que son los escenarios naturales para desarrollar la prevención) esto a su vez se sustenta con el orden prioritario en que dichas estrategias se encuentran, pues frecuentemente son atendidas otras necesidades que de igual forma merecen atención, pero que son ocasionadas indirectamente por la adicción a las sustancias psicoactivas.

El consumo de drogas y las consecuencias de toda índole a que esto conlleva, sin duda es uno de los temas que preocupan a los ciudadanos y que por tanto refleja una seria amenaza para la convivencia social. Por tal razón, la inquietud que se plantea desde la docencia, es hasta dónde se está contribuyendo a concienciar a la sociedad sobre el fenómeno de las drogas y 
con qué instrumento estamos guiando la participación social en las tareas preventivas.

Estimando a los entes gubernamentales como instituciones organizativas y esquematizadoras en los procesos de interés social, es necesario como representante del sector educativo, detectar fallas y limitantes en la actual forma de ejercer prevención, siendo estas últimas las que se orienten técnicamente, para que en los sectores de influencia sean ejecutables y sirvan como laboratorio, actuando luego como solución en la realidad de las personas y de esta forma potencializando sus capacidades de interacción del propio yo en entornos culturales, sociales y familiares.

Gracias a que actualmente los índices de consumo de SPA se han incrementado y que, por otro lado, esta situación hoy por hoy ha tocado a poblaciones muy vulnerables (niños, adolescentes, jóvenes y últimamente, a mujeres de todas las edades); diferentes instituciones se han caracterizado por efectuar, desde el imaginativo o desde la percepción algunas acciones que contemplan talleres y puntos de información con el único objetivo de detener estas conductas; pero dejan de lado la integralidad y por tanto no logran penetrar lo suficiente en las poblaciones, sobre todo, en las vulnerables. Esta situación es superficial porque su accionar no contempla las características sociales y culturales que dan construcción al cuerpo y no se logra, entonces, determinar cuáles son las prácticas que dan paso e inicio a esta situación de dependencia.

Por esta razón, la situación que se pretende investigar es, en primera instancia, los argumentos que ha tenido la Secretaría de salud de lbagué para realizar acciones que a su criterio, previene la drogodependencia y que han sido efectuadas desde el año 2004 al 2007 y posteriormente, el concepto de cuerpo que sustenta las acciones antes mencionadas, desde luego se espera compartir algunas consideraciones al respecto y dar algunas luces desde la Educación Corporal para aportar a las iniciativas de prevención. 


\section{CAPÍTULO I}

\section{DE LOS ORIGENES A LA PROHIBICION}

El uso de sustancias psicoactivas es una práctica cuya primer aparición en la región se registra desde el primer encuentro con el antiguo continente, donde en los territorios cubiertos actualmente por Venezuela y Colombia fueron encontradas algunas plantas de principios activos a base de alcaloides con efectos sorprendentes a la hora de citar el fin de molestias físicas, evitar el cansancio, para trascender durante sus rituales de cohesión tribal y prolongar la actividad en jornadas de trabajo.

Hablar de una planta común en nuestra época, como es la coca, cuyos orígenes según los historiadores fue sagrada, existiendo leyendas al respecto y al libre uso por parte de ciertas castas (mambeada, referida como el mantenimiento de la planta en el interior de la boca) hasta la llegada de los conquistadores (citada como ejemplo), es citar una práctica que acentuada de principios del año 1500, donde Antonio Escohotado refiere "en 1530, usar liberalmente coca era privilegio de la corte y hacerlo sin autorización constituía un desafío a la autoridad, parte considerable de la corvea o tributo popular de trabajo se empleaba en producir los llamados panes de coca, consumidos por la nobleza en grandes cantidades, mientras que para los demás estamentos reinaba un sistema de prohibición ${ }^{1}$. Lo anterior explica que la conquista supusiera en un primer momento la monopolización del consumo y así pensar en que algunos españoles consiguieran fortunas.

De igual manera, es de mencionar como ejemplo otra droga extendida y venerada en la región desde sus inicios, es el tabaco; consumida como comida, bebida o siendo fumada, esta planta era fundamental en las celebraciones y rituales propios de las culturas antecesoras.

\footnotetext{
${ }^{1}$ Escohotado Antonio - señala que el inquisidor veía en el uso de la planta una práctica idolatra y los terratenientes eran insistentes en sus bondades, disputa que se zanja con el otorgamiento al clero un diezmo sobre todo comercio de la planta. Las Drogas - Pág. 58 editorial Alianza, Madrid - España 1994.
} 
Esta planta ocasionaba (según el autor Antonio Escohotado) ${ }^{2}$ una serie de efectos en el organismo que trascendían en sus creencias y rituales, ubicándola como una de las sustancias que en el nuevo continente eran usadas con el fin de producir estados psicóticos alucinatorios pasajeros ${ }^{3}$, igualmente por sus efectos sobre el cansancio, la enfermedad, el hambre o la sexualidad.

Otra planta con efectos alucinógenos era el Yagé, esta planta se consumía especialmente en los ritos espirituales, Ayahuasca (yagé) viene del lenguaje Quechua (lenguaje de comunidades indígenas propias del Amazonas) que significa "vida de los antepasados" o "vida de los muertos" o "vida de las almas". AYA en Quechua "Espíritu" "antepasado" "persona muerta" HUASCA en Quechua significa "vida". Su uso era con fines espirituales, para entablar comunicaciones con difuntos y/o antepasados. ${ }^{4}$

Otro de los cultivos más antiguos de la humanidad y que ofrece múltiples aplicaciones como uso médico o narcótico es la marihuana o cannabis, esta planta es el producto obtenido de la desecación de la planta de cáñamo, cuya práctica se remonta a la misma época de la conquista y consistía en echar las semillas de tal planta en un conjunto de piedras al fuego, allí, estas semillas arrojadas despedían de sí un sahumerio y este a su vez era lo que provocaba sensaciones extrañas, además de ocasionar alegría y risa; igualmente sus prácticas y usos trascendían a tal punto de estar bajo el efecto de su consumo durante las guerras, bajo la oferta de tranquilidad y recompensas fuesen en esta vida o en la otra (explícito en Herodoto 1974 los nueve libros de la historia-pag.186-187).

A los ejemplos mencionados anteriormente se les suman muchas otras sustancias que comparten el uso médico y el ser fuente de adicción, puesto que desde las últimas décadas y especialmente para el mercado norteamericano de adolescentes, jóvenes y niños, el consumo y la

${ }^{2}$ Concepto recogido de un tratado hallado por él en el año de 1926. El tratado se llama El tabaco, panacea universal, está escrito por J. Leander - donde defiende su capacidad para elevar el éxtasis y crear una comunicación con los dioses.

${ }^{3}$ El estado psicótico alucinatorio pasajero es cuando el inconsciente está presente, pero no funciona, y se señala la importancia de hacerlo funcionar; es decir, que el paciente no quede apabullado por sus automatismos. Al respecto un camarada de Lacan, Henri Ey, comenta en su manual de Psiquiatría de 1980: "Es así como el síndrome de automatismo mental, está centrado sobre la producción espontánea, involuntaria y en cierta manera mecánica, de impresiones, ideas, recuerdos, que se imponen a la conciencia del sujeto a pesar suyo, por así decirlo fuera de él aunque en el centro del mismo".

${ }^{4}$ Escohotado Antonio. Opt. Cit. 
producción de la droga ha tocado cifras impensables y su comercio produce cifras que, involucran todo tipo de personas e instituciones; de igual manera crecen los esfuerzos para su control, enfatizando en controlar su producción, su tráfico y el consumo, ya que sus fines han cambiado y la comercialización es cada vez mayor.

Claro está que, al mencionar estas plantas implícitas desde el mismo instante de la conquista en nuestro continente, empezamos también a mencionar y/o definir el concepto sobre el cual se hace el análisis del proceso preventivo objeto de este estudio; entendiendo al referir el término droga como la alusión a cualquier sustancia que al introducirse en el organismo vivo, ocasiona alteraciones en su funcionamiento o estructura, relacionados estos como cambios a nivel físico y mental; esta sustancias a diferencia de lo que se conoce como alimento, no constituye fuente de nutrición y su única utilidad se reflejaría si estas se emplean para curar enfermedades, motivo que permitiría entonces llamarlas medicamentos ${ }^{5}$.

En este mismo sentido, la Organización Mundial de la Salud (OMS) define el término droga como toda sustancia que, introducida en el organismo por cualquier vía de administración, produce una alteración de algún modo, del natural funcionamiento del sistema nervioso central del individuo y es, además, susceptible de crear dependencia, ya sea psicológica, física o ambas.

Esta apreciación conlleva a que el interés de esta investigación se canalice hacia aquellas sustancias que son capaces de ocasionar dependencias graves y que, por consiguiente, pueden causar problemas individuales y sociales, es decir, las drogas psicoactivas (también conocidas como psicotrópicas), ya que estas son las que directamente actúan sobre el SNC (Sistema Nervioso Central) y provocan cambios en la percepción, los sentidos, los sentimientos y la conducta de los seres humanos que las consumen.

\footnotetext{
${ }^{5}$ Medicamentos, Toda sustancia medicinal y sus asociaciones o combinaciones destinadas a su utilización en las personas o en los animales que se presente dotada de propiedades para prevenir, diagnosticar, tratar, aliviar o curar enfermedades o dolencias o para afectar a funciones corporales o al estado mental.
} 
Del grupo de sustancias psicoactivas a los que se hará mención, la autora Edith Massün las clasifica en tres grupos:

1. Psicolépticos (depresores del sistema nervioso central). A este grupo pertenecen el alcohol, los sedantes (barbitúricos y tranquilizantes), los narcóticos (opio, morfina, heroína, codeína) y las sustancias volátiles o inhalables (aunque estas son igualmente alucinógenas).

2. Psicoanalépticos o psicotónicos (estimulantes del sistema nervioso central), grupo al que pertenecen las anfetaminas, la cocaína, el tabaco y la cafeína.

3. Psicodislépticos (perturbadores del sistema nervioso central), que incluyen a los alucinógenos (LSD, mescalina, psilocibina) y el cannabis (marihuana). Esta última es una droga ambivalente, a la vez estimulante y tranquilizante, pero puede también provocar distorsión sensorial y en casos raros, alucinaciones. Puesto que tienen otras características aparte del grupo principal, se suele igualmente clasificar al cannabis y a los inhalables como dos categorías independientes de drogas.

Como se anunció al inicio, algunas de estas drogas son naturales, como el cannabis (marihuana); la coca y uno de sus componentes activos: la cocaína, el opio y sus componentes (la morfina y la codeína). Otras de ellas son sintéticas, es decir, se necesita de algún complemento químico y/o elaboración química para su obtención, como la LSD, las anfetaminas, los barbitúricos y los tranquilizantes. Y otras más que se constituyen o se forman con productos enteramente industriales como los que se llaman inhalables, ejemplo de ellos son la gasolina, el thinner, el cemento plástico, el líquido corrector y los pegamentos industriales.

De igual manera, diferentes sociedades le dan a las drogas su nombre (en jerga popular) y su clasificación; para este caso, se cita una clasificación controvertida y poco usual por estos tiempos, cuya pretensión era la de agrupar las drogas según su potencialidad farmacológica ${ }^{6}$, siendo este conjunto el de drogas duras y drogas blandas.

\footnotetext{
${ }^{6}$ Potencialidad farmacológica, esta clasificación se argumentaba en la peligrosidad de cada droga en el sentido de producir dependencia y la reacción que cada individuo pudiese tener al respecto de su consumo.
} 
El término duras, refiere a aquellas drogas que están directamente relacionadas con adicción física y provocan violencia y en muchos casos, la muerte (ejemplo de ellos son la cocaína y la heroína); contrario a esto, el término blandas da significancia a aquellas que no producen adicción física (para algunos casos) y no han registrado relación alguna a violencia, muertes o crímenes (ejemplo de ello, la marihuana).

Ahora bien, mucho se ha mencionado de las drogas y resulta muy pertinente empezar a conocer más a fondo cada una de ellas, por esta razón, se hace mención a las drogas que circundan el mercado local:

\section{- Depresores del SNC}

Alcohol: El alcohol es una sustancia depresora del sistema nervioso central; además de tener efecto sobre el cerebro y variar algunas de sus funciones (coordinación, atención, memoria...), su uso continuado también afecta a otros órganos como el riñón, el hígado o el sistema circulatorio. Inicialmente, los efectos del alcohol son sutiles, pero pueden ser peligrosos porque una persona bajo sus efectos no es un buen juez de su conducta.

Barbitúricos y tranquilizantes ${ }^{7}$ : igualmente depresor del Sistema Nervioso Central (SNC). Pueden actuar tanto en el cerebro como en el SNC produciendo efectos que pueden ser tanto positivos como dañinos. Esto depende de la condición individual de cada persona y su respuesta a la dosis de la medicina tomada. Algunos de los barbitúricos pueden ser usados antes de una cirugía para aliviar la ansiedad o tensión. Además algunos de estos son usados como anticonvulsivos para ayudar a controlar algunos síntomas tales como la epilepsia.

Los Barbitúricos se encuentran dentro de las drogas más adictivas. Son generalmente un sustituto para el alcohol (ya que produce efectos similares). La gente los utiliza para obtener una sensación de euforia y relajación. De todas formas, su uso es ilegal sin prescripción y supervisión médica.

\footnotetext{
${ }^{7}$ También han sido utilizados para tratar el insomnio; pero si son usados con regularidad, no serán efectivos luego de las dos semanas de toma consecutiva. Los barbitúricos también han sido usados para aliviar el nerviosismo o alteración durante el día. Sin embargo, han sido reemplazados en su mayoría por medicación más segura ya que si se utiliza en grandes cantidades, o por largos períodos produce hábito.
} 
Igualmente y pertenecientes a este grupo, los tranquilizantes son capaces de controlar la ansiedad patológica y a dosis más elevadas de inducir sueño. Son un grupo de fármacos muy eficaces. El problema surge cuando no se emplean adecuadamente 0 durante períodos de tiempo excesivamente prolongados.

Los Narcóticos, por su parte, son aquellas sustancias que producen aturdimiento, es decir, una especie de torpeza personal, de somnolencia y de falta de interés hacia el mundo exterior (sustancias entre las que se encuentran el opio, la heroína, la morfina y la codeína), su principal efecto farmacológico se lleva a cabo en el sistema nervioso central y gastrointestinal. La analgesia, que es el efecto clásico y el más estudiado, se produce por acción de los narcóticos a nivel supraespinal y espinal, inhibiendo la transmisión del dolor y los componentes emocional y afectivo asociados, igualmente la dependencia física que produce es una respuesta farmacológica al uso crónico de los narcóticos y se manifiesta al suspender la droga como un síndrome de abstinencia (lacrimación, agitación, temblores, insomnio, fiebre, taquicardia y otros signos de hiperactividad del sistema nervioso simpático); su prevención requiere de una disminución gradual de la droga ${ }^{8}$.

Por otro lado, las sustancias volátiles o inhalables son compuestos cuyos vapores se aspiran para producir efectos similares a la embriaguez; en su gran mayoría son productos industriales legales de venta abierta, lo que facilita su adquisición y uso indebido: sus breves efectos hacen que se tienda a repetir la aspiración con frecuencia, produciendo una rápida adicción y daños en el cuerpo ${ }^{9}$.

\section{- Estimulantes del SNC}

Anfetaminas: las anfetaminas son aquellas sustancias estimulantes del sistema nervioso central, estas drogas aparecieron en las farmacias norteamericanas hacia 1930, como recurso para mantener despiertos a

\footnotetext{
${ }^{8}$ Referenciales del Boletín de la escuela de Medicina de la Universidad Católica de Chile en 1994, bajo el título analgésicos narcóticos de los doctores Alejandro González y Jorge Dagnino.

9 Entendido el cuerpo como organismo (Carballo y Crespo, UNLP 1998), ya que los inhalables causan daños en el cerebro, el hígado, el corazón y los pulmones: esta intoxicación puede ser crónica y desencadenar en trastornos epilépticos.
} 
sujetos sobre dosificados por sedantes. Poco después se lanzan en forma de inhaladores para catarro y todo tipo de congestiones nasales, y algo más tarde como píldoras contra el mareo y la obesidad, para finalmente emplearse como antidepresivos.

Igualmente se emplean de manera ocasional para aumentar el rendimiento físico, retrasar el sueño y aumentar el rendimiento intelectual. Con este objetivo es utilizada en ocasiones por conductores de largas distancias, estudiantes o para evitar la fatiga y aumentar el rendimiento en deportistas. Un empleo habitual es la búsqueda del estado de euforia y de bienestar, así como tratamiento para la obesidad y en los estados depresivos.

Cocaína: La cocaína es una sustancia psicoactiva de uso ilegal. Se obtiene de las hojas del Erythroxylon coca, esta es una planta originaria de América que se cultiva en regiones con temperaturas entre 15 y $20^{\circ} \mathrm{C}$. Su uso se remonta a muchos años atrás del descubrimiento de América; allí por ejemplo, los incas mascaban las hojas para disminuir la fatiga y el hambre. La cocaína es un derivado principal de la hoja de coca, compuesto que no tiene raíces culturales y es mucho más potente y dañina que la hoja en su estado natural. Es un estimulador del sistema nervioso y supresor del hambre, usado en medicina como anestésico, incluso en niños, específicamente en cirugías de ojos y nariz, de igual manera sus efectos se potencializan cuando esta se inyecta directamente en la sangre.

El Tabaco y la Cafeína: El Tabaco es el nombre común de dos plantas de la familia de las Solanáceas cultivadas por sus hojas que, una vez curadas, se fuman, se mascan o se aspiran en forma de rapé. La especie más cultivada alcanza entre 1 y $3 \mathrm{~m}$. de altura y produce de 10 a 20 hojas anchas alternas que brotan de un tallo central. Contiene un alcaloide llamado la nicotina ${ }^{10}$; esta sustancia es tóxica y puede producir alteraciones en el aparato circulatorio y los pulmones del ser humano, así mismo es relevante enunciar que uno de sus usos más comunes es como insecticida, puesto que el humo emanado aleja los insectos.

\footnotetext{
${ }^{10}$ La NICOTINA (su principal alcaloide) es un estimulante que se encuentra en forma natural en las hojas de la planta de tabaco. De naturaleza volátil, se vaporiza en humo cuando el tabaco es quemado y es la sustancia que le da su olor característico, siendo además la que genera la dependencia física.
} 
La planta del tabaco es uno de los principales productos agrícolas no alimenticios del mundo. La planta madura mide de 1 a $3 \mathrm{~m}$. de altura y produce entre 10 y 20 hojas grandes. Éstas se secan, curan y utilizan para fabricar cigarrillos, puros y tabaco de pipa y de mascar.

Por su parte, la cafeína es una sustancia alcaloide estimulantes del SNC de sabor amargo que se puede encontrar en una gran variedad de alimentos, bebidas y/o medicinas. La cafeína es naturalmente una droga psicoactiva, lo que significa que tiene la potencialidad de alterar el pensamiento, el comportamiento y los estados de ánimos de las personas.

En su forma más pura la cafeína tiene forma de cristales de sabor amargo y se encuentra en muchas sustancias de uso cotidiano como el café, el té, el mate, la cocoa, el chocolate, las bebidas cola y algunos preparados médicos (pastillas para el dolor de cabeza y analgésicos).

\section{- Perturbadores del SNC}

LSD, Mescalina, psilocibina: La LSD (dietilamida del ácido lisérgico) es una de las principales drogas en la categoría de los alucinógenos. Los alucinógenos causan alucinaciones-distorsiones profundas en la percepción de la realidad, igualmente logran sus efectos interrumpiendo la interacción de las células nerviosas y el neurotransmisor serotonina. El sistema de serotonina está distribuido en el cerebro y la espina dorsal y está involucrado en el control de los sistemas de la conducta, percepción y regulación, incluyendo el estado de ánimo, el hambre, la temperatura en el organismo, el comportamiento sexual, el control muscular y la percepción sensorial.

La mescalina y la psilocibina son los componentes activos de origen vegetal que, al ingerirlas, producen distorsiones en la percepción auditiva, visual y táctil con un componente de alteración emocional muy fuerte, los efectos de estas drogas son similares a los efectos de la LSD, pero no tan violentos y/o fuertes; el uso de estas drogas no descarta la dependencia física ni la motivación psicológica para volver a consumirla.

Es de anotar que bajo la influencia de los alucinógenos, las personas ven imágenes, oyen sonidos y sienten sensaciones que parecen reales pero que no lo son; algunos alucinógenos también producen cambios emocionales rápidos e intensos. 
La Cannabis (Marihuana): La Marihuana es una planta herbácea anual cuya única especie es la Cannabis sativa que presenta tres variedades: Cannabis sativa indica, Cannabis sativa Americana y Cannabis sativa Rudelaris. La planta (marihuana) se compone de hojas, tallo, semillas y flores secas de la planta, mientras que el hachís es obtenido de la resina de la planta. Su aspecto es el de una pasta más o menos dura y aceitosa; el color varía del marrón al negro. Usualmente es fumada en cigarrillos, pipa o adicionada a alimentos como galletas, brownies y té de hierbas. La resina de la planta puede ser secada y comprimida en bloques llamados hachís que de igual manera se fuma. Todas las partes de la planta poseen las sustancias psicoactivas $\mathrm{THC}^{11}$ que caracterizan su acción tóxica.

Este compuesto es el que ocasiona ciertas impresiones visuales, olfativas 0 táctiles, identificadas fácilmente por el estado de toxicidad del consumidor o "traba" (jerga popular), que es el efecto típico de la marihuana, variando, como es lógico de persona a persona.

\section{DROGADICCION}

Resulta indispensable indagar y unificar el criterio referencial al término, puesto que diferentes autores perciben este fenómeno desde diferentes flancos y su concepto puede, aunque no en todos los casos, confundir o desviar el foco de atención para esta investigación.

Comúnmente se suele ver el consumo de droga, en particular aquella que no es legal, como un flagelo que corrompe las costumbres y lleva a quien la consume a su destrucción, haciendo parecer que, el solo hecho de consumir y de deteriorar la personalidad, explicará por sí sola el consumo de SPA; razón por la cual se considera que las personas que intervenimos en los procesos de educación corporal, al mismo tiempo que se generan represiones entorno al consumo, generemos un entorno preventivo.

Por consiguiente y resaltando algunos conceptos de drogadicción, se señala que la OMS entiende las drogas como una sustancia (natural o química) que, introducida en un organismo vivo por cualquier vía de administración (ingestión, inhalación, por vía intravenosa o intramuscular), es capaz de

${ }^{11}$ El principio activo de la marihuana es el THC o tetrahidrocannabinol, este compuesto se encuentra en cantidades superiores en el hachís. 
actuar sobre el cerebro y producir un cambio en las conductas de las personas debido a que modifica el estado psíquico (experimentación de nuevas sensaciones) y tiene capacidad para generar dependencia ${ }^{12}$.

Por su parte, Álvaro Rodríguez ${ }^{13}$, en su libro ¿Qué son las drogas? y la fundación Génesis ${ }^{14}$ en una apreciación semejante definen la drogadicción como una enfermedad que tiene su origen en el cerebro de un gran número de seres humanos, la enfermedad se caracteriza por su cronicidad o larga duración, su progresividad y las recaídas.

Otras fuentes ${ }^{15}$ interpretan la adicción a las drogas como el resultado de un progresivo establecimiento de tolerancia farmacológica y dependencia tanto física como psíquica; así pues, el organismo empieza a tener la necesidad de que se le administre continuamente droga para de esta manera evitar que sus sistemas fisiológicos se alteren a causa de la modificación efecto de las drogas que sufrió inicialmente.

De igual manera es considerada una dependencia psíquica, en el cual el individuo siente una imperiosa necesidad de tomar droga o, en caso contrario, un desplome emocional cuando no la ingiere y una dependencia física producida por los terribles síntomas de abstinencia al no ingerirla.

También se puede definir como el estado psíquico y a veces físico (psíquicoentendido como el proceso a nivel neural y físico-entendido como el proceso causado por la interacción entre un organismo vivo y una droga). Caracterizado por modificaciones del comportamiento, y por otras reacciones que comprenden siempre un impulso irreprimible al tomar la droga en forma continua o periódica con el fin de experimentar sus efectos síquicos y a veces para evitar el malestar producido por la privación.

Ahora bien, señalando los fenómenos propios de la drogadicción y de los drogadictos, propiamente dichos, no se puede dejar de lado la dependencia a

${ }^{12}$ Concepto emitido por la O.M.S. Organización Mundial de la Salud. 2006.

${ }^{13}$ Rodríguez, A. ¿Qué son las Drogas? Imprenta nacional de Colombia, Santa fe de Bogotá 1996.

${ }^{14}$ La Fundación Génesis es un centro ubicado en Santa fe de Bogotá - Colombia, especializado en el tratamiento de adicciones, allí se aborda al adicto como ser humano y se acompaña en sus posibilidades y limitaciones. Enlace Web: http:// www.fundagenesis.org.

${ }^{15}$ Martín Zurro y Cano Pérez. Manual de Atención Primaria, Tabaquismo, alcoholismo y otras drogodependencias. 
causa del consumo, por lo que se ha señalado la dependencia en dos flancos, principalmente:

Dependencia física: La entendemos cuando el organismo se vuelve necesitado de las drogas, tal es así que cuando se interrumpe el consumo sobrevienen fuertes trastornos fisiológicos, lo que se conoce como síndrome de abstinencia.

Dependencia psíquica: Es el estado de euforia que se siente cuando se consume droga, y que lleva a buscar nuevamente el consumo para evitar el malestar u obtener placer. El individuo siente una imperiosa necesidad de consumir droga, y experimenta un desplome emocional cuando no la consigue.

\section{DROGODEPENDENCIA}

Como se mencionó con anterioridad, la drogodependencia es el estado en el cual el ser humano ha llevado al extremo el abuso de las drogas, siendo el consumidor un ser atrapado en esta conducta y sintiendo deseos irreprimibles de consumir la droga a la cual ha estado acostumbrado, pues reincide en su consumo, bien sea para experimentar de nuevo sus efectos y saciar su ansiedad o para evitar el malestar que le produce la ausencia de la sustancia que frecuentemente consume.

En algunas bibliografías, el término se modifica por farmacodependiente (aunque este término quede designado únicamente para señalar la dependencia a los medicamentos), pues la connotación social en diversos lugares del mundo para el término drogadicto, es despreciativo y marginalizante.

Un ejemplo de lo anterior, es el realizado por la OMS, donde señala:

"La farmacodependencia es el estado psíquico y a veces físico causado por la acción recíproca entre un organismo vivo y un fármaco; la farmacodependencia se caracteriza por modificaciones del comportamiento y por otras reacciones que comprenden siempre un impulso irreprimible a tomar el fármaco en forma continua o periódica a fin de experimentar sus 
efectos psíquicos y a veces para evitar el malestar producido por la privación. La dependencia puede ir o no acompañada de tolerancia y de igual forma, una misma persona puede ser dependiente de uno o más fármacos" ${ }^{\prime 16}$.

Como se aprecia en esta referencia, el término droga ha sido modificado por el de fármaco, dándole la misma significancia a la acción de consumir y depender a nivel físico y psicológico del consumo de diversas sustancias; sin distinguir que, en Colombia y más específicamente en la ciudad de lbagué, dadas las circunstancias, es necesario separar ambas apreciaciones (fármaco/droga) debido a su connotación social de consumo, igualmente a que, para el caso de esta investigación, el significado será semejante aún cuando el término Drogodependencia se mantenga.

Ahora bien, ¿qué le sucede al cuerpo de quien consume?

En cuanto a los sucesos en el cuerpo de un ser humano que consume drogas es mucho lo se puede mencionar, incluso, algunos autores manifiestan sus posturas y reflexiones al respecto con referencias plasmadas desde la inexperiencia, y no es para menos, seguramente no se necesita ser consumidor para conocer lo que pasa o lo que ocurre cuando esta práctica se manifiesta; aunque esto no suponga un análisis de esta situación desde otros enfoques disciplinares, si es importante hacer notorio lo que le ocurre al cuerpo entendido como organismo humano ${ }^{17}$, inicialmente; para luego dar paso a lo que ocurre en la construcción social que el mismo cuerpo preside, caso en estudio del presente trabajo.

De esta manera es importante, entonces, recordar que la sigla SPA hace referencia a sustancias Psicoactivas y ellas comprenden, a su vez, a estimulantes, depresores y alucinógenos del sistema nervioso, motivo por el cual este primer evento hay que tenerlo en cuenta sobre los efectos en referencia al sistema nervioso central en la intoxicación aguda del individuo consumidor de SPA; desde luego este efecto depende de la sustancia consumida.

\footnotetext{
${ }^{16}$ Organización Mundial de la Salud. Informe técnico La Juventud y las Drogas. 1973, № 516.

${ }^{17}$ En este sentido, Bagú hace mención a la realidad social como un proceso que se lleva a cabo cuando las totalidades biológicas se ven afectadas, alteradas y complejizadas. [Citado por Carballo, C. y Crespo, B. (2001). Aproximaciones al concepto de Cuerpo].
} 
En cuanto a otros efectos nocivos sobre el organismo del individuo es responsable, desde la perspectiva del escritor, el apoyo que ofrece una disciplina como la toxicología, que es la ciencia que estudia los efectos adversos de las sustancias y productos químicos sobre los organismos vivos. A la entrada en el organismo, las sustancias tóxicas o toxones (SPA), siguen las siguientes fases:

Fase de Exposición: esta fase inicia desde el momento que el individuo la ingiere o introduce al organismo, bien sea por vía oral (pastillas, alcohol), fumada (cigarrillo, marihuana, heroína, basuco), inhalada (cocaína), parenteral o inyectada (Heroína), anal o rectal (marihuana) etc.

En la exposición, se desintegra la sustancia ingerida y ésta libera los principios activos, los retiene dentro del organismo y los deja disponible para la absorción e introducción al sistema sanguíneo del individuo consumidor.

Fase Toxocinetica: esta fase significa que, una vez liberado el principio activo, se inicia la presente con la absorción de dicho principio activo al sistema circulatorio (vasos sanguíneos y arterias), estos a su vez, lo distribuye hacia los órganos donde posteriormente se realizará el metabolismo, es decir, donde el principio activo adquirirá la disponibilidad biológica que será diferente para cada sustancia, (se conocen cerca de 11 metabolitos activos para la marihuana, cerca de 9 metabolitos activos para la cocaína $)^{18}$ y finalmente la excreción o eliminación de la sustancia, que puede ser por cualquier vía (urinaria, fecal, biliar, lacrimal, salival, sudorifera, mamaria, flujo menstrual, pulmonar).

Igualmente puede permanecer un depósito de dichas sustancias, pero esta situación solo se presenta a nivel óseo, adiposo, capilar, dental, gingival. ${ }^{19}$

Fase toxodinamica: esta fase comprende la interacción del metabolito activo $^{20}$ o toxon con disponibilidad biológica sobre el receptor del tejido del

\footnotetext{
18 Comentario efectuado por el médico Germán Cardona durante la exposición de prevención realizada en las instalaciones de la Alcaldía Municipal de Ibagué, en la cual se promovía la elaboración de diagnósticos comunitarios entorno a los factores de riesgo del consumo de SPA.

${ }_{19}^{19}$ Cardona, G. op. Cit.

20 Un metabolito activo generalmente se refiere al producto que queda después de la descomposición (metabolismo) del fármaco por parte del organismo. En revista virtual
} 
órgano donde producirá los efectos psico activos (estimulante, depresor 0 alucinatorio). También hay que tener en cuenta los efectos las acciones que dichas sustancias producen en la arquitectura citológica, tejidos y órganos, que en el caso de la marihuana se han descrito en las células de la reproducción y en el caso de la cocaína en el sistema cardio vascular y sistema nervioso. ${ }^{21}$

Aun más de cerca, es muy pertinente revisar, aunque de manera tangencial, los efectos y las experiencias que ocurren con cada una de ellas; tal es el caso del Tabaco, y llama mucho la atención el consumo del mismo, pues en edades de adolescencia y juventud, es catalogada una práctica socialmente aceptada y llamativa (aunque con ciertas limitaciones) y con mucha "facilidad", las disposiciones legales en Colombia ${ }^{22}$ distinguen en lugares públicos y privados los sectores para "fumadores" y "no fumadores".

El consumidor de tabaco y en especial, el organismo del mismo, se encuentra con el humo del tabaco y en este, con el monóxido de carbono; residuo que una vez ingresa por la vías aéreas, pasa a la sangre a través de los pulmones y "Es el responsable del daño en el sistema vascular por una parte, y de la disminución del transporte de oxígeno a los tejidos de nuestro organismo, por otra. Produce fatiga, tos y expectoración". ${ }^{23}$

Por su parte, la nicotina actúa sobre las áreas del cerebro que regulan las sensaciones placenteras, provocando la aparición de dependencia. También actúa sobre el sistema cardiovascular aumentando la frecuencia cardiaca y la posibilidad de arritmias, síntoma que se suma a la producción de cambios en la viscosidad sanguínea y el aumento de los niveles de triglicéridos y colesterol. ${ }^{24}$

Continuando con este enfoque, se da paso al Alcohol, razón de ser de muchas prácticas corporales que se modelan a partir de los efectos que este

Medline plus, servicio de la biblioteca Nacional de Medicina de EE.UU. enlace Web. http://www.nlm.nih.gov/medlineplus/spanish/ency/article/002258.htm

${ }^{21}$ Cardona, G. op. Cit.

22 Resolución 01956 de 2008, por medio del cual se adoptan medidas en relación al consumo de cigarrillo y tabaco. Ministerio de la Protección Social.

${ }_{23}$ Guía sobre Drogas, Ministerio de Sanidad y Consumo, Delegación del Gobierno para el Plan Nacional sobre drogas. Gobierno de España, 2007.

${ }^{24}$ Solo verificables bajo exámenes de laboratorio, para el presente caso se mencionan como referente. 
consumo produce (desinhibición, euforia, relajación, aumento de la sociabilidad, descoordinación motora) y que se imponen a las "sensibilidades vulnerables" [(Levinas, 1987) citado por Cachorro, 2009] en esa misma capacidad de afectar y ser afectado.

A nivel orgánico, el alcohol ingerido en una bebida es absorbido en el aparato digestivo, desde donde pasa a la circulación sanguínea en la que puede permanecer hasta 18 horas y es eliminado finalmente a través del hígado. La presencia continuada de alcohol en el organismo y su consumo repetido es responsable de la mayoría de las lesiones que esta sustancia produce en él mismo, como la cirrosis hepática o las encefalopatías en las que el funcionamiento de hígado y cerebro se ve gravemente alterado.

Pocos minutos después de haber bebido, pueden aparecer una serie de efectos, (mencionados anteriormente) cuya manifestación varía según la cantidad ingerida y las características de cada persona.

El consumo de cannabis o marihuana genera unos efectos algo "similares" en relación a las prácticas corporales producto de este consumo; aunque experimenta inmediatamente y tras el consumo lo que se llama "borrachera cannábica", con sequedad de boca, enrojecimiento ocular, taquicardia, descoordinación de movimientos, risa incontrolada, somnolencia, alteración de la memoria, de la atención y de la concentración.

Posterior a estos efectos, las prácticas corporales que empiezan a aflorar son, en su mayoría, aquellas que afectan a los seres humanos no consumidores, y los afectan porque son víctimas de atracos, robos, maltrato físico y verbal; no siendo menos, está presente en el cuerpo del consumidor "la seducción por el peligro, el coqueteo con la muerte, la provocación del límite reglamentario..." produciendo igualmente que el entorno se vea trastornado, "la densidad de algunos barrios, el clima pesado de la noche turbia, las balaceras de zonas liberadas, la latencia de apariciones sorpresivas de violadores, delincuentes, secuestradores, elementos que empapan a los ciudadanos de niveles de pánico, miedo, terror, horror, perversión, morbosidad, entre otras propiedades sujetas a infinitas combinaciones, en la construcción siempre incompleta de la inalcanzable subjetividad." 25

${ }^{25}$ Cachorro, G. 2009. Op. Cit. 
En el contexto orgánico, el consumo de marihuana activa el sistema cannabinoide ${ }^{26}$, desempeña un papel fundamental en el área de la memoria y hace que, de forma natural, nos acordemos más de lo agradable que de lo desagradable, ayudando a eliminar aquellos recuerdos que produjeron un impacto negativo en nuestras emociones. Cuando se sobre activa por el consumo de cannabis se olvida todo, y es más difícil recordar cualquier acontecimiento ocurrido.

Por otro lado, el sistema cannabinoide controla la atención y la percepción y también se encuentra implicado en la regulación de la actividad motora, lo que explica que el consumo de cannabis (marihuana) produzca una disminución del nivel de actividad y mayor dificultad en la coordinación de movimientos.

Una situación muy similar es la que ocurre cuando en el organismo se presenta el consumo de Cocaína, heroína y las llamadas drogas de síntesis $^{27}$, pues el consumidor de éstas, al igual que las otras sustancias convergen en búsqueda de sentidos para su vida y el apoyo que éstas (sustancias) ofrecen, llevan al cuerpo a mostrarse de una manera poco aceptada, de socializar con comportamientos irreverentes, de apostarle a no pasar desapercibido y de buscar la "trascendencia individual". ${ }^{28}$

Ahora bien, el consumo de estas sustancias (cocaína, heroína, de síntesis) puede producir problemas físicos y psicológicos además de la adicción; sin embargo, el consumo habitual afecta al funcionamiento cerebral y puede provocar trastornos psíquicos como ideas paranoides (de persecución, de grandeza...) o depresión, y desencadenar cuadros de psicosis y esquizofrenia. "También provoca daños muy importantes en los sistemas circulatorio y respiratorio y complicaciones neurológicas y gastrointestinales.

\footnotetext{
${ }^{26}$ El sistema cannabinoide endógeno es un sistema propio de nuestro organismo que realiza funciones relacionadas con el comportamiento, el aprendizaje, la gratificación, la ingesta de comida, el dolor y las emociones, entre otros. Cuando se consume cannabis, se activa este sistema endógeno de forma externa y artificial y se alteran muchas de las funciones que desarrolla. A dosis pequeñas el efecto es placentero, mientras que a dosis altas puede producir cuadros de gran ansiedad.

${ }^{27}$ Contienen distintos derivados anfetamínicos o de otras sustancias que poseen efectos estimulantes y/o alucinógenos de intensidad variable, y que se encuentran en el mercado en diversas formas (pastillas, cápsulas, polvo, líquidos...) que pretenden resultar atractivas para los más jóvenes.

${ }^{28}$ Cachorro, G. 2009. Op. Cit.
} 
A estos daños hay que añadir los propios de la vía de administración. Si la vía es nasal puede provocar pérdida del olfato, hemorragias nasales, ronquera o incluso la perforación del tabique nasal; en el caso de inyectarse puede provocar reacciones alérgicas a la propia droga o a algunos de los componentes con los que se adultera, así como enfermedades infecciosas asociadas a la vía endo venosa ( $\mathrm{VIH}$, hepatitis, etc.)."29

Además de los efectos mencionados en el consumo de drogas, cualquiera que sea el tipo de SPA, es importante tener muy en cuenta que cada ser humano es feliz como quiere y como puede, y desde esta posición se acompaña el pensamiento de Cachorro, cuando frente a esta situación y las prácticas corporales que se producen como consecuencia del consumo de SPA, empiezan a representar conglomerados de comportamientos y roles que la sociedad no acepta, pero con la cual convive; comportamientos que van desde una simple sensación individual, hasta una seducción por alterar lo plural y obtener ese valor que, al cuerpo, le permita hacer que pase algo y por ende, permitan que el cuerpo obtenga "episodios valiosos en el trayecto de vida". ${ }^{30}$

De manera lamentable, en la ciudad de Ibagué, las prácticas corporales producto del consumo de SPA, están muy atadas a la aparición de conductas delictivas, conductas que permanentemente atentan contra la tranquilidad y que ponen en riesgo la construcción de las prácticas corporales de otros sujetos (ejemplo, salir al parque a caminar en horas de la noche, constituye un riesgo latente porque puede ser atracado; una mujer que se dirija a su trabajo y que esté sola, corre peligro de sufrir maltrato y ser violada). Ante esto, no es menos importante el suceso de ser consumidor y estar plenamente identificado gracias a los síntomas físicos que el consumo de SPA manifiesta, razón que genera un impacto visual de mucha vulnerabilidad para las generaciones más nuevas.

${ }^{29}$ Guía sobre drogas, 2007. Op. Cit.

${ }^{30}$ Cachorro, G. Op. Cit. 


\section{PREVENCIÓN}

La prevención y su significancia en el contexto de esta investigación, se encamina a esclarecer la sensibilidad del acto como tal de evitar el consumo de las drogas y las actividades que para este fin fueron realizadas desde la Secretaría de Salud de Ibagué; desde este enlace terminológico, es igualmente donde se difumina sus límites hasta terminar con su precisión y su utilidad como concepto, la dificultad en definir apropiadamente qué acciones son prevención ${ }^{31}$ primaria, secundaria o terciaria obstaculiza la comunicación entre profesionales, siendo la principal implicación de esta ausencia de precisión terminológica la confusión en la planificación, práctica y evaluación de las actividades llamadas "preventivas".

Aunque, consecuente con el canal de prevención en drogodependencia, se encierran todos los esfuerzos que se puedan orientar a disminuir las dificultades y riesgos asociados con el uso de estas sustancias, así pues, la prevención se enfoca sobre tres estrategias ${ }^{32}$ fundamentales:

- Estrategias orientadas a reducir la demanda con el objeto de reducir el deseo de utilizar drogas y dificultar su adquisición. Estas estrategias diseñadas para prevenir, reducir y/o retardar el consumo de drogas dañinas, pueden incluir estrategias predicadas en la abstinencia.

- Estrategias orientadas a reducir la oferta que buscan obstaculizar la producción y suministro de drogas ilícitas y restringir el acceso y disponibilidad de drogas lícitas bajo ciertas circunstancias. En el entorno escolar, esto incluye tomar medidas para restringir el uso, la posesión y venta de drogas ilícitas al interior de la escuela.

\footnotetext{
${ }^{31}$ FERRER Xavier, SANCHEZ P. José - Prevención: trampas y riesgos del Lenguaje. Instituto para el Estudio de las Adicciones. España, 2001. Enlace Web. http://www.lasdrogas.info.

${ }^{32}$ Iniciativas expuesta por la UNESCO (Organización de las Naciones Unidas para la educación, la Ciencia y la Cultura).
} 
- Estrategias orientadas a reducir las consecuencias adversas del uso de drogas a objeto de reducir el impacto asociado con el uso de drogas y actividades relacionadas con éstas en las personas y en las comunidades. Estas estrategias también se conocen como estrategias de "reducción del daño".

\section{PROBLEMAS RELACIONADOS CON LA PREVENCIÓN DE DROGODEPENDENCIAS}

Es muy difícil lograr que la gente renuncie a todas las prácticas y costumbres que le generan alivio y/o placer y claro, más aún si estas acciones se ven estimuladas por el entorno social; lo que sí es posible es intentar mejorar el comportamiento de las personas frente al consumo de algún tipo de sustancia (sea legal o ilegal), este mejoramiento se enfatiza en conseguir que no se sienta la necesidad de consumir drogas y es ahí, precisamente, donde cobra valor la palabra y el acto propio de prevenir.

El consumo de sustancias psico activas es un comportamiento, una conducta del ser humano que, igual a otras, una vez analizadas en su origen, son susceptibles de modificar a través de la educación, exaltando fundamentalmente que, no es la droga, por muy peligrosa que sea la que produce el problema, sino la persona que la consume. ${ }^{33}$

Si bien es cierto, el cuerpo no corresponde a ser, para el caso de esta tesis, lo que la fisiología y la psicología idealizaron para unir cuerpo y mente, como tampoco lo es natural ni propio de cada individuo, sino aquel que corresponde a la construcción misma de la cultura "Antes bien, es un cuerpo atravesado por las estructuras de significación propias de cada cultura - la lengua, el idioma, en primer lugar - y construido con ellas. De allí que los miembros de las distintas culturas no realizan ni significan de la misma manera ni siquiera las destrezas elementales comunes a todas las culturas. Pero, para que ese atravesamiento y la consecuente construcción del cuerpo tengan lugar, hacen falta otros que lo incorporen a la cultura mediante la incorporación en él de la cultura"34

\footnotetext{
${ }^{33}$ Massün, E. Prevención del uso indebido de Drogas. México 1991.

${ }^{34}$ Crisorio, R. El Cuerpo y las Prácticas Corporales, revista El Monitor - Publicación del Ministerio de Educación de la Nación, República Argentina 2009.
} 
$Y$ en el mismo sentido, "En nuestra sociedad, una de esas instituciones fundamentales es la familia; pero otra, sin duda, es la escuela. El cuerpo, entonces, como realidad construida, en tanto toda realidad es construida por agencias y prácticas diversas, pierde en parte su unidad e individualidad y se multiplica. El cuerpo, más allá de las construcciones históricas, por ende, políticas, que pretenden unificarlo y normalizarlo, muestra en las prácticas sociales, en los usos, en las relaciones, en las significaciones, toda su complejidad y multiplicidad.

Por tanto, en el complejo camino de significaciones que traza las prácticas corporales (Cachorro, 2009), es injustificable omitir la realidad que desde estas prácticas y para este caso (la prevención), ayuda a construir la educación.

Y por qué la Educación?

En la ciudad de lbagué, la prevención hasta ahora efectuada con resultados poco favorables, ubica al ser humano y más específicamente a su cuerpo, como el organismo vivo que no se puede dañar, aquel organismo humano que permanece en condiciones de fragilidad y sanidad y que hay que prevalecer y/o rescatar, aquel organismo que en el debido caso que en él ingresen sustancias químicas ajenas al mismo, sufre alteraciones fisiológicas o psicológicas; en este orden y siguiendo un poco a Carballo y Crespo se puede complementar que "...el organismo humano se relaciona con su ambiente a través de instintos sumamente inespecíficos y carentes de dirección. Esto significa que el organismo humano es capaz de aplicar el equipo de que está dotado por su constitución interna a un campo de actividades muy amplio y que además varía y se diversifica constantemente...,36

Así pues, si se considera la mencionada ubicación en el marco de unas acciones de prevención, resulta, desde una perspectiva benevolente, un poco incuestionable, aun más cuando se desarrolla a través de una Secretaría de Salud; pero ésta, a su vez apoyada por la Educación Corporal debe de ir mas allá e intentar ubicar al cuerpo en una relación más estrecha

\footnotetext{
${ }^{35}$ Crisorio, R. op. Cit.

${ }^{36}$ Carballo C. y Crespo B. - Aproximaciones al Concepto de Cuerpo - Material de apoyo Maestría en Educación Corporal - Facultad de Humanidades y Ciencias de la Educación U.N.L.P. - Argentina 2004.
} 
con el sujeto (Crisorio, 2009), de manera tal que la mente y el cuerpo logren igual relevancia.

En esa misma dirección, el profesor Mario V. Mamonde afirma que "el sujeto moderno se concibe como resultado de la gestión social, gestión iniciada con la educación del Cuerpo y su inserción en el lenguaje y que atrae el interés fundamental de los discursos y prácticas orientadas a darle una forma particular al ser humano..." y continúa "...la pedagogía, la higiene y la salud, las diversas versiones de la Educación Física y todas las disciplinas y saberes interesados en educar al niño en particular, pero también al adulto. Su denominador común es ocuparse del cuerpo para formar y afectar, por su intermedio, otras entidades que se reconocen en el ser humano moderno, sean estas el espíritu, el intelecto o la mente..."37

Ya que no hay una orientación clara desde las instituciones educativas para que promuevan la prevención, como tampoco un mecanismo preventivo que se realice no solo por la prohibición y la penalización a la que se exponen los pertenecientes a estas conductas (consumidores de SPA), es necesario que la actividad preventiva no solo se encamine a justificar, y al mismo tiempo, contrarrestar el fenómeno de la comercialización, sino que se aplique desde un enfoque que busque la no afección del cuerpo, transformando el conocimiento que construye la realidad del mismo; en este sentido, Ricardo Crisorio afirma que "el cuerpo como realidad construida desdibuja sus contornos individuales para aparecer como un cuerpo literalmente social, del cual cada cuerpo singular es un ejemplo particular, particularmente construido en la confluencia de significados privados y sociales, familiares y culturales, sencillos y complejos, presentes y pasados; cuya historia comienza antes del nacimiento y se prolonga más allá de la muerte no solo en los términos que ha señalado el psicoanálisis sino en el sentido de un cuerpo cuya incorporación a la cultura le exige in-corporar en sí mismo a la cultura." 38

En líneas anteriores se mencionó un apoyo de la Educación Corporal a la prevención; (inexistente la prevención en el sistema educativo Colombiano y

\footnotetext{
${ }^{37}$ Mamonde M. Cuerpo, Salud y Política. Un nudo posible - trabajo presentado en el $7^{0}$ Congreso argentino y $2^{0}$ Latinoamericano de Educación Física y Ciencias. Facultad de Humanidades y Ciencias de la Educación. U.N.L.P. Argentina 2007.

${ }^{38}$ Crisorio, R. Constructivismo, cuerpo y lenguaje - Revista Educación Física y Ciencia, año 4, Departamento de Educación Física, Facultad de Humanidades y Ciencias de la educación, UNLP, La Plata - Argentina 1998.
} 
más específicamente en los currículos de educación física en Colegios y Escuelas) por tal razón y ante la ausencia de esta clase de contenidos, es inevitable que sea la educación física la única, aparentemente, llamada a efectuar su viejo rol de instrucción y de automatización de hábitos socialmente aceptables, ${ }^{39}$ aun más cuando el saber que tiene en sus manos un docente no es para que sean transmitidos y apropiados por el sujeto que aprende, sino para que el docente "pueda desarrollar una operación técnica que genere los efectos deseados por el sistema". ${ }^{40}$

De esta forma y sin, de manera respetuosa, "atacar" los contenidos implícitos en los currículos del sistema académico Colombiano, sería la Educación Física la más próxima, dentro del área del conocimiento, a desarrollar de manera implícita la prevención; sin embargo y siguiendo aun más de cerca a Ricardo Crisorio, se puede entender que las habilidades y las destrezas de las que la Educación física se ha ocupado tradicionalmente, cuando son consideradas de manera aislada, carecen de significado y tan solo promueven el aprendizaje por imitación y repetición; por tal razón, la consideración de que la Educación Corporal debe de ir mas allá, pues "...estas habilidades y destrezas no se dan aisladas ni en la cultura, ni en el comportamiento humano. En la primera hallan su significación como parte de configuraciones de movimiento socialmente construidas en relación con la organización del trabajo y, especialmente, el ocio (juegos, deportes, gimnasia, actividades de la naturaleza). En el segundo responden a una totalidad organizada de manifestaciones que se da con una unidad motivacional, funcional, objetal, significativa y estructural". ${ }^{41}$

Entonces, fijando una posición un tanto más concreta en relación a la prevención, un aporte significativo de la Educación en los procesos de prevención de las conductas drogodependientes, se podrá concretar, más claramente, con la educación del cuerpo a través de la adecuación de sus espacios de participación ciudadana ${ }^{42}$, y así, dar paso a la construcción social de un cuerpo prevenido.

${ }^{39}$ Carballo C. En Educación Física, el saber no ocupa lugar (lamentablemente) - Encuentro nacional e Internacional de Investigadores en Educación Física. Uruguay 2004. Documento elaborado como apoyo del Departamento de Educación Física. U.N.L.P. Argentina 2005.

${ }^{40}$ Carballo C. op. Cit.

${ }^{41}$ Crisorio, R. El Problema de los Contenidos de la Educación Física. Serie pedagógica Facultad de Humanidades y Ciencias de la Educación U.N.L.P. Argentina. 1995.

${ }_{42}$ Cachorro G. Prácticas Corporales. Traducción de Sentidos en la Ciudad. Texto pedagógico F.A.H.C.E. - U.N.L.P. Argentina. 2009. 
En el camino de prevenir y de formular estrategias entorno al no consumo de drogas, es muy delicado el manejo que se le destine a la información con la cual se intente cumplir con el propósito preventivo, pues es recomendable que toda información que se emita camino a prevenir el consumo de drogas, se ajuste a algunas reglas elementales ${ }^{43}$ frecuentemente ignoradas, a tener en cuenta:

- No exagerar no mentir, puesto que la información debe ser objetiva, desapasionada, igualmente debe estar amparada en los resultados del conocimiento científico.

- No discriminar entre drogas legales e ilegales, ya que esta discriminación puede ocasionar un desfase entre los jóvenes y el mundo; resulta un poco más convincente enunciar los daños que pueden ocurrir en el organismo independientemente de si son prohibidas o no.

- Evitar la información tipo "manual de uso", esta clase de información tan explícita acerca de las drogas y las formas que existen para su consumo, puede desatar en el mundo y en aquellos inexpertos el deseo y la curiosidad por probarlas, estas informaciones involuntariamente enseñan técnicas de consumo.

Consecuentes a esto, existen algunas acciones y/o distinciones que, frecuentemente se relacionan y en una apreciación más atrevida, se encuentran implícitas en las campañas de comunicación y en los complementos informativos ${ }^{44}$ destinados a la población en general, allí se han referenciado:

- Valoraciones negativas sobre el ser humano "drogadicto", puesto que son estigmatizados como seres anormales y esencialmente malignos.

- La atención en un alto porcentaje centrada en la droga como tal y sus efectos en el ya drogadicto, ignorando por completo los motivos que llevaron al ser humano a ser dependiente del consumo de drogas.

\footnotetext{
${ }^{43}$ Massün Edith, op. Cit.

${ }^{44}$ Los complementos informativos a que la gente del común tiene acceso, como prensa escrita, folletos, cartillas, revistas, gacetas institucionales, volantes etc.
} 
- La carencia en la distinción del consumidor, el que vende droga por necesidad y aquel que vende la droga con propósitos lucrativos.

- Bastantes contenidos informativos de sustancias que aún se desconocen en la comunidad y un diminuto interés por aquellas que vienen causando problemas significativos en el país ${ }^{45}$.

\section{FACTORES CONEXOS}

Los factores, fundamentalmente, conexos a las actividades preventivas se enfocan desde los riesgos que existen en la comunidad asociados con la potencialidad del consumo y la protección, asociada siempre con una reducción del consumo de SPA.

Ahora bien, de las consideraciones a que refieren estos factores de riesgo, van a ser diferentes y dependientes de la etapa de desarrollo; por esta razón y argumentando lo expuesto, el instituto NIDA $^{46}$ señala aquellos factores de riesgo que pueden afectar el desarrollo temprano de la familia, estos son:

- Ambiente hogareño en caos, con mayor énfasis cuando los padres consumen alguna droga o tienen problemas mentales.

- Ejemplo paternal ineficiente, aún más con niños de temperamentos difíciles y desordenes de conducta.

- La ausencia de comunicación, de afecto y cariño en el proceso de crianza.

Otros de los factores de riesgo son las relaciones entre los niños y otros agentes sociales fuera de la familia, especialmente en la escuela, con los compañeros y en la comunidad. Algunos de estos factores son:

- Comportamiento inadecuado de timidez y agresividad en las aulas.

\footnotetext{
${ }^{45}$ No es tan común ver en la comunidad consumidores de cocaína o heroína; abunda si el consumo de inhalables, el alcohol y marihuana.

${ }_{46}$ NIDA, National Institute on Drug Abuse. Señala los factores de riesgo en sus investigaciones realizadas para Estados Unidos y hogares latinoamericanos, lo que a esta cita refiere, son sus conclusiones.
} 
- Dificultad al relacionarse con semejantes.

- Empatía y asocio con compañeros desviados o de conducta inadecuada.

- Percepción de aprobación del uso de drogas en el ambiente escolar y social, así como entre sus compañeros.

- Mal desempeño escolar.

También han sido identificados ciertos factores de protección. Estos no son siempre opuestos a los factores de riesgo y su impacto varía durante el proceso de desarrollo. Los factores de protección más notables incluyen:

- Relaciones y/o la vinculación estrecha con instituciones Prosociales, tales como, la familia, escuela, organizaciones religiosas.

- Estar expuesto a reglas claras de conducta dentro del núcleo familiar y el envolvimiento de los padres en la vida de sus hijos.

- Conocimiento y adopción de normas convencionales sobre el uso de drogas.

- Fuertes lazos familiares.

- Excelente desempeño escolar.

Sumado a lo anterior, existen otros factores que pueden ser tanto de riesgo, como de protección, es decir, de acuerdo a su presencia o no; ejemplo de ello es la disponibilidad de drogas ${ }^{47}$; otra es si en el entorno existe 0 prevalece la idea de tolerar el consumo y sin lugar a dudas, el narcotráfico ${ }^{48}$.

\footnotetext{
${ }^{47}$ Haciendo referencia a la presencia de drogas ya sea, cerca del hogar, del colegio o si se está expuesto a situaciones donde se comercialice o se consuma.

${ }^{48}$ El narcotráfico es una industria ilegal mundial que consiste en el cultivo, manufactura, distribución y venta de drogas ilegales.
} 


\section{CAPÍTULO II}

\section{DIAGNÓSTICO}

Dado que en la actualidad se han incrementado los consumos de sustancias psicoactivas y que además esta conducta ha alcanzado a poblaciones altamente vulnerables como lo son los niños, adolescentes, jóvenes y mujeres; diferentes instituciones gubernamentales y $\mathrm{ONG}^{49}$ (organizaciones no gubernamentales) han pensado siempre en realizar campañas y talleres informativos que detengan a como dé lugar estas conductas, sin tener en cuenta que con las formas que emplean la prevención no han logrado penetrar suficientemente en las poblaciones vulnerables. Estas formas de abordaje de la prevención se conocen comúnmente como "periféricas", porque se limitan a realizar acciones parciales sobre el fenómeno, sin ahondar en el manejo de la problemática con estrategias adecuadas y con los agentes institucionales fundamentales propios de esta sociedad, como lo es la familia y la escuela. ${ }^{50}$

Ante la presencia de este problema de patología social, es necesario el registro de las variables claves para monitorizar la evolución de la situación y su caracterización; es así como surgieron diversos estudios epidemiológicos descriptivos en el país que condujeron al diseño del sistema VESPA ${ }^{51}$, así como al aporte de información válida y uniforme sobre los indicadores de medición del consumo para formular las políticas de promoción de la salud, de la prevención del consumo y del manejo del drogodependiente y su entorno en tanto familiar como social.

\footnotetext{
${ }^{49}$ En el caso de la ciudad de lbagué, los entes gubernamentales son: la Secretaría de Salud de la Ciudad, con incidencia directa de la Secretaría de Salud del Departamento y el Ministerio de la Protección social, así como la cooperación del ICBF(Instituto Colombiano de Bienestar Familiar), el DANE (Departamento Administrativo Nacional de Estadística). En el caso de las no gubernamentales, la Fundación FEI (Familia Entorno Individuo) ha trabajado de la mano con la Secretaría de Salud Municipal y ha contribuido en la elaboración de diagnósticos comunitarios y en la construcción de acciones encaminadas a publicitar el no consumo, a recopilar la información y a unificar las tareas de acción de la Secretaría de Salud.

${ }^{50}$ Crisorio R. El Cuerpo y las Prácticas Corporales, revista El Monitor - Publicación del Ministerio de Educación de la Nación, República Argentina. 2009.

${ }^{51}$ Sistema de Vigilancia Epidemiológica de Sustancias Psicoactivas.
} 
En este sentido "EI VESPA ha servido de modelo y ha sido adoptado en otros países de América con resultados valiosos en la lucha contra la drogodependencia y contra la complejidad de los fenómenos de producción, distribución, tráfico y consumo; para el caso de Colombia que, durante las últimas décadas, ha sido el fenómeno que ha incurrido negativamente en la sociedad por sus numerosas víctimas, por la violencia asociada y por su influencia directa en el cuerpo." Afirmó Germán Cardona ${ }^{52}$, durante una charla de prevención realizada en las instalaciones de la Alcaldía Municipal de Ibagué, en la cual se promovía la elaboración de diagnósticos comunitarios entorno a los factores de riesgo.

\section{IBAGUE Y SU CULTURA ENTORNO AL CONSUMO}

Realizar un análisis en torno al consumo de sustancias psicoactivas en la ciudad de lbagué debe pasar por entender, de manera inicial, las dinámicas en torno a los consumos paralelos que propone la sociedad misma, entender esto significa ubicar a las sustancias psicoactivas en la dinámica del mercado, es decir, como un objeto en circulación al cual se puede acceder como todos los demás. En este aspecto, es importante retomar el concepto de Consumo de Bourdieu, 2000 (citado por Alonso L. 2002), "...el consumo son comportamientos estructurados en el hábito de clase que están construidos como las demás en la expresión dinámica de una posición social (o sea el consumo es una práctica constituyente y no sólo un epifenómeno construido de las relaciones de producción y dominación). Dicho de otro modo, hay homología estructural entre el campo de las prácticas de consumo y el campo de las relaciones sociales. ${ }^{353}$ Concepto que, si bien se refiere a una categoría general, puede resultar aplicable a lo particular, para este caso al consumo de sustancias psicoactivas. En ese sentido, Bourdieu también manifiesta que los habitus no están simple o mecánicamente superpuestos a

\footnotetext{
${ }^{52}$ Germán Cardona es Médico Cirujano, magister en Drogodependencia, egresado de la Universidad Complutense de Madrid, España; director de la fundación FEI, cuya ardua tarea ha sido focalizada en promover la prevención de conductas drogodependientes a través de mecanismos de información.

53 Alonso, L.E. El estructuralismo genético y los estilos de vida: Consumo, Distinción y Capital Simbólico en la obra de Pierre Bourdieu, España - 2002.
} 
los sujetos, como se observa claramente en el tema del consumo, sino que son parte de la expresión de los sujetos mismos.

Así, el consumo además de ser un comportamiento constitutivo de las sociedades modernas que aporta al proceso de construcción de identidad real ${ }^{54}$ en la medida que otorga distinción y reconocimiento, es un lugar en el cual de manera permanente se recrean significaciones y sentidos colectivos, por ejemplo, es claro que el consumismo ha sido un comportamiento ampliamente criticado, sin embargo, no solo permanece sino que muchos quieren integrarse a él y, tal vez esta forma desencadena en el flagelo más grande del país, ampliando un poco el contexto, como lo es el narcotráfico.

En el consumo de sustancias es claro entender cómo se mueven por lo menos una racionalidad que involucra aspectos simbólicos y estéticos en tanto la apropiación otorga distinción y status, ${ }^{55}$ la lógica que allí se mueve no es la de la escasez de los bienes si no la imposibilidad de que otros los tengan, es común encontrar como en el ambiente del consumo de sustancias, el usar basuco es catalogado como una degradación y generalmente es asociado a bajo mundo o incapacidad económica, el uso de la marihuana es indistinto, es decir, pueden acceder diferentes sectores sociales mientras que el del éxtasis está asociado a poder de adquisición. Igualmente, la racionalidad integrativa y comunicativa de una sociedad se hace presente en el consumo de psicoactivos en tanto aglutina socialmente y en ese sentido el consumo tiene una doble dinámica, por un lado agrupa a quienes comparten ciertos significados y por otro quienes no los comparten por lo menos los reconocen.

Desde cualquier tipo de racionalidad, es claro que el consumo genera ciertas prácticas alrededor de los bienes y servicios que se eligen: habitus, (Bordieu), o "sistemas de disposiciones duraderas, estructuras estructuradas predispuestas a funcionar como estructuras estructurantes, es decir, en tanto

\footnotetext{
54 “... el conocimiento humano construye con la palabra realidad, dejando "real" para significar lo que queda fuera de la acción constructiva del sujeto humano y que construye la referencia necesaria de esa construcción. La respuesta a la primera pregunta de Martí, ¿Qué se construye?, sería: se construye la realidad por referencia a lo real." Crisorio R. Constructivismo, cuerpo y lenguaje - 1998.

${ }^{55}$ En este caso, Carusso, M. y Dussel proponen una definición provisoria que analiza y define "al sujeto como una construcción explicativa de la constitución de redes de experiencias en los individuos y en los grupos". Carusso, M. y Dussel, I - 1997 "Yo, Tu, El: ¿Quién es el Sujeto?" en cinco conceptos para pensar la educación contemporánea. Texto pedagógico de la Maestría en Educación Corporal, F.A.H.C.E - U.N.L.P. - Argentina.
} 
que principios de generación y de estructuración de prácticas y representaciones..." (Bordieu 2000, citado por Alonso L. 2002), las prácticas de consumo, en tanto que prácticas, y las representaciones que de ellas tienen los individuos, son, a priori, susceptibles de revelar un enfoque en términos de habitus, si se admite, al menos provisionalmente, que estas prácticas y sus representaciones son sólo, en el mejor de los casos, casos particulares que revelan, en lo que no les es específico, el mismo enfoque que toda otra práctica o representación.

Por su parte, el análisis del consumo de bienes permite por tanto esbozar la relación singular que el sujeto teje entre su posición y percepción de la cultura de su tiempo y las tácticas que esgrime para asegurar o transformar su lugar en el mismo.

Los anteriores planteamientos revelan como en el consumo de cualquier tipo de bienes operan las mismas lógicas, lo que cambia son los objetos, y en lo específico de las sustancias que generan dependencia física y psicológica (probablemente los otros objetos generan dependencia psicológica); paralelo a lo anterior, la sociedad misma cuando establece la división tajante entre sustancias legales e ilegales señala la incapacidad de vivir sin ellas otorgándole un carácter de irrenunciable.

Por lo anterior, algunas personas se preguntaran entonces, si la única posibilidad de encontrar cultura en el consumo de sustancias se amarra a la tradición indígena y ancestral? Y bueno, es importante dejar claro, en primer lugar, que no se trata esto de un debate conceptual, como también es importante resaltar que cada concepto interactúa con una historia y una experiencia, cambiantes las dos y de igual manera se trata de entender qué pasa con el consumo de psicoactivos en el contexto urbano en lbagué y la manera como dicho consumo está inserto a una idea amplia de cultura, entendida esta con la significancia " ...al principio, al medio, al entorno, más como contexto que como texto que atraviesa - textualiza- al individuo humano." (Crisorio, 1998), con esta plataforma teórica, entonces, es muy acertado seguir a Cachorro ${ }^{56}$ y entender que "las prácticas corporales desplegadas en la ciudad sirven para consolidar relaciones y contactos sociales entre parientes, compañeros de trabajo, generando un encuadre de la relación diferente al ofrecido por el tiempo productivo, (...) en esas

${ }^{56}$ Cachorro G. Prácticas Corporales. Traducción de Sentidos en la ciudad. 2009 
prácticas corporales se exteriorizan solidaridades, servidumbres, miserias, honestidades, mecanismos de poder, enfermedades y en realidad eso es lo que se pone en juego. En la práctica corporal se pone la densidad de la subjetividad a través del cuerpo. Por lo tanto, se juega cosas distintas para cada participante."

Así pues, entender el consumo, debe pasar por entender que allí hay rasgos culturales porque se hace parte de una cultura y en ese sentido hay resignificaciones a pesar de la ausencia de tradición e identidad con el pasado, dichos rasgos deben ser entendidos desde la comprensión y no desde la descalificación o la negación.

Existen algunos aspectos del consumo de SPA en las ciudades capitales de un país como Colombia (por supuesto, Ibagué no es la excepción), aclarando que en este entorno cultural no existen los mismos patrones que en la mayoría de países consumidores; puesto que en este, existen unas particularidades y tal vez, irrepetibles situaciones que vale la pena tener en cuenta:

- La edad es lo de menos; en lbagué, el consumo va desde los 7 u 8 años hasta los 70 , sobresaliendo aquellas personas que se encontraban sin una actividad económica reconocida de manera formal, dicho de otra forma, aquellos que no estaban matriculados en alguna escuela o aquellos desempleados, en ambos casos, según se logra sustraer de las fuentes de información, como el VESPA, se presenta al parecer por simple curiosidad y por las mal llamadas "pruebitas" o por "saber que se siente" y en este mismo enfoque, los hombres han sido quienes más tipos de sustancia han consumido y en este orden sobresale el basuco, consumido por los estratos ${ }^{57}$ bajos; la

\footnotetext{
${ }^{57}$ El estrato social es un segmento de la población que difiere de otros, en cuanto a riqueza, acumuladas, valores comunes, posesiones personales y prestigio social. Respecto a los criterios teóricos de la estratificación social, cabe señalar que las ciencias sociales comprenden numerosas y variadas corrientes del pensamiento social. Cada una tiene sus propios criterios para estratificar a la sociedad, entre estas corrientes destaca el estructuralismo funcionalista, que contempla desde su particular punto de vista el conocimiento de la organización social; de ahí que las bases de estas corrientes sociales sean de manera natural, las desigualdades o diferencias de carácter económico entre los individuos que integran una sociedad. Las diferencias se acentúan en función de las capacidades individuales que le conducen a ocupar diversas posesiones en la escala social y en consecuencias roles diferenciados, lo que significa que entre mayor capacidad individualista que exista, mayor será la recompensa que se obtenga de los beneficios sociales que obtengan.
} 
cocaína y la heroína son utilizadas por las personas de los estratos altos y, por último, la marihuana ocupa el primer lugar de atracción por su preferencia en todos los estratos.

- Se ha adoptado una situación de comportamientos "cantineros" y no es para menos, en muchos de los casos de consumo que se reportaron a la Secretaría de Salud, estaban muy ligados al consumo de alcohol, incluso, aquellas situaciones como el maltrato, el abuso sexual y el hurto, eran producto de esta misma situación; a lo anterior se suma, que este es el único país del mundo en el cual se adulteran las bebidas alcohólicas ${ }^{58}$ y que la Ley tan solo prohíbe la venta a menores de edad y exige una recomendación en la publicidad de toda bebida nacional y extranjera. ${ }^{59}$ Esta situación está complementada con el consumo de tabaco, sexta causa de mortalidad de Colombia y que a la fecha no es considerada un problema en al país, tanto así, que la ley 124 de 1994 quitó la prohibición del expendio a menores de edad.

- Otro aspecto que vale la pena resaltar, aunque este sea un caso más de relevancia país, no deja de inquietar y es el transporte de drogas, ya que es una causa que origina también la sobredosis, consiste en que el ser humano lleve en sus cavidades pequeñas cápsulas de aproximadamente 10 a 20 gramos de cocaína que, por su diminuto tamaño, permite el acceso de un mínimo de 50 cápsulas. Una vez que fortuitamente una cápsula se rompe y su contenido es absorbido por el organismo del ser humano, empieza en él una serie de efectos devastadores con su salud y, aunque logre salvar su vida, será inminente su traslado a un centro penitenciario.

- Igual consideración merece lo que ocurre con el basuco, el quinto psicoactivo más consumido después del alcohol, el tabaco, la marihuana y la cocaína, solo se consume en los países de la región andina y únicamente se fabrica en Colombia. Por esta razón, ninguna nación, aparte de la mencionada, ha producido investigaciones sobre

\footnotetext{
${ }^{58}$ La Dirección Nacional de Estupefacientes emite de manera permanente, informes acerca de lotes y cargamentos de bebidas alcohólicas adulteradas, razón por la cual tan solo ha elevado los controles, pero esta medida está atada más al control por evasión de impuestos, que por una medida que favorezca la prevención del cuerpo.

${ }^{59}$ Ley 30 de 1986 - Artículo 16․ En todo recipiente de bebida alcohólica nacional o extranjera deberá imprimirse, en el extremo inferior de la etiqueta y ocupando al menos una décima parte de ella, la leyenda "El exceso de alcohol es perjudicial para la salud". En la etiqueta deberá indicarse, además, la gradación alcohólica de la bebida.
} 
el basuco; este, posee más del 20 ó $25 \%$ del alcaloide, por la concentración del alcaloide, la absorción por parte del organismo es más rápida y su efecto no dura más de los 20 minutos, ${ }^{60}$ entonces, el consumidor entra en depresión frecuentemente, fuma otro "cigarro o papeleta", luego uno más y así, de manera consecutiva hasta que, con facilidad, fuma 100 cigarros en una noche.

Y bueno, que efectos son estos? (los anteriormente descritos), por lo general, aquellos que de manera crónica consumen el basuco sufren las mismas enfermedades que los fumadores de tabaco, tan solo que con la primera, logran desarrollar los efectos en menos tiempo; también se cree que el permanganato de potasio presente en muchos de los excipientes afecta al páncreas y entonces ya no se puede producir insulina y así, los "basuqueros" son también diabéticos de por vida. (Mencionando tan solo lo que ocurre en el organismo de quien consume).

- Otra situación que no se puede pasar por alto en la ciudad, es la venta incontrolada de fármacos y su posterior consumo, este es un problema de mucha relevancia, especialmente porque la fármaco-vigilancia es muy precaria y los controles son poco eficaces, de tal forma que no hay como evitar que las personas puedan obtener medicamentos sin necesidad de prescripción médica, ni que las farmacias puedan venderlos. (Tal caso puede verse con mayor detenimiento en la venta de antidepresivos, tranquilizantes, calmantes y aquellos que producen somnolencia, medicamentos que son consumidos sin conocer sus advertencias y que sin la respectiva dosificación, producen adicción.

- Por último, es de vital importancia destacar que en lbagué, los expendedores de sustancias ilícitas acostumbran a diluir las drogas y mezclarlas con otros elementos más tóxicos y peligrosos con el fin de incrementar sus ganancias, (el basuco es mezclado con el polvo de ladrillo, la cocaína con cal y la heroína con agua) además de los riesgos para los usuarios, esto no permite determinar con claridad acerca del consumo de una persona, induciendo a pruebas de laboratorio más complejas.

Ahora bien, la ciudad de Ibagué, tiene algunas características geográficas y demográficas que vale la pena mencionar como referente para comprender,

${ }^{60}$ Uribe C. La toxicología de los psicoactivos en Dirección nacional de Estupefacientes. Problemática de las drogas en Colombia. DNE. Bogotá. 2002. 
tal vez, el ángulo de acción de las actividades con la cual se efectuó la prevención.

La división Administrativa de la ciudad de lbagué, en el área Urbana, está compuesta por 13 Comunas $^{61}$ (según muestra la figura 1 y su distingo de color) en su zona urbana y 17 corregimientos que, entre ellos, suman 139 veredas.

Figura 1. Mapa de lbagué

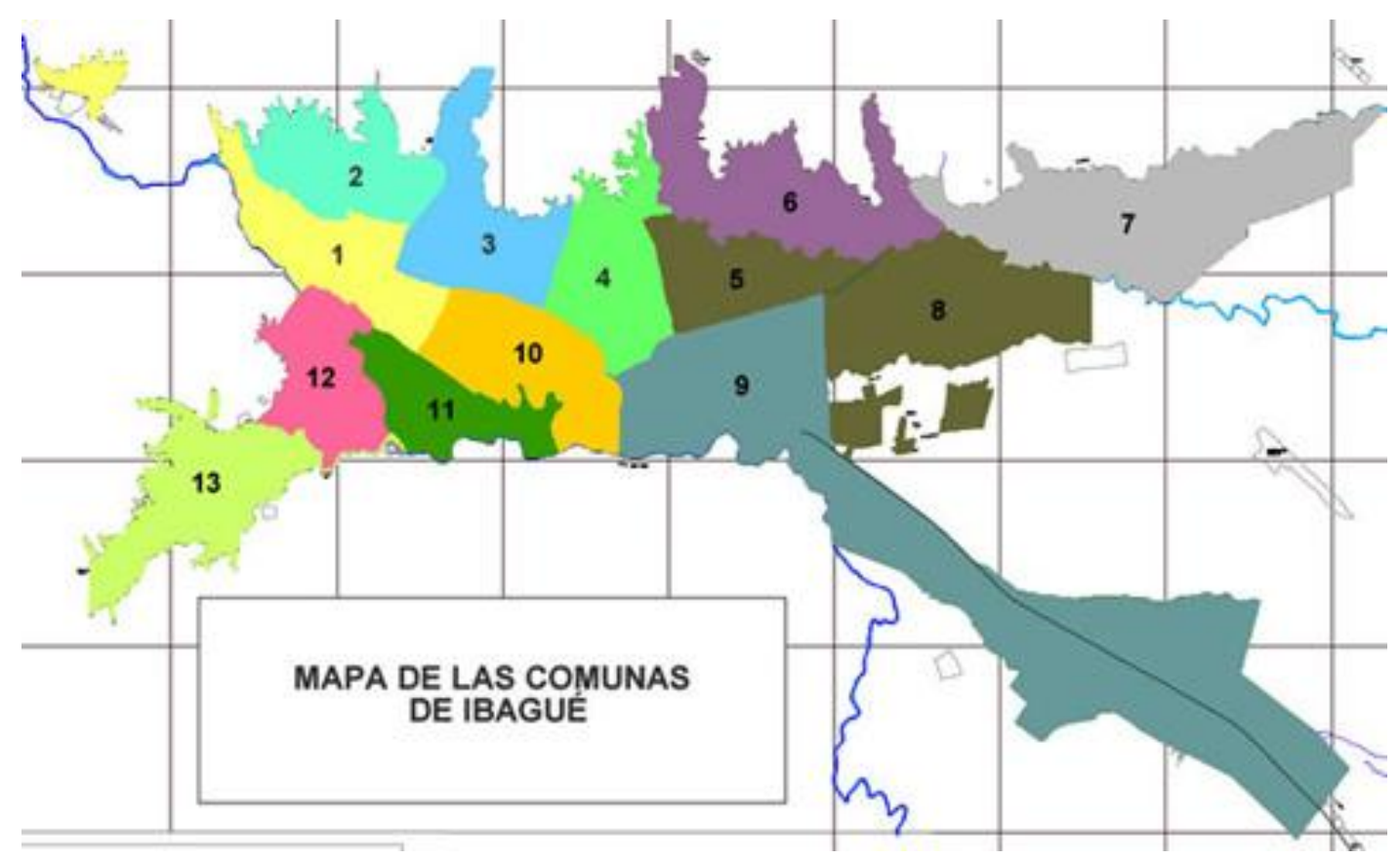

FUENTE: Anuario Estadístico de lbagué 2003.

En esta misma línea de información geográfica que se ofrece de la ciudad de Ibagué, aunque de manera tangencial, se destacan aspectos como la

61 Las Comunas son unidades de gestión política y administrativa descentralizada con competencia territorial, patrimonio y personería jurídica propia. (http://www.lacomuna12.com.ar), en lbagué, el proceso de descentralizar por comunas se dio por medio del Acuerdo número 044 del 21 de junio de 1.989 expedido por el Concejo de Ibagué, donde se establece la División Territorial Urbana del municipio de Ibagué en donde queda estipulado que la ciudad cuenta con trece comunas. 
ubicación en la geografía nacional, ya que la ciudad de lbagué es la capital del departamento del Tolima, está enclavada de la vertiente oriental de la cordillera central de Colombia, en el nacimiento de un amplio valle formado por el Río Coello y su afluente el Río Combeima, que toma sus aguas de las cimas nevadas del Tolima y hacen parte del Parque Nacional Natural Los Nevados de Colombia, que en buena parte pertenece al Municipio de Ibagué. La ciudad no presenta ciclo estacional, pero su área rural disfruta de todos los niveles térmicos de montaña, con cumbres nevadas a 4.200 metros de altitud y temperaturas bajo cero o zonas calurosas, en amplios valles por debajo de los 800 metros de altitud que alcanzan valores térmicos superiores de 40 grados $C$.

Es una ciudad amable, de construcciones bajas y de ambiente festivo, no en vano ostenta el rotulo de "Ciudad Musical de Colombia"; al inicio del periodo objeto de este estudio, tenía una población de 439.785 habitantes, con multiplicidad de ofertas en espacios de ocio y con prácticas corporales densas y subjetivas como los mencionadas por Cachorro "la necesidad de estar con otros se renueva constantemente. Se exterioriza al pertenecer a cofradías, tener espacios de reconocimiento motriz, recibir las felicitaciones por logros deportivos o elogios por maniobras técnicas, exhibir ejecuciones individuales habilidosas en el juego motor, progresar en logros de competencia motrices. Son espacios de felicidad corporal obtenidas en momentos esporádicos. Se halla a veces en las propuestas de arraigo populares. ${ }^{62}$

De esta manera y siguiendo a Carballo, se tiene como posición (o por lo menos para quien escribe estas líneas) que el ser humano vive y tiene diversas experiencias en los diferentes roles que sus cuerpos (existen de acuerdo a cada rol que pone en práctica) ha desempeñado y que van determinando la realidad social que el cuerpo construye, pero como menciona Bagú, 1974, (citado por Carballo y Crespo, 2001) esta construcción social del propio yo "...varía con los distintos tipos de sociedad, el ciclo histórico que estas últimas atraviesan y las funciones que el individuo va cumpliendo en las variadas etapas de su existencia." ${ }^{, 63}$

62 Cachorro, G. Prácticas Corporales. Traducción de Sentidos en la Ciudad. Texto pedagógico F.A.H.C.E. - U.N.L.P. Argentina 2009.

${ }^{63}$ Carballo, C. y Crespo, B. 2001. Op. Cit. 
Por tanto, sería poco justificable no hacer referencia al índice poblacional de acuerdo a las etapas de cada sujeto, según la clasificación por sexo y edad que se muestra a continuación; donde claramente se observa que la mayor concentración de población, existe entre los 15 y los 45 años y es, de una manera respetuosa, la población más permeable porque las etapas de existencia son vulnerables a todo tipo de práctica y este rango es donde más está presente el consumo de SPA.

Tabla 1. Población por Rangos de Edad y Sexo. 2.003

\begin{tabular}{|c|c|c|c|}
\hline \multirow{2}{*}{ EDAD } & \multicolumn{2}{|c|}{ SEXO } & \multirow{2}{*}{ TOTAL } \\
\hline & MASCULINO & FEMENINO & \\
\hline Menos de 1 año & 3.351 & 3.156 & 6.507 \\
\hline 1 año & 4.238 & 4.074 & 8.312 \\
\hline 2 años & 5.438 & 5.084 & 10.522 \\
\hline 3 años & 5.392 & 5.047 & 10.439 \\
\hline 4 años & 5.244 & 4.928 & 10.172 \\
\hline 5 años & 4.833 & 4.715 & 9.548 \\
\hline 6 años & 4.535 & 4.512 & 9.047 \\
\hline 7 años & 4.715 & 4.587 & 9.302 \\
\hline 8 años & 4.789 & 4.658 & 9.447 \\
\hline 9 años & 4.403 & 4.431 & 8.834 \\
\hline 10 años & 4.857 & 4.885 & 9.742 \\
\hline 11 años & 4.679 & 4.796 & 9.475 \\
\hline 12 años & 5.159 & 5.068 & 10.227 \\
\hline 13 años & 4.979 & 5.051 & 10.030 \\
\hline 14 años & 4.562 & 4.723 & 9.285 \\
\hline 15 - 19 años & 19.836 & 23.046 & 42.882 \\
\hline
\end{tabular}




\begin{tabular}{|l|l|l|l|}
\hline $20-24$ años & 17.641 & 21.691 & 39.332 \\
\hline $25-29$ años & 17.780 & 21.551 & 39.331 \\
\hline $30-34$ años & 17.031 & 20.179 & 37.210 \\
\hline $35-39$ años & 14.175 & 17.024 & 31.199 \\
\hline $40-44$ años & 11.969 & 13.045 & 25.014 \\
\hline $45-49$ años & 9.333 & 10.282 & 19.615 \\
\hline $50-54$ años & 8.129 & 8.918 & 17.047 \\
\hline $55-59$ años & 6.113 & 6.598 & 12.711 \\
\hline $60-64$ años & 5.633 & 6.259 & 11.892 \\
\hline $65-69$ años & 3.989 & 4.331 & 8.320 \\
\hline $70-74$ años & 2.922 & 3.269 & 6.191 \\
\hline $75-79$ años & 1.909 & 2.217 & 4.126 \\
\hline 80 años y más & 1.815 & 2.211 & 4.026 \\
\hline TOTAL & 209.449 & 230.336 & 439.785 \\
\hline
\end{tabular}

FUENTE: Secretaría de Salud Municipal

Tabla 2. Población por grandes Grupos de Edad. Estimada a Junio 30 $2.003-2.004$

\begin{tabular}{|l|c|c|c|c|c|c|}
\hline AÑo & TOTAL & $\begin{array}{c}\mathbf{0} \text { a 2 } \\
\text { años }\end{array}$ & $\begin{array}{c}\mathbf{3} \text { a } \mathbf{6} \\
\text { años }\end{array}$ & $\begin{array}{c}\mathbf{7} \text { a 15 } \\
\text { años }\end{array}$ & $\begin{array}{c}\mathbf{1 6} \text { a } \mathbf{2 4} \\
\text { años }\end{array}$ & $\begin{array}{c}\mathbf{2 5} \text { años y } \\
\text { más }\end{array}$ \\
\hline 2.003 & 439.785 & 23.740 & 31.055 & 80.061 & 72.617 & 232.312 \\
\hline 2.004 & 444.460 & 23.601 & 30.546 & 79.894 & 73.360 & 237.059 \\
\hline
\end{tabular}

FUENTE: DANE

Una vez la Secretaría de Salud de Ibagué conoció de manera previa las proyecciones poblacionales y los registros de población por grupo etáreo, se procedió a revisar los registros nacionales para en cierta manera "asemejar" la situación local con la nacional y causarla por las directrices y disposiciones 
que el Ministerio de la Protección Social había dispuesto para tratar tal situación.

Siguiendo este proceder, el programa RUMBOS ha sido el encargado de realizar la investigación y de recopilar información válida de manera periódica sobre el consumo de Psicoactivos y así, tener un registro de la situación del país en esta materia; pero, que es RUMBOS?, RUMBOS fue creado en 1998 por decisión expresa del Presidente de la República. Es un programa que desde el comienzo incluyó como uno de sus procesos fundamentales el de investigación, consciente de la necesidad de contar con información válida, confiable y oportuna sobre el consumo de psicoactivos.

En 1999 RUMBOS, con la entonces existente Comisión Nacional de Investigación en Drogas ${ }^{64}$, realizó el ejercicio de aplicación de un sondeo a jóvenes de 10 a 24 años en todo el país, como una medida rápida y de bajo costo para obtener datos sobre el consumo de drogas. Se intentó suplir la falta de una muestra probabilística con un gran tamaño de muestra que finalmente ascendió a la cifra de 305.869 jóvenes, aunque sabiendo que sería imposible calcular los errores de muestreo para las estimaciones.

Para 2001 la Comisión Nacional de Investigación en Drogas, asumió la realización de la Encuesta Nacional sobre Consumo de Sustancias Psicoactivas en Jóvenes de 10 a 24 años, con la coordinación de RUMBOS y particularmente el Observatorio Colombiano sobre Consumo de Sustancias Psicoactivas.

Anteriormente se mencionó que en lbagué, el mayor grupo poblacional previo al periodo objeto de este estudio estaba entre los 15 y los 45 años y que, este grupo es el de mayor vulnerabilidad al consumo de SPA; pues bien, la encuesta Nacional realizada por el programa Rumbos se realizó tomando como muestra los estudiantes desde los 10 y hasta los 24 años a razón de que los casos nuevos de consumo se registraban antes de los 25 años, y también por economía del mismo programa, pues anteriormente las encuestas se realizaban tomando a la población en sus hogares y desde los 10 hasta los 60 años, situación que correspondía a un costo elevado, a una

64 En esta Comisión participó la Dirección Nacional de Estupefacientes, la Unidad Coordinadora de Prevención Integral de la ciudad de Bogotá D.C., la Policía Antinarcóticos, la Secretaría de Salud de Bogotá D.C., el Vice ministerio de la Juventud del Ministerio de Educación, el Fondo Nacional de Estupefacientes y otras entidades invitadas. 
disposición superior y a una encuesta aun más amplia. (Se tomó como referencia esta última encuesta, ya que es la realizada antes del 2004).

"Una de las más importantes tareas del Programa RUMBOS y de su Observatorio Colombiano sobre Consumo de Sustancias Psicoactivas (OCCSP) es la coordinación de la Encuesta Nacional sobre Consumo de SPA en Jóvenes. Esta Encuesta tiene como propósito fundamental, determinar el estado del consumo de drogas en nuestro país, específicamente en los jóvenes que son la población de más alto riesgo y en la que deben centrarse de manera prioritaria las acciones de prevención. El OCCSP es un sistema que coordina la generación de información sobreconsumo de SPA, produce informe sobre consumo, la analiza y la difunde. Comenzó formalmente a funcionar en 2001, año en que recibió la directriz de RUMBOS de coordinar la realización de la Encuesta Nacional sobre Consumo de Sustancias Psicoactivas en Jóvenes de 10 a 24 años"65.

La muestra para elaborar la mencionada encuesta, fue de 200.876 estudiantes encuestados en 27 ciudades capitales de todo el país, (incluida lbagué); es muy importante aclarar que se menciona la encuesta realizada por el Programa RUMBOS y los datos arrojados por la misma, tan solo para tener una referencia tangencial de la realidad de la ciudad (pues en lbagué aun no se hace un estudio similar, y el objeto del presente no corresponde a la recopilación de datos).

Encuesta Nacional sobre Consumo de Sustancias Psicoactivas en Jóvenes de 10 a 24 años elaborada por RUMBOS. 2.001 (en el caso de lbagué, la población encuestada fue de 8.038).

Tabla 3. Distribución de la Población Encuestada. 2.001

\begin{tabular}{|c|c|c|c|}
\hline \multicolumn{2}{|l|}{} & NÚMERO & PORCENTAJE \\
\hline GÉNERO & Masculino & 3.956 & $49.2 \%$ \\
\hline
\end{tabular}

65 Observatorio Colombiano sobre el Consumo de Sustancias Psicoactivas, http://www.nuevosrumbos.org/documentos/Encuesta\%202001.pdf 


\begin{tabular}{|c|c|c|c|}
\hline \multirow{3}{*}{ EDAD } & Femenino & 4.082 & $50.8 \%$ \\
\cline { 2 - 4 } & $10-14$ & 4.201 & $52.0 \%$ \\
\cline { 2 - 4 } & $15-19$ & 3.193 & $39.5 \%$ \\
\hline \multirow{2}{*}{ ESCOLARIDAD } & $20-24$ & 690 & $8.5 \%$ \\
\cline { 2 - 4 } & Bachillerato & 7.044 & $86.5 \%$ \\
\hline \multirow{3}{*}{ OCUPACIÓN } & Universidad & 1.095 & $13.5 \%$ \\
\cline { 2 - 4 } & Estudia & 6.901 & $86.7 \%$ \\
\hline & Estudia y trabaja & 1.060 & $13.3 \%$ \\
\hline
\end{tabular}

FUENTE: Encuesta Nacional Programa Rumbos

Tabla 4. Descripción del Consumo de Alcohol. 2.001

\begin{tabular}{|c|c|c|}
\hline \multicolumn{2}{|c|}{ VARIABLES } & VALORES \\
\hline \multirow{7}{*}{ Promedio de edad inicio } & 12.7 años \\
\hline \multirow{3}{*}{ Edad Inicio } & Menos de 10 años & $19.1 \%$ \\
\cline { 2 - 3 } & $10-14$ años & $65.3 \%$ \\
\cline { 2 - 3 } & $15-19$ años & $15.4 \%$ \\
\hline \multirow{3}{*}{ Frecuencia } & $20-24$ años & $0.2 \%$ \\
\cline { 2 - 3 } & De 3 a 6 días a la semana & $2.2 \%$ \\
\cline { 2 - 3 } & De 1 a 2 días por semana & $9.5 \%$ \\
\hline
\end{tabular}




\begin{tabular}{|l|c|c|}
\hline & De 1 a 3 veces al mes & $23.8 \%$ \\
\cline { 2 - 3 } & De 4 a 11 veces al año & $22.1 \%$ \\
\cline { 2 - 3 } & Menos de 4 veces al año & $41.8 \%$ \\
\hline
\end{tabular}

FUENTE: Encuesta Nacional Programa Rumbos

Tabla 5. Descripción del Consumo de Cigarrillo. 2.001

\begin{tabular}{|c|c|c|}
\hline \multicolumn{2}{|c|}{ VARIABLES } & VALORES \\
\hline \multirow{7}{*}{ Promedio de edad inicio } & 13.6 años \\
\cline { 2 - 3 } Edad Inicio & Menos de 10 años & $5.7 \%$ \\
\cline { 2 - 3 } & $10-14$ años & $63.0 \%$ \\
\hline \multirow{5}{*}{ Frecuencia } & $15-19$ años & $30.1 \%$ \\
\cline { 2 - 3 } & $20-24$ años & $1.2 \%$ \\
\cline { 2 - 3 } & Te 1 a 2 días por semana & $12.8 \%$ \\
\cline { 2 - 3 } & De 1 a 3 veces al mes & $14.8 \%$ \\
\cline { 2 - 3 } & De a 6 días a la semana & $10.4 \%$ \\
\hline & De 4 a 11 veces al año & $22.1 \% 12.5 \%$ \\
\cline { 2 - 3 } & Menos de 4 veces al año & $41.8 \% 26.9 \%$ \\
\hline
\end{tabular}

FUENTE: Encuesta Nacional Programa Rumbos 
Tabla 6. Descripción del Consumo de Marihuana. 2.001

\begin{tabular}{|c|c|c|}
\hline \multicolumn{2}{|r|}{ VARIABLES } & VALORES \\
\hline \multicolumn{2}{|c|}{ Promedio de edad inicio } & 14.9 años \\
\hline \multirow{4}{*}{ Edad Inicio } & Menos de 10 años & $1.9 \%$ \\
\hline & $10-14$ años & $40.4 \%$ \\
\hline & $15-19$ años & $54.5 \%$ \\
\hline & $20-24$ años & $3.3 \%$ \\
\hline \multirow{6}{*}{ Frecuencia } & Todos los días & $9.8 \%$ \\
\hline & De 3 a 6 días a la semana & $9.4 \%$ \\
\hline & De 1 a 2 días por semana & $10.6 \%$ \\
\hline & De 1 a 3 veces al mes & $15.0 \%$ \\
\hline & De 4 a 11 veces al año & $14.6 \%$ \\
\hline & Menos de 4 veces al año & $40.6 \%$ \\
\hline
\end{tabular}

FUENTE: Encuesta Nacional Programa Rumbos

Tabla 7. Descripción del Consumo de Cocaína. 2.001

\begin{tabular}{|c|c|c|}
\hline \multicolumn{2}{|c|}{ VARIABLES } & VALORES \\
\hline \multirow{2}{*}{ Promedio de edad inicio } & 15.1 años \\
\hline \multirow{2}{*}{ Edad Inicio } & Menos de 10 años & $2.7 \%$ \\
\cline { 2 - 3 } & $10-14$ años & $36.4 \%$ \\
\cline { 2 - 3 } & $15-19$ años & $58.2 \%$ \\
\hline
\end{tabular}




\begin{tabular}{|c|c|c|}
\hline \multirow{7}{*}{ Frecuencia } & $20-24$ años & $2.7 \%$ \\
\hline & Todos los días & $3.6 \%$ \\
\cline { 2 - 3 } & De 3 a 6 días a la semana & $7.2 \%$ \\
\cline { 2 - 3 } & De 1 a 3 veces al mes & $18.1 \%$ \\
\cline { 2 - 3 } & De 4 a 11 veces al año & $10.8 \%$ \\
\cline { 2 - 3 } & Menos de 4 veces al año & $47.0 \%$ \\
\hline
\end{tabular}

FUENTE: Encuesta Nacional Programa Rumbos

Como ya se mencionó, no es el objetivo del presente estudio la simple recopilación de datos que arrojaron investigaciones anteriores a esta, pero es muy fructífero conocer e interpretar los datos que esta arrojo en Ibagué, para tener una breve reseña de lo más cercano al periodo de la presente tesis. En este orden de ideas, se deduce lo siguiente:

- La mayoría de los jóvenes iniciaron el consumo de estas sustancias entre los 15 y los 19 años o entre los 10 y los 14 años en segundo lugar.

- En general, el consumo de marihuana y de cocaína es mayor entre los 10 y los 19 años de edad.

- La edad más frecuente de inicio de consumo de alcohol y cigarrillo está entre los 10 y los 14 años.

- Existe un número importante de consumidores frecuentes, es decir, realizan el consumo de SPA entre dos y cuatro veces por semana.

Bueno, estas aseveraciones tal vez sean muy sencillas de extraer, aun más cuando los suministros de datos se encuentran o se hallan según sea la necesidad de la propia búsqueda; pero como pensador del cuerpo, es estrictamente necesario ir mucho más allá de lo que arrojan los datos, es fundamental pensar que esto no solo es una situación actual para el grupo 
etareo que se ha señalado, sino que estas prácticas corporales hacen parte de la construcción del cuerpo cuya "....dirección del desarrollo del organismo humano está determinada socialmente...."66 y como tal, se construirá afectado; tal afección, en el contexto de ciudad, arroja prácticas que van en dirección a perturbar a otros cuerpos y a alterar otras prácticas (ejemplo, las prácticas corporales que se generan por estar presente la violencia intrafamiliar); esta situación está un poco más detallada a continuación y está recopilada a través de los sistemas de información de los centros de salud, información que hace parte de los registros de la Secretaría de Salud de lbagué, previos a iniciar el periodo $2004-2007$.

\section{Tabla 8. Porcentaje de Incidencia del Maltrato según Factores de Riesgo del Agresor. 2.002}

\begin{tabular}{|l|c|}
\hline FACTOR DE RIESGO DEL AGRESOR & \% DE INCIDENCIA \\
\hline Conflictos Familiares & $75 \%$ \\
\hline Antecedentes de maltrato & $7 \%$ \\
\hline Bajo control emocional & $4 \%$ \\
\hline Rechazo a la persona agredida & $4 \%$ \\
\hline Enfermedad mental & $1 \%$ \\
\hline Desempleo & $3 \%$ \\
\hline Consumo de Psicoactivos & $\mathbf{2 \%}$ \\
\hline Alcoholismo & $\mathbf{4 \%}$ \\
\hline
\end{tabular}

FUENTE: Secretaría de Salud de la Ciudad de Ibagué. Análisis del Sistema de Vigilancia en Salud Pública de Violencia Intrafamiliar - Ibagué - 2002

En el cuadro se puede observar que los factores de riesgo que inciden en el maltrato intrafamiliar, con un porcentaje acumulado del $6 \%$, se encuentran el alcoholismo y el consumo de psicoactivos.

${ }^{66}$ Carballo, C. y Crespo, B. 20012. Op. Cit. 
En el año 2004, la Secretaría de Salud empezó a recopilar información del periodo anterior y esta no fue una información sólida y concreta; razón que llevó entonces a convocar a los principales líderes comunitarios a acompañar unas reuniones programadas por la misma Secretaría en la que, la misión fundamental era la de elaborar un diagnóstico comunitario de las principales dificultades que aquejaba la población, los eventos mórbidos ${ }^{67}$ y de mortalidad sentidos por la comunidad urbana y rural de la ciudad; esta seguidilla de reuniones comunitarias se diseñó como una estrategia de participación de las comunidades en la planeación de los planes y proyectos dentro de la administración municipal, principalmente de la Secretaría de Salud a través del Plan de Atención Básica en salud.

Esta actividad se realizó con la idea de realizar un análisis situacional, para argumentarse posteriormente en la toma de decisiones para la disminución de eventos que pudieran afectar la salud y el bienestar de la población Ibaguereña, de igual manera se elaboró con el objetivo de complementar la elaboración del perfil epidemiológico y posteriormente para el Plan local de salud de la ciudad.

Por otra parte, es importante hacer un reconocimiento especial a los líderes y a la comunidad en general que en diversas instancias aceptaron la invitación y que asistieron puntualmente a las reuniones citadas por la Secretaría de Salud, porque participaron activamente en este diagnóstico con el único objetivo de ver reflejadas sus necesidades de salud en planes y proyectos de desarrollo comunitario para así mejorar su calidad de vida, depositando su confianza en la voluntad política, el compromiso y la búsqueda en conjunto de alternativas de intervención y disminución de los eventos que originan la morbi-mortalidad en su población.

Este diagnóstico comunitario de salud se realizó a través de convocatorias escritas, telefónicas y personalizadas efectuadas a los presidentes de las Juntas de Acción Comunal y Comuneros, con el fin de lograr una mayor participación de líderes y comunidad en general; se realizaron 16 reuniones en el área urbana con la asistencia de 282 personas y 6 reuniones en la zona rural con la asistencia de 245 personas.

Cabe mencionar que en algunos sectores se presentaron inconformidades porque la comunidad no cree en estas acciones o por escepticismo hacia

${ }^{67}$ Los eventos Mórbidos son los que causan o producen una enfermedad. 
éste tipo de trabajos y porque ha sido frecuente el incumplimiento de parte del gobierno municipal ante sus necesidades sentidas.

Es importante anotar que se observó mayor compromiso y receptividad de los presidentes de las Juntas de Acción Comunal para éste trabajo, que en los Comuneros o líderes de barrios, ya que estos últimos mostraron poca capacidad de convocatoria y poca disponibilidad de tiempo. ${ }^{68}$

Para la consecución de la información se utilizó una guía temática que fue desarrollada en el transcurso de la reunión apoyada en el papelógrafo y en algunos casos, en los tableros acrílicos de las escuelas que facilitaron su acceso y sus instrumentos para este fin.

Teniendo en cuenta que para efectos de la programación de planes y proyectos de prevención y de intervención, es indispensable hacer la priorización de eventos mórbidos y de mortalidad, esta priorización fue hecha por la comunidad, con sus intervenciones, con sus ideas y con sus aportes, desde luego con base en conceptos técnicos como son: magnitud del daño (número de personas afectadas), gravedad (alta mortalidad, letalidad o generación de secuelas invalidantes), vulnerabilidad del daño (posibilidad de prevención, control o erradicación) y la trascendencia (impacto en la salud pública y/o valores dados a los grupos de población afectada).

A continuación se presentan los resultados del mencionado diagnóstico, se relacionan los hallazgos de cada una de las comunas y del sector rural, posteriormente se presenta el condensado de la morbi-mortalidad mostrando en las gráficas y tablas los aspectos relevantes, la priorización de eventos (realizada por la comunidad) y finalmente la relación de acciones que las comunidades consideran indispensable realizar para disminuir la presentación de estos eventos en la población.

\section{Los Resultados del Diagnóstico}

A continuación se presentan las tablas que describen las frecuencias que fueron encontradas al hacer las sumatorias de los eventos en cada una de

\footnotetext{
${ }^{68}$ Es importante anotar que la convocatoria y asistencia en la zona rural fue difícil por falta de compromiso de los líderes contactados y por el desplazamiento de las comunidades a otros sectores para la concentración, por este motivo se optó por escoger algunas veredas con un buen número de población, y finalmente se pudo cumplir con los objetivos propuestos. Diagnóstico Comunitario de Salud, Ibagué - 2004.
} 
las reuniones en cuanto a la percepción de la comunidad referente a eventos de morbilidad y de mortalidad. Las puntuaciones de las frecuencias se dan cuando en una reunión es referido cierto evento, por ejemplo los homicidios tienen una frecuencia de 10 , es decir que en 10 reuniones fueron referidos como una de las causas de muerte más frecuente por la comunidad.

Tabla 9. Eventos referidos vs. Frecuencia de mención

\begin{tabular}{|l|c|}
\hline \multicolumn{1}{|c|}{ EVENTOS } & FRECUENCIA \\
\hline IRA & 22 \\
\hline EDA & 20 \\
\hline HIPERTENSION & 16 \\
\hline DENGUE & 14 \\
\hline DESNUTRICION & 14 \\
\hline DIABETES & 10 \\
\hline DERMATITIS & 8 \\
\hline DROGADICCION & 7 \\
\hline ESTRÉS & 7 \\
\hline COLESTEROL & 6 \\
\hline ARTRITIS & 6 \\
\hline CANCER & 6 \\
\hline VARICELA & 6 \\
\hline HEPATITIS & 5 \\
\hline ALCOHOLISMO & 5 \\
\hline ENFERMEDAD MENTAL & 5 \\
\hline MIGRAÑA & 4 \\
\hline PROB. VISUALES & 4 \\
\hline
\end{tabular}




\begin{tabular}{|l|c|}
\hline DEPRESION & 3 \\
\hline OSTEOPOROSIS & 3 \\
\hline TABAQUISMO & $\mathbf{3}$ \\
\hline
\end{tabular}

FUENTE: Secretaría de Salud Municipal, Ibagué 2004

La tabla expuesta anteriormente, muestra como los índices referidos por la comunidad son causa de muerte; al tomar los tres indicadores de SPA, (Drogadicción, Tabaquismo, Alcoholismo) da como resultado que la comunidad refiere que en 15 reuniones, el consumo de SPA hace que el cuerpo genere prácticas que lo afectan a él y que, además, son una causa principal de muerte del ciudadano, razón por la cual la ubican en el cuarto factor a prevenir.

Una vez este diagnóstico comunitario culminó, se dio a conocer sus resultados y fue la misma comunidad quien propuso algunas alternativas, claro, sin algún fundamento teórico o empírico que guiara esta construcción, sin embargo, y para este caso, es conveniente mencionarlas, pues estas son las que guiaron el proceder de la Secretaría de Salud y con la cual se argumentó (según la opinión pública) la propuesta de los dispositivos de prevención.

De esta manera, se señala entonces las acciones propuestas planteadas por la comunidad, en este listado están incluidas las acciones para prevenir la drogadicción, el tabaquismo y el alcoholismo.

* Supresión de la dosis personal (proyecto de ley)

* Educación comunitaria enfocada hacia la vida familiar, la armonía, la convivencia, la resolución pacífica de conflictos, tolerancia, valores humanos, valores sociales

* Educación en factores protectores en instituciones educativas y comunidad en general

* Implementación de estrategias de fortalecimiento de la unión familiar

* Actividades para la utilización creativa del tiempo libre

* Control a expendios de drogas 
* Reforzamiento de la seguridad ciudadana

* Creación de instituciones de atención a personas consumidoras de drogas

* Ampliación de oportunidades para la ocupación y la educación de niños y jóvenes

* Establecimiento de CAI móviles

* Ampliación de espacios deportivos y de recreación

* Compromiso y honestidad de la Policía en la erradicación de los expendios de drogas

* Educación comunitaria en auto cuidado de la salud y sensibilización de la comunidad

* Alternativas de recreación y deporte

Los otros eventos fueron igualmente priorizados y de igual manera se elaboraron listados de acciones propuestas, pero no se hace mención a ello en este trabajo por no ser objeto del mismo. 


\section{CAPÍTULO III}

\section{LAS ACCIONES PREVENTIVAS}

En los capitulos anteriores, se habló mucho acerca de las acciones efectuadas en materia de prevencion, se hizo mención tangencial a la situación geográfica y demográfica de la ciudad de lbagué y por ende, de su cultura del consumo, se insistió en la prevención y en la situación una vez inició el periodo que en este caso, se estudia; pero ya que se empezará a hablar sobre lo que realmente se realizó, sobre las pautas y los lineamientos reales de prevención, resulta muy prudente guiar al lector acerca de la estructura legal en la cual se amparan los dispositivos de prevencion.

En la ciudad de Ibagué, la Secretaría de Salud Municipal es una dependencia de la administración Municipal, cuya finalidad es la programación, la coordinación, el desarrollo y la supervisión de los planes, los programas y los proyectos del sector salud en la jurisdicción de su competencia en armonía con los lineamientos nacionales regidos a través del Ministerio de la Protección Social; de acuerdo a esto, la Secretaría de Salud de lbagué fué creada mediante el Acuerdo 085 de 1991 del Concejo municipal de la ciudad (ver anexo 1).

Con la descripción explícita de las funciones (ver anexo 1), la Secretaría diseña y programa las acciones entorno a la salud y se apoya en otros campos del conocimiento que incidan en ella y que, de manera articulada, la auxilie en la búsqueda de sus objetivos. Por tal razón, y para dar cumplimiento a lo mencionado y como resultado de lo explícito en el literal I (según anexo 1), el Gobierno Nacional a través del Ministerio de la Protección Social y mediante la circular 0018 del 18 de Febrero de 2004, imparte los lineamientos para la formulación y ejecución de los planes estratégicos y operativos del $\mathrm{PAB}^{69} 2004-2007$ (ver Anexo 2), allí se plantea como prioridad las acciones de salud pública para Colombia, la reducción del impacto en salud de la violencia e implementación de las políticas de salud mental y de reducción del consumo de sustancias Psicoactivas. ${ }^{70}$

\footnotetext{
${ }_{70}^{69}$ PAB. Plan de Atención Básica.

${ }^{70}$ Lineamientos para la formulación y ejecución de los planes estratégicos y operativos del PAB 2004 - 2007, numeral 1, literal f, según anexo.
} 
Adjunto a estos lineamientos se encuentra como anexo técnico las metas, las actividades e indicadores de las acciones de estricto cumplimiento del Plan de Atención Básica que, de igual manera, especifica lo pertinente a salud mental que deberá desarrollar el PAB, en cuyo numeral 1.6 la implementación de la Política de Salud Mental, señala uno de sus ítems lo siguiente:

"Desarrollar una política Nacional de Reducción de la demanda de sustancias Psicoactivas que reduzca el impacto que el uso y el abuso que estas genera en las condiciones generales de vida y de salud de la población Colombiana y en especial en la población más vulnerable, los jóvenes, y que opere en todos los niveles territoriales."

Luego de ofrecer la revisión a la estructura de la secretaria (según anexo 1) En el primer grupo, el de Salud Pública, el área de Vigilancia Epidemiológica y políticas de salud pública es la encargada de estructurar y ejecutar lo referente al PAB, de hacer frente a la salud mental de los lbaguereños y de tener en cuenta los factores que inciden en las conductas drogodependientes, como también los factores que así mismo propician las acciones preventivas relacionadas con las conductas mencionadas.

Las actividades que desarrolla el área de vigilancia epidemiológica y de políticas de salud pública, encaminadas a la prevención de las conductas drogodependientes y a la reducción del impacto producido por el uso y abuso de sustancias psicoactivas, son las siguientes:

(Es preciso elaborar e incorporar a los Planes de Atención Básica municipales y distritales, contenidos que incluyan por lo menos las siguientes actividades que a continuación se mencionan):

\section{ACTIVIDADES ${ }^{71}$}

- Elaboración de un diagnóstico situacional de salud mental en el municipio y priorización de necesidades de intervención en los componentes detectados en el diagnóstico.

- El diagnóstico deberá construirse con enfoque integral, de manera que articule elementos relacionados con la oferta de servicios existente,

${ }^{71}$ Estas actividades están dispuestas por la organización misma de la Secretaría, bajo disposiciones del plan de desarrollo de la administración local. 
las fuentes de financiación por medio de las cuales se realizan las acciones en la materia, el total de recursos invertidos por vigencia en los diferentes componentes, el recurso humano especializado y no especializado, por medio del cual se cubren las necesidades de atención, la participación social en salud mental (asociaciones de usuarios, redes sociales, etc.), existencia de experiencias demostrativas de atención integral en salud mental, especialmente de carácter comunitario y demás información que se considere relevante, para el diseño de los planes territoriales.

- Análisis del diagnóstico situacional de salud mental y priorización de necesidades de intervención en los componentes detectados en el diagnóstico, en lo referente a drogas.

- Sensibilización de los diferentes actores sociales presentes en el Municipio, con el fin de conformar redes de apoyo social mutuo que adelanten acciones de promoción de la salud mental, la prevención de la enfermedad mental y del comportamiento y prevención del consumo de sustancias psicoactivas.

- Concertación e implementación de acciones intersectoriales para la promoción de los factores protectores y prevención de factores de riesgo para la salud mental y la prevención del consumo de sustancias psicoactivas teniendo en cuenta ciclo vital y grupos vulnerables.

- Desarrollar actividades de información, educación y comunicación a grupos de riesgo para fomentar factores protectores como la formación y construcción de valores, resolución de conflictos, equidad de género, pautas adecuadas de crianza y fortalecimiento de vínculos afectivos, manejo de la afectividad y la sexualidad y comunicación efectiva a nivel personal, familiar y social, entre otros, y reducir factores de riesgo para la salud mental tales como consumo de alcohol y sustancias psicoactivas y violencia intrafamiliar, manejo de estrés, tolerancia a la frustración, etc.

- Impulsar en los establecimientos educativos el desarrollo de la estrategia habilidades para vivir y otras estrategias validadas para la promoción de proyectos de vida sin drogas y la prevención del consumo. 
- Identificar, orientar y realizar el seguimiento a la población hacia los servicios de salud según lo establecido en el SGSSS. ${ }^{72}$

- Apoyar programas de promoción de la salud y generación de alternativas ocupacionales, capacitación para el trabajo y apoyo a proyectos productivos dirigidos a jóvenes en riesgo y a población rehabilitada.

Las anteriores son las acciones estructurales y de acción de la mencionada Secretaría; ahora bien, para analizar realmente la perspectiva con la que fue visto el cuerpo en el desarrollo de estas acciones preventivas, es importante dar paso a los aspectos generales y de diagnóstico objeto de este estudio en el periodo $2004-2007$.

Las siguientes situaciones se amparan en las actividades expuestas en el capítulo anterior, son también las tenidas en cuenta por la Secretaría de Salud de lbagué para prevenir el consumo de SPA en la Ciudad; cabe resaltar que la Secretaría de Salud, en sus planes operativos para el cuatrienio 2004 - 2007, argumentó la base que constituiría las acciones con la cual se conformarían las acciones que darían como resultado, la posible prevención de las conductas drogodependientes.

El Plan Operativo del PAB para la vigencia 2004 - 2007 en materia de prevención del consumo de SPA fue:

\section{Problema y Línea Base}

El incremento de la problemática social, política, económica de la población está acelerando la salud mental, la cual se va determinando en el acumulo de lesiones infringidas, consumo de sustancias psicoactivas, trastornos mentales, las cuales cada día deterioran la capacidad productiva y desarrollo intelectual de la población ${ }^{73}$.

\footnotetext{
72 Sistema General de Seguridad Social en Salud, este sistema comprende lo siguiente: EPS: Entidades Promotoras de Salud; IPS: Instituciones Prestadoras de Servicios de Salud; ARS: Administradoras del Régimen Subsidiado; ESE: Empresas Sociales del Estado.

${ }^{73}$ Secretaría de Salud Municipal, Plan operativo de Salud 2004.
} 


\section{Propuesta de Intervención}

Prevención de la violencia y su impacto; Consumo de Sustancias Psicoactivas y Trastornos Mentales y comportamentales entre otros.

\section{Objetivo de los Cuatro Años}

- Impulsar el fomento y protección de la salud mental y seguridad vial, a través del desarrollo de estrategias de promoción, información, educación, capacitación, seguimiento, evaluación, investigación y participación comunitaria; como elementos coadyuvantes del desarrollo integral, reducción del impacto en la problemática existente y el mejoramiento de la calidad de vida de la población Ibaguereña.

- Fortalecimiento de la Salud Mental de los jóvenes con actividades lúdicas, recreativas y deportivas como estrategia de ocupación del tiempo libre y en busca de la prevención de consumo de sustancias psicoactivas.

\section{Acciones Plan Operativo PAB - 2004}

- Una capacitación en Política Pública a todos los sectores

- Seguimiento y evaluación del Programa VESPA

- Campañas masivas de comunicación (IEC)

- Capacitación líderes escolares, el gobierno escolar, maestros, integrantes de la red del buen trato, escuela de padres. En estrategia de prevención del suicidio e identificación de signos de alarma.

- Revisión de la información existente de los grupos de salud mental, recopilación de información a través de reuniones y concertaciones con la comunidad y los espacios ya organizados, copacom, alianza de usuarios, comuneros, presidentes de juntas, entre otros.

- Actividades de coordinación intersectorial, para la potencialización de los recursos físicos, técnicos, financieros y humanos, existentes en el municipio para el desarrollo de actividades lúdicas, deportivas, culturales y recreacionales para la población de 12 a 17 años, como una estrategia de fortalecimiento de la Salud Mental y Prevención del Consumo de Sustancias Psicoactivas. 


\section{Acciones Plan Operativo PAB - 2005}

- Conformar la Red Comunitaria de Clubes Juveniles, pertenecientes a las 13 parroquias del municipio de Ibagué y capacitar en Prevención del consumo de Sustancias Psicoactivas.

- Conformar la Red Interinstitucional de Prevención del Consumo de Sustancias Psicoactivas, realizar reuniones y seguimiento.

- Jornadas grupales de Interiorización personal, comunidad educativa y población vulnerable (desplazados, mujeres cabeza de hogar, menor trabajador) sobre temas Psicoactivos, Buen trato, Salud mental.

- Seguimiento y evaluación del Programa VESPA.

- Capacitación a las 13 comunas del Municipio en promoción de la salud Mental.

\section{Acciones Plan Operativo PAB - 2006}

- Actividades de coordinación intersectorial, para la potencialización de los recursos físicos, técnicos, financieros y humanos, existentes en el municipio para el desarrollo de actividades lúdicas, deportivas, culturales y recreacionales para la población de 12 a 17 años, como una estrategia de fortalecimiento de la Salud Mental y Prevención del Consumo de Sustancias Psicoactivas.

- Realizar visitas para el seguimiento de los casos priorizados de violencia intrafamiliar, abuso sexual y consumo de SPA.

- Realizar 3 talleres a instituciones educativas pertenecientes a las nuevas escuelas saludables en fortalecimiento de la unidad familiar e implementación de programas alternativos de formación a padres en promoción de los factores protectores y prevención de factores de riesgo para la salud mental y prevención del consumo de SPA.

- Visitas de seguimiento a Unidades Notificadoras, control de calidad a los reportes y análisis de la información de violencia intrafamiliar, abuso sexual y consumo de SPA.

- Realizar talleres en los establecimientos educativos pertenecientes a las escuelas saludables para impulsar el desarrollo de la estrategia Habilidades Para Vivir.

- Jornadas culturales en prevención del suicidio, prevención de la violencia intrafamiliar y promoción de la convivencia pacífica, prevención del consumo de SPA y seguridad vial, dirigidas a 
comunidad educativa, integrantes de los clubes juveniles y comunidad en general.

- Talleres de sensibilización de los diferentes actores sociales del SGSSS (ARS, EPS, ARP e IPS) del municipio con el fin de conformar redes de apoyo social que adelanten acciones de promoción de la salud mental, la prevención de la enfermedad mental y del comportamiento y prevención del consumo de SPA.

- Realizar campañas de movilización social para la promoción de la Salud Mental, la prevención de la enfermedad mental y del comportamiento y consumo de SPA.

\section{Acciones Plan Operativo PAB - 2007}

- Realizar cuñas radiales para sensibilizar y motivar a la denuncia oportuna de casos de maltrato, divulgación de los servicios de la Red de Buen Trato, Derechos y Deberes, prevención del consumo de SPA, fortalecimiento en seguridad vial para la apropiación colectiva de valores fundamentales, desarrollo de actividades de convivencia ciudadana, respeto a los demás y a lo público.

- Rumba sana dirigida a menores de edad de las 13 comunas del municipio en prevención del consumo de Sustancias Psicoactivas.

- Jornadas culturales dirigidas a comunidad educativa y comunidad en general en prevención del consumo de Sustancias Psicoactivas.

- Capacitar a comunidad educativa, directivos y docentes de los colegios privados y públicos en prevención, detección y manejo de los estudiantes consumidores y expendedores de Sustancias Psicoactivas.

- Publicaciones formularios del Programa SIVIF y VESPA ${ }^{74}$.

- Capacitación a la Red de apoyo como líderes, red del buen trato, sacerdotes, líderes afectivos, comuneros, auxiliares de enfermería, miembros de la constituyente; en lineamientos de promoción, remisión y detección temprana.

\footnotetext{
${ }^{74}$ SIVIF: Sistema de Vigilancia de Violencia Intrafamiliar.

VESPA: Vigilancia Epidemiológica del Consumo de Sustancias Psicoactivas
} 


\section{MECANISMOS DE EVALUACION}

En la actualidad la Secretaría de Salud Municipal no cuenta con un sistema de Evaluación que le permita cumplir con el papel que debe desempeñar como ente rector de la salud en el Municipio de Ibagué.

Sin embargo, para reunir la información y contemplar datos aproximados en referencia al consumo de SPA, la Secretaría de Salud de lbagué empleó el sistema VESPA; este sistema actuó con el objetivo de ser comprensivo y unificado y brindar, además, la información sobre la situación del consumo de sustancias psicoactivas a través de fuentes múltiples de información, llamadas por este sistema "ventanas", con el fin de contribuir en la elaboración de un diagnóstico útil y fundamental para la posterior formulación de políticas de prevención integral.

Ahora bien, el sistema VESPA es un formulario (ver anexo 3)creado para los centros de atención en Drogodependencia. Debe ser aplicado por el profesional en la primera consulta 0 entrevista a todo paciente que tenga Inicio o haya realizado algún tipo de consumo de SPA, bien sea por uso, abuso o dependencia de sustancias como morbilidad principal.

Una vez diligenciado el formulario, la entidad o los centros de atención que notifiquen el caso, guardan copia en la base de datos en la entidad y lo remiten a la base de datos de la Secretaría de Salud Municipal con una periodicidad promedio de treinta días (mensual) por lo menos.

El Formulario mencionado recoge la siguiente información. (Ver anexo 3)

I. Institución quien reporta

II. Datos de Identificación del paciente

III. Lugar y Área de Residencia Habitual

IV. Nivel Educativo

V. Estado Civil

VI. Ocupación u Oficio

VII. ¿Cómo acudió a la Institución? 
VIII. ¿Ha estado alguna vez por tratamiento por consumo de psicoactivas?

IX. Patrones de consumo:

- Tipo de droga: proporciones de prevalencia e incidencia.

- Frecuencia del consumo.

- Edad de inicio del consumo.

- Severidad (abuso o dependencia).

- Vía de administración.

- Reportan unos códigos para el diligenciamiento de los patrones de consumo.

Las variables que arroja esta información en cuanto a factores de riesgos o de protección, podría contribuir en la realización de un análisis funcional del usuario que consume SPA.

Vale la pena mencionar que el VESPA ha servido de modelo o ha sido adoptado en otros países de América, con resultados valiosos en la lucha contra la drogo-dependencia. Colombia, por su parte, ha realizado muchos esfuerzos por implantar este sistema de registro y seguimiento en varias entidades territoriales; la primera ciudad del país en emplear este sistema fue Medellín, donde se probó este formulario y cuyo resultado se tomó como punto de referencia para los estudios realizados en otros lugares.

\section{RESULTADOS}

Entre los años 2004 y 2007, se produjo un incremento en la adicción a sustancias psicoactivas y la dependencia al alcohol, fenómenos asociados con la generación de violencia y de otras situaciones que afectaron a la sociedad, los cuales fueron auspiciados por las organizaciones involucradas en la producción, procedimiento, distribución y tráfico de las mencionadas sustancias. La consecuencia es un impacto social negativo sobre la sociedad Ibaguereña, afectando a individuos y familias, produciendo su desintegración 
y convirtiéndose en una amenaza frente a los valores humanos, éticos y de convivencia nacional.

Ante la presencia de este problema de patología social, fue necesario el registro de las variables que ocasionaban esta realidad y con la cual se pudiera monitorear la evolución de la situación y su caracterización. Es así como surgieron diversos estudios epidemiológicos descriptivos en el país que condujeron al diseño del sistema VESPA (Sistema de Vigilancia Epidemiológica de Sustancias Psicoactivas) como mecanismo de aporte de información válida y uniforme sobre los indicadores de medición del consumo de SPA en el periodo mencionado.

De otra parte, los patrones que conllevan a la ingesta de bebidas alcohólicas, profundamente arraigados, así como el consumo de cigarrillo, continúan siendo las principales sustancias psicoactivas legales que sirven de puerta de entrada al uso indebido de psicoactivos ilegales tales como la marihuana, el bazuco, la cocaína y más recientemente, la heroína y las anfetaminas, entre otros. Sumado a este hecho, que tiene consecuencias socialmente significativas, se encuentra la frecuente asociación entre el consumo de alcohol y los accidentes de tránsito, la riña, la violencia callejera y la disfunción familiar.

En términos de salud pública (y solo para beneficio de la Secretaría de Salud), resultó de esencial importancia contar con un sistema de vigilancia epidemiológica, con este, se logró la identificación de la aparición de nuevos consumidores, se pudo determinar la variabilidad en la ingesta de psicoactivos por parte de los diferentes segmentos poblacionales, su distribución según variables referidas al lugar y al sexo, así como el comportamiento de diversos factores asociados al consumo.

El suministro de este tipo de información solo es útil, solo si los dispositivos de prevención o de intervención que la Secretaría de Salud diseña, se soportan con un fundamento teórico claro y definido que ataque estos indicadores desde la promoción de la salud; por tal razón, este estudio no se centra en analizar los datos como indicadores, sino como una breve referencia cuantificada del consumo, de manera tal que los diversos sectores, instituciones y para que la comunidad en general tenga una posición clara y un enfoque diferente hacia esta situación, que los actores conozcan del cuerpo y a partir de esto, se puedan orientar los procesos y acciones encaminadas hacia la prevención del uso indebido de drogas. 
Consolidado del Consumo de SPA en Ibagué a 2007

De los casos notificados al Sistema de Vigilancia en Sustancias Psicoactivas y por ende a la Secretaría Municipal de Salud Ibagué, se ratifica definitivamente que la droga con la cual se da inicio a la conducta que lleva al consumo de sustancias psicoactivas corresponde al TABACO con 632 casos, le sigue en importancia la MARIHUANA con 324 casos, el ALCOHOL con 72 casos, los inhalantes con 52 casos, el bazuco con 36 casos y la cafeína con 28 casos. (Según figura)

Figura 2. Casos notificados de consumo de SPA según droga de inicio. Ibagué $2.004-2.007$

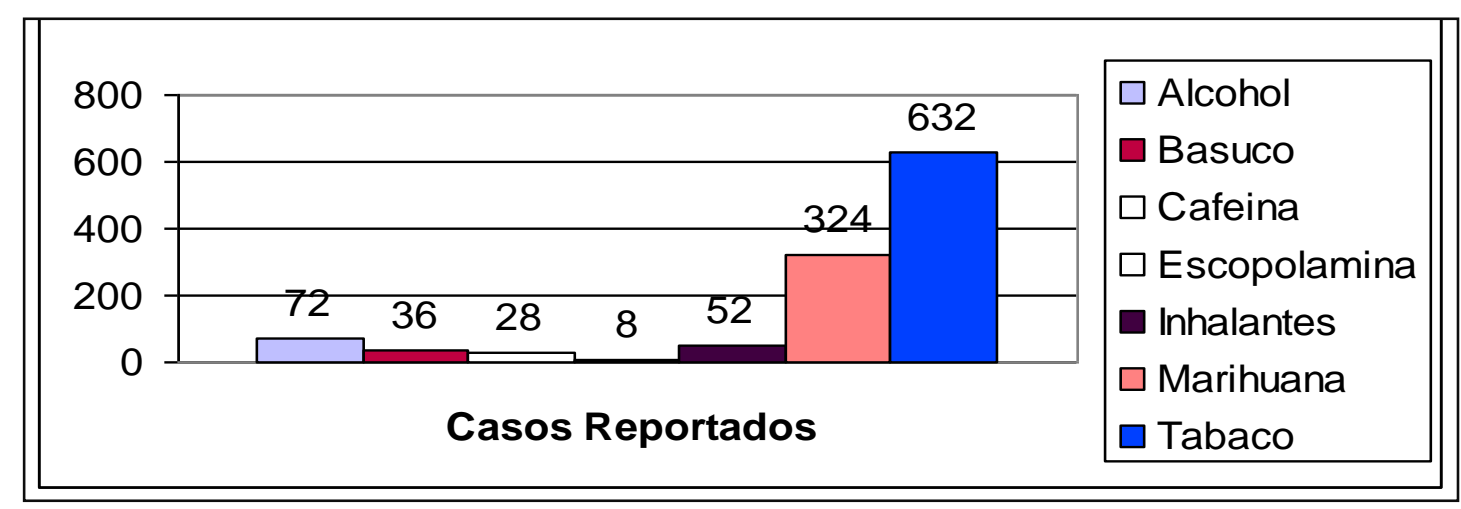

FUENTE: VESPA S.S.M. Ibagué 2004 - 2007

Otro resultado significativo que arrojan estas cifras, es que la edad de inicio para el consumo de sustancias psicoactivas como el alcohol, la Marihuana y el tabaco según registros del VESPA reportados a la Secretaría de Salud Municipal de lbagué, tiene comienzo a partir de los 10 años, en donde las edades que presentaron el mayor número de casos fueron 12, 13 y 14 años. Esta situación confirma que se debe continuar arduamente con las estrategias de prevención y control en el programa con el fin de evitar que el número de casos se incrementen en los próximos años.

Con los datos notificados al VESPA durante el periodo mencionado, se ratifica que la población masculina con 1052 casos (91\%) es la que más consume sustancias psicoactivas si se compara con el género femenino que fue solo de 104 casos (9\%). (Según figura) 
Figura 3. Porcentaje de casos notificados por VESPA en el consumo de SPA según género. lbagué $2.004-2.007$

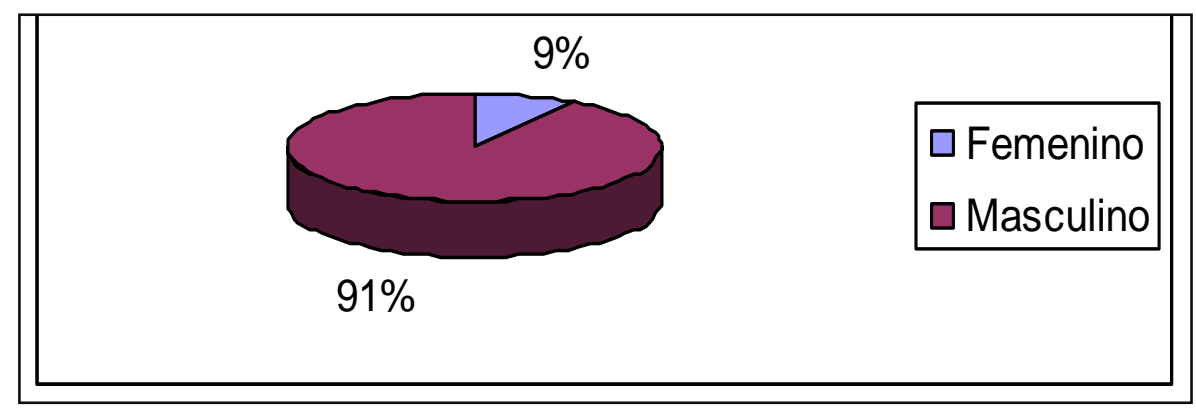

FUENTE: VESPA S.S.M. Ibagué 2004 - 2007

Por otra parte, el mayor consumo de sustancias psicoactivas en el municipio de lbagué según el grupo de edad se presentó en los adolescentes de 14 a 17 años de edad con 824 casos, le sigue el grupo de edad de 18 a 29 años con una participación de 40 casos, en el grupo de 10 a 13 años se presentaron 168 casos y en el grupo de edad de 32 a 44 años se obtuvieron 24 casos. (Según Figura)

Figura 4. Casos notificados de consumo de SPA por grupos etáreos. lbagué 2.004- 2.007

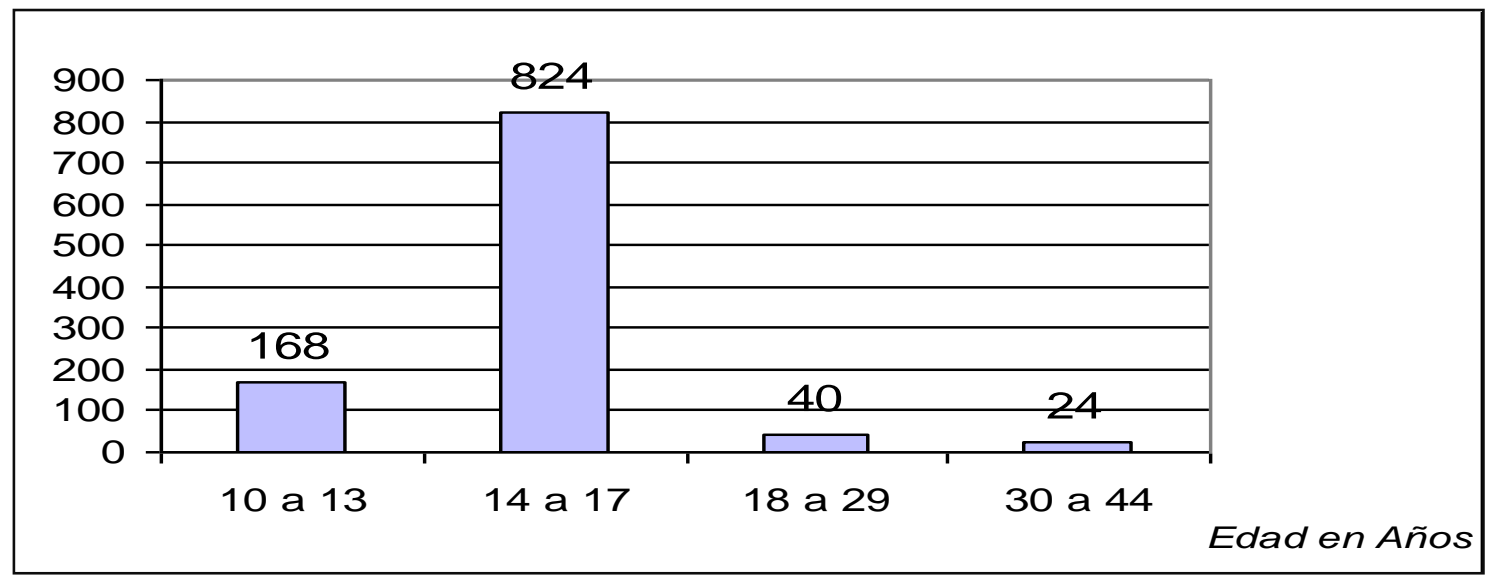

FUENTE: VESPA S.S.M. Ibagué 2004 - 2007 
La sustancia psicoactiva de mayor consumo en la ciudad de lbagué fue la Marihuana con 524 casos, le siguen en orden de importancia el tabaco con 184 casos, el bazuco con 150 casos, el alcohol con 120 casos, los inhalantes con 108 casos. Otras sustancias psicoactivas que presentaron un consumo mínimo por parte de la población lbaguereña son: Cafeína, cocaína, éxtasis, escopolamina, entre otras.

Figura 5. Casos notificados por el VESPA según tipo de SPA consumida en lbagué $2.004-2.007$

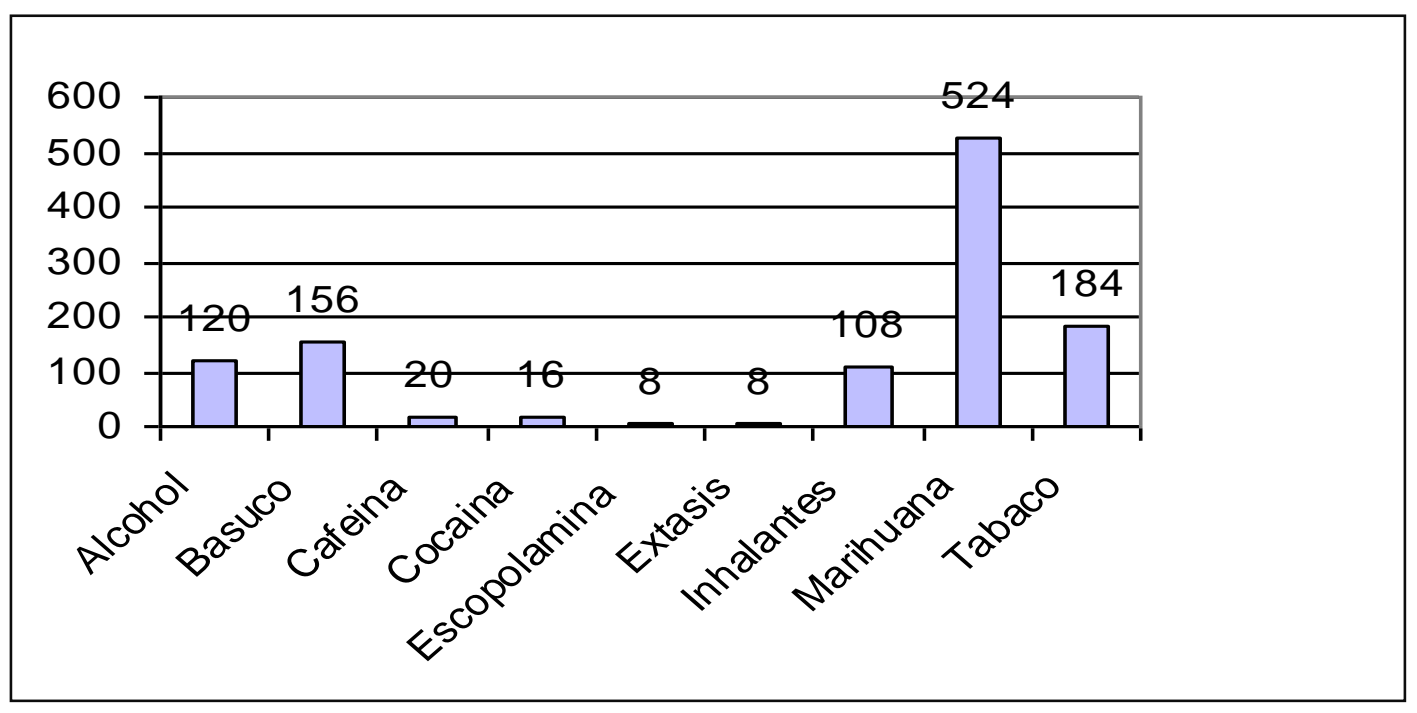

FUENTE: VESPA S.S.M. Ibagué 2004 - 2007

Nota: en los casos notificados según el tipo de SPA consumida, es importante resaltar que los casos por escopolamina son inducidos, es decir, este consumo es involuntario, más sí inducido con fines criminales.

Igualmente, en un alto porcentaje, la población que acude a la institución rehabilitadora lo hace con indicación legal (968 casos), y se mantiene (tal vez con referencias anteriores) la forma voluntaria de asistir a los centros de atención, así como la intervención de los amigos, que en un alto grado acude a sus amigos y les facilita el acceso a estos centros de atención

Como último comentario acerca de los registros notificados de consumidores de SPA durante el periodo 2004 al 2007, surge un aspecto que es muy relevante, para este caso y para este estudio y es, desde un enfoque no tan descriptivo, el gran número de casos reportados en situación donde carece la escolaridad y la gran ventaja que se otorga cuando no existe un mecanismo 
que supla esta situación y que ofrezca la posibilidad de tener prácticas corporales con "experiencias distintas" ${ }^{\text {" }}$, de manera tal que se pueda representar el cuerpo, el yo propio, a través del colectivo social sobre la base de un organismo ${ }^{76}$, pero que este, no esté alterado de manera artificial. (Con el consumo de SPA).

Por lo anterior, es importante enfatizar y dar a conocer el efecto que produce en el ser humano la carencia de educación, o por lo menos de una manera tangencial, en cuanto al consumo de sustancias psicoactivas se refiere.

En el capitulo anterior se hacía énfasis, o mejor, se mencionaba la importancia que debe jugar la educación en los procesos de prevención; pero para argumentar lo anterior, no basta solo con revisar las cifras que se muestran a continuación (ver tabla), como tampoco de estas, es pertinente sacar una conclusión apresurada y afirmar que el sujeto escolarizado es menos propenso al consumo de SPA, pues esta situación, si se considera de una forma simple, carecería de significancia.

Estas cifras sencillamente motivan a que la educación propicie la tenencia de un cuerpo, de esta manera y como se enfatizó anteriormente, no basta con pensar que el ser humano es un cuerpo y que toda la problemática gira únicamente entorno a solucionar su situación orgánica; hay que pensar también, que el ser humano se apropia de significados, y como se apropia sobre la base de su organismo, es muy considerable educar al cuerpo desde su naturalidad, hasta su relación en los contextos sociales. ${ }^{77}$

En la figura que se presenta a continuación, claramente se muestra que los mayores consumidores de sustancias psicoactivas de la ciudad de lbagué pertenecían al nivel educativo de secundaria incompleta y primaria incompleta.

\footnotetext{
${ }^{75}$ Cachorro, G. 2009 Op. Cit.

${ }^{76}$ Carballo C. y Crespo B. 2001. Op. Cit.

${ }^{77}$ Mamonde, M. 2007. Op. Cit.
} 
Figura 6. Casos Notificados de Consumo de SPA según el nivel educativo- Ibagué 2004 - 2007

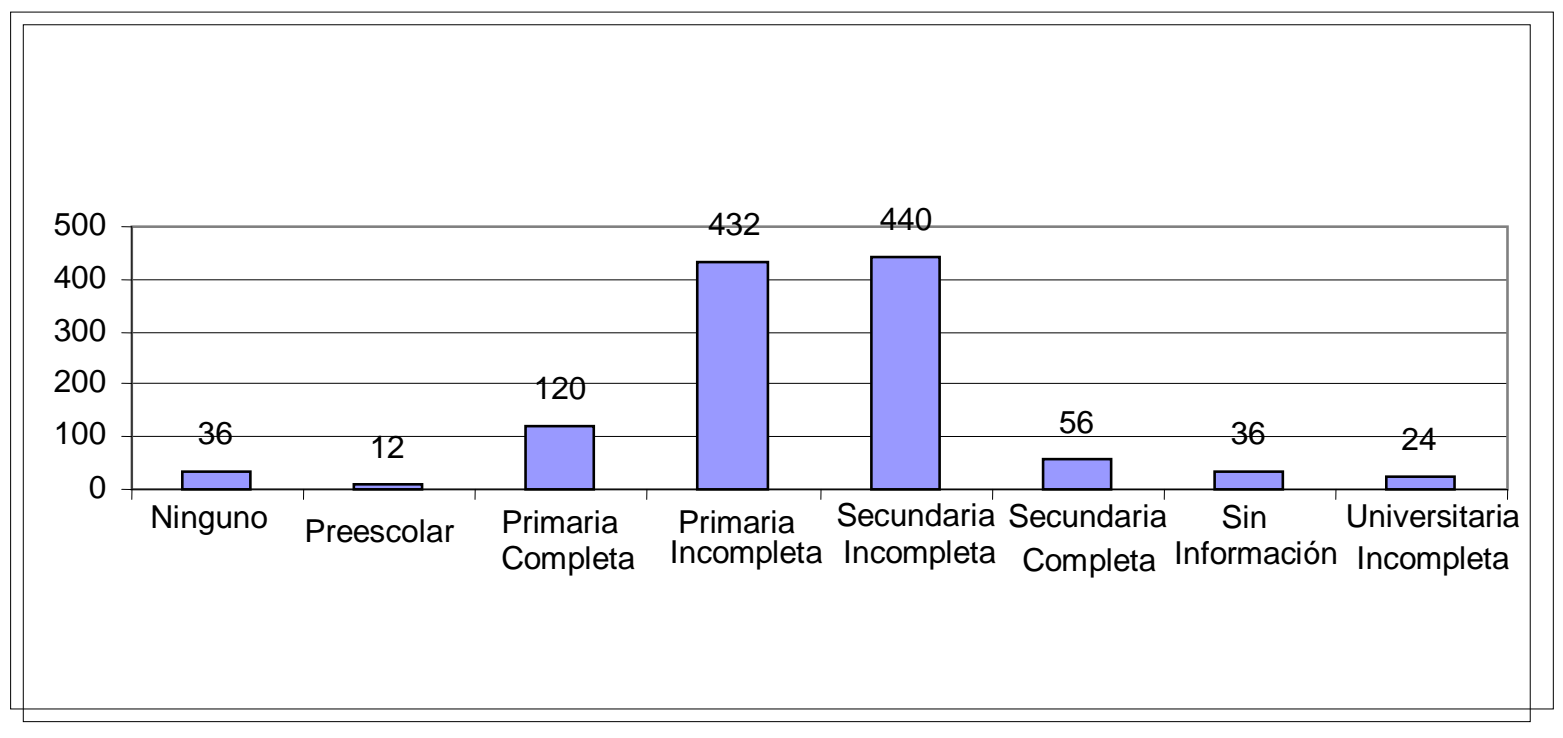

FUENTE: VESPA S.S.M. Ibagué 2004 - 2007

Al respecto, una deferencia a tener en cuenta es la realizada por Stenhouse, 1991, citado por Ricardo Crisorio ${ }^{78}$ y en el cual afirma que "...la escuela tiene por misión poner a disposición del niño o del adolescente una selección del capital intelectual, emocional y técnico con que cuenta la sociedad, es a este capital al que se le ha designado como tradiciones públicas..." en este sentido, la escuela entonces evita lo no-tradicional, aquello que está fuera de público, incluso, aquello que esta fuera de los parámetros legales ${ }^{79}$ de la misma sociedad.

\footnotetext{
${ }_{78}^{78}$ Crisorio, R. 1995. Óp. Cit.

${ }^{79}$ Mencionar los parámetros legales, es hacer alusión a los dispositivos de control frente aquello que no es válido en la sociedad y que por tanto, tiene penalidades.
} 


\section{CAPITULO IV}

\section{CONSIDERACIONES FINALES}

Luego de recopilar esta información, de analizar algunos factores que promueven el consumo y las conductas drogodependientes y con base en los resultados obtenidos y consolidados a 2007, se sostuvo una conversación con las personas que integraron el grupo de salud pública de la Secretaría de Salud y quienes fueron las encargadas de llevar a cabo el desarrollo del PAB; de estas conversaciones de carácter informal, subyacen algunas situaciones del orden administrativo y operativo que, compartidas en este trabajo, se espera que el lector deduzca la posición de la administración municipal, sus enfoques y sus argumentos:

- La dificultad más notoria en el desarrollo de todas las actividades fue la contratación, pues esta contratación (regida por norma nacional) se realizó con las E.S.E ${ }^{80}$., y estas a su vez, efectúan contratación con terceros y en muchas ocasiones estos terceros no son la mejor oferta para ejecutar las acciones, no las realizan con plena convicción del objetivo a lograr o simplemente, esta situación, da paso a que las personas carezcan de idoneidad.

- La segunda falencia en importancia que se encontró es que, la destinación presupuestal para tales fines fue muy escasa, pues con el recurso lo único que se podía realizar era priorizar y en este orden, las primeras comunidades en atención eran las que la Secretaría consideraba más vulnerables, según lo indicó Carminia Varón Balbuena, epidemióloga del grupo de salud pública; de igual manera, los lineamientos del Ministerio de la Protección Social son muy claros y específicos en cuanto a la sugerencia de inversión de los recursos, lo que imposibilita un accionar que pudiera, en algún momento, ser "autónomo".

\footnotetext{
${ }^{80}$ Empresas Sociales del Estado, Las Empresas Sociales del Estado constituyen una nueva categoría de entidad pública, descentralizada funcionalmente o por servicios, creada por la ley 100 de 1993, con el propósito de mejorar las formas organizativas para la prestación de los servicios de salud cuando el Estado los presta directamente en cualquiera de sus niveles.
} 
- En el proceso de atender a la población en materia de prevención priorizada, se atendió de acuerdo al perfil epidemiológico, es decir, las diez prioridades y/o causa de muerte indicadas anteriormente.

- La falta de coordinación interinstitucional, esta ausencia se presentó por la prisa de cada organización y/o institución en mostrar resultados de forma individual.

- La multiplicidad de acciones hacia una misma población fue otra falencia que marcó un acento importante en las acciones preventivas, pues las comunidades se fragmentaron y el interés por las mismas fue mínimo.

- Que el consumo y la adicción aparecen en la población en edades tempranas y como se observó en las cifras, la no coordinación con las instituciones educativas en materia de cobertura elevó los índices de consumo.

- El personal muy poco preparado o sin experiencia en el trabajo o desarrollo de las acciones.

En este mismo sentido, los errores con mayor frecuencia, según indicó la funcionaria de la Secretaría de Salud de Ibagué, fueron:

- La misma estructura de las acciones, pues no contemplan apoyos interdisciplinarios.

- La planeación y ejecución de las acciones preventivas sin que se haya realizado un diagnóstico previo, en el cual sean vinculadas las instituciones educativas. ${ }^{81}$

- La falta de auditoría y supervisión en la ejecución de las acciones. ${ }^{82}$

- La realización de los ajustes durante el desarrollo de las mismas ocasionó trastornos e inconformidades en la comunidad, de igual manera se puso al descubierto la falta de planeación.

${ }^{81}$ Las acciones preventivas realizadas a través de la Secretaría de Salud de Ibagué, no se estructuraron con un componente pedagógico claro, como tampoco se apoyaron en las instituciones educativas para llegar más fácilmente a las primeras edades.

${ }^{82}$ No existió, por otra parte, un control en diferentes momentos de la prevención; nadie realizó controles y nadie evaluó la calidad de las acciones. 
La Epidemióloga Carminia Varón, jefe del grupo de salud pública y directa responsable de la ejecución del PAB, añadió que la estructura de las acciones preventivas no tiene un respaldo consolidado en la educación y que, además, las prácticas corporales no son empleadas en las mismas porque no se tienen las bases que integren estos componentes.

\section{El cuerpo en las acciones preventivas}

La participación del cuerpo en las actividades preventivas realizadas por la Secretaría de Salud de Ibagué, no estuvo legitimada ni siquiera por un aporte instrumental de la Educación Física, como tampoco por el aporte que esta misma disciplina ofrece desde la escolaridad aún cuando exista en ideas futuras la implementación de la misma; sin embargo, en los dispositivos de prevención, el cuerpo fue percibido como el del sujeto-organismo humano consumidor, y dejó relegado el significado que el mismo (cuerpo) construye en la proyección de las expresiones del colectivo social, por tal razón, en el despliegue preventivo no se enfocó, ni siquiera transitoriamente, los efectos sociales que desencadenan en las adicciones de las comunidades.

De esta manera, el dispositivo de prevención implícito en el PAB, solo reconoció al cuerpo en el sentido mismo de la materia o del organismo, sin tener en cuenta las representaciones que ayudaron a construir al cuerpo desde el mismo entorno cultural en que se formó, por tanto, las acciones se encaminaron más a enlutar el comportamiento y la modificación de los roles sociales, lo que dio paso al apelativo de comunidades consumidoras o comunidades vulnerables, lo que deja al descubierto la carencia de la individualización y la visión del cuerpo como único, como un sujeto de significados diferentes; como individuo.

Lo anteriormente expuesto concluye que no hay presencia alguna de Prácticas Corporales "...no en función de estereotipias sociales, o de buenas costumbres ciegamente aceptadas, sino de una relación a la vez ética y estética consigo mismo, con los otros y con el mundo." ${ }^{83}$, que sean utilizadas como colaboradoras en el proceso de representar "naturalmente" al cuerpo; de igual manera, al no tener la estructura que vincule como apoyo a los

${ }^{83}$ Crisorio, R. 2009. Op. Cit. Aludiendo a la importancia de la regulación y distribución de los tonos y las sinergias musculares en todos los casos. 
planteles educativos, es poco probable que la Educación Física actúe como contraparte de la medicina ${ }^{84}$, ejerciendo un canal preventivo.

Por tanto, es importante razonar que, la educación física entendida como educación del Cuerpo y no de lo físico, ${ }^{85}$ debe apoyar con la construcción sujeto-cuerpo bajo una relación crítica con la cultura. En este mismo orden de ideas, Ricardo Crisorio continúa afirmando que "...la educación física debe tomar a su cargo introducir, en concepto y en acto, el valor de esta relación; el provecho de la adecuación de los gestos y posturas a los requerimientos de las situaciones no solo lúdicas, gímnicas o deportivas, sino a todas y cada una de ellas." ${ }^{86}$

De todas maneras, la educación corporal vincula a toda la educación y por ende, a toda la escuela a que desde sus distintas situaciones le den al cuerpo y a la mente el mismo valor y de esta manera, la prevención pueda apropiarse y estar implícita en las prácticas corporales.

\section{Qué se espera de las Prácticas Corporales en un dispositivo de prevención?}

Benevolente con las afirmaciones de Cachorro y de la mano de él, se observa como las prácticas corporales constituyen acciones producto del pensamiento y éste, a su vez, está construido desde una matriz cultural; desde una posición meramente instrumental, las prácticas corporales referidas a los desplazamientos de las palancas, los movimientos agónicos y antagónicos del músculo y todo el contexto biomecánico procedente de lo físico, son insumos para que el cuerpo tenga su reacción cuando hace parte del entorno próximo (es decir, que las posibilidades de movimiento posibiliten la existencia física del cuerpo).

Razón sólida que guía a que el sujeto tenga prácticas corporales continuas bajo ciertas "estructuras estructuradas" [Bourdieu, (1984); citado por Cachorro, 2009] y si bien Cachorro a firma que es una premisa difícil de

\footnotetext{
${ }^{84}$ Vicente Pedraz, M. "Poder y Cuerpo. El (incontestable) mito de la relación entre ejercicio físico y salud", en Revista Educación Física y Ciencia № 2, Departamento de Educación Física, Facultad de Humanidades y Ciencias de la Educación, UNLP, La Plata. 1997.

${ }^{85}$ Crisorio, R. 2009. Op. Cit.

${ }^{86}$ Crisorio, R. 2009. Op. Cit.
} 
lograr; la búsqueda de experiencias nuevas, de escenarios diferentes con personas diferentes, de la puesta en marcha en la búsqueda de logros y objetivos en la cual la persistencia y la disciplina sean constantes, no debe ser difícil cuando existe una multiplicidad de ofertas y en el cual, la aparición de la discontinuidad se vea suplida por la aparición de otra clase de práctica; esto en una apreciación muy personal.

Por otra parte, y desde una posición de relevancia social, se espera que las prácticas corporales ayuden a construir ciudadanía ${ }^{87}$ con el cual el cuerpo viva uno a uno los escenarios que dan paso a la pertenencia por algo, indistinto de lo que sea, que el cuerpo se identifique y que en su rol de ser ciudadano genere necesidades de seguridad, genere respeto por la integridad física de quienes retroalimentan al cuerpo en la misma construcción social.

Igualmente es necesario que las prácticas corporales conformen la cultura de lo corporal, "....así se conjugan tiempos históricos, políticos, económicos y su composición abierta establece una rica relación dialéctica con los actores." 88 De esta manera entonces no se garantiza, pero se encaminan y se plantan las bases para que los sujetos asuman posiciones críticas frente a lo que les afecta su propio cuerpo.

Por último y no menos importante, se espera que las prácticas corporales sean conducidas a romper con las rutinas, las costumbres aburridoras y los patrones arraigados que carecen de significados; queriendo decir con esto que, el cuerpo se conozca y se conmueva, que descubra y se emocione, que viva y descubra aquellos espacios que aun no conoce, que renueve sentidos y que pueda "disfrutar" las diferentes vertientes que ofrece la vida social (sin necesidad de que estas sensaciones aparezcan de manera inducida y/o artificial), "el que no entró a un burdel, algo se ha perdido". ${ }^{89}$

\footnotetext{
${ }^{87}$ Cachorro, G. 2009. Op. Cit.

${ }^{88}$ Cachorro, G. 2009. Op. Cit.

89 Bernard Arcand. 1993. Citado por Cachorro Gabriel en su texto, Prácticas Corporales. Traducción de Sentidos en la Ciudad. 2009.
} 


\section{Qué aportes se esperan de la escuela?}

En líneas anteriores, se hizo énfasis en la falta de presencia de la educación en los dispositivos de prevención y claro, la falta de apoyo que la misma, desde su rol en la escuela; pero no queriendo dejar esta tarea (la de prevenir), nada fácil, en manos solamente de la salud, es que se espera un aporte manifiesto, también, de la Educación Física.

Amparando los comentarios que se emiten a continuación, se puede, en una primera instancia, reflexionar acerca de la manera de cómo se educa y qué se educa; siendo este componente el que puede determinar la capacidad de resistencia de las personas ante la oferta de las drogas.

La educación del cuerpo, para estos fines, surge como un elemento fundamental en la búsqueda de la prevención, lo que significa modificar la disposición frente a la presencia de las drogas; pues como se indicó al inicio de este estudio, drogas ha habido y habrán siempre, seguramente, lo que conduce a pensar que hay que aprender a convivir con ellas, tal vez como el hombre ha tenido que aprender a convivir con otras creaciones, con otras amenazas y con otras dificultades.

Por tal motivo la educación, con enfoques preventivos, debe facilitar suficientes habilidades para inspirar todo tipo de actividades que conformen una opción diferente al consumo de drogas, siendo efectiva solo si se consigue cambiar las actitudes y comportamientos favorables a la salud, refiriendo la misma y la manera de realizarla, no solo como una transmisión de conocimientos, también como la formación del cuerpo y su representación, es decir, de generar una comunicación de doble sentido entre educadores y educandos, siendo los dos componentes trasmisores y receptores del mensaje.

Desde esta perspectiva, Carballo afirma que "...los contenidos son un conjunto de saberes que por su significado social y cultural, merecen ser transmitidos a quienes aprenden (generalmente, las generaciones más jóvenes). ${ }^{90} \mathrm{Y}$ son muchas las situaciones que subyacen de los escenarios

${ }^{90}$ Carballo, C. 2005. Op. Cit. Haciendo alusión al contenido de la clase de educación Física. 
en el que se lleva a cabo la clase de Educación Física en la escuela, aun cuando, en algunos casos, esta carezca de contenido. ${ }^{91}$

Pero este contenido debe aparecer con la legitimidad, que se debe dar tanto a los profesores de educación física como a la misma clase; esta legitimización no solo debe exigirse, sino que, "...la legitimidad del saber de la Educación Física puede hallarse en la capacidad de los profesionales para resolver los problemas extracurriculares..."92 y estrechar la innegable distancia que existe de esta última, con la formación académica.

Esta relación también comprende que desde el sistema educativo, funden el contenido de operaciones preventivas, de manera que sean apropiadas por el sujeto que aprende.

Desde luego, los contenidos que soportan el sistema educativo y por ende, la clase de Educación Física, "se extraen de la cultura de la sociedad, son tradiciones sociales que se transmiten, aprenden y comparten..."; "...históricamente constituidas y socialmente organizadas." ${ }^{93}$

Por último y compartiendo lo manifestado por Ricardo Crisorio, en la educación física "...se trata de hallar haceres y saberes con los que el sujetoalumno pueda interactuar para desarrollar estructuras y capacidades, con la guía y participación del docente, y no tratar a esas capacidades y estructuras como contenidos." ${ }^{94}$

${ }^{91}$ En relación a tal afirmación, Carlos Carballo en su estudio, reforma educativa y contenidos básicos comunes en educación Física; el significado que los docentes del área les otorgan y su impacto en las prácticas. Definió 6 categorías de análisis vinculadas con la ausencia de contenidos de la clase de Educación Física.

${ }_{92}$ Carballo, C. 2005. Óp. Cit.

${ }^{93}$ Crisorio, R. 1995. Op. Cit.

${ }^{94}$ Crisorio, R. 1995. Op. Cit. 


\section{Factores de riesgo y de protección a tener en cuenta en el consumo de drogas}

Mucho es lo que diferentes autores han abordado en el campo de la prevención de las drogodependencias y aún más es el camino que queda por recorrer para estar cerca de una situación ideal, para llegar a esto es indispensable apostarle a un enfoque científico en la prevención, lo que hace que toda acción que se tome como prevención se tenga que retroalimentar y que se desarrolle tanto como la investigación le aporte, de igual forma implica que permanentemente se adopten posturas críticas y que cada acción se tome también como un momento bidireccional, para intentar mejorar el campo de la investigación.

Ahora bien, para poder avanzar en entender los factores de riesgo, recomendados a tener en cuenta, es importante entender a este, como a la frecuencia y a la distribución en un sector poblacional, donde situaciones particulares son los causantes de patologías de incidencia orgánica ${ }^{95}$.

Es importante resaltar que no solo son relevantes los factores, sino también la forma de cómo se relacionan e influyen entre ellos; como respaldo a lo anteriormente enunciado, el Plan nacional sobre drogas $^{96}$ enuncia tres problemas que el campo de la investigación en prevención encuentra:

1. "frecuentemente en los estudios se consideran un tipo de factores concretos y se dejan de lado otros que si se tuvieran en cuenta podrían modificar las conclusiones de dichos estudios (en consecuencia: ¿se deben las asociaciones encontradas a las variables que hemos manejado $o$ se modificarían los resultados si introdujéramos nuevos parámetros? Por ejemplo, si en un estudio sobre factores de riesgo de la familia no incluimos variables externas a la misma, es posible que el peso de las asociaciones que encontremos se deba a estas carencias)."

2. "la investigación sobre estos factores tan solo ha podido demostrar asociaciones entre determinadas situaciones y el uso de drogas, pero no demostrar la potencial causalidad de estos factores."

\footnotetext{
${ }^{95}$ Concepto de la epidemiología clásica, en el que el término como tal, hace referencia a que los efectos ocurren en el cuerpo, entendido este como organismo humano (UNLP - 2006).

${ }^{96}$ Plan Nacional Sobre Drogas, Secretaría General del Ministerio del Interior - España 1997.
} 
3. "a estas dos dificultades, nada desdeñables, hay que añadirle otra, que consiste en el hecho de la falta de unificación de criterios, tanto en lo que a conceptos se refiere, como a instrumentos de evaluación de los mismos, resultando que bajo una misma denominación se acogen factores que no corresponden, o que incluyen distintos tipos de variables, o bien que utilizan diferentes indicadores."

En este sentido, la delegación del gobierno de España (citado como ejemplo) para el Plan nacional sobre drogas ha clasificado los factores de riesgo en: Factores de Riesgo Ambientales y Factores de Riesgo del individuo y sus relaciones con el entorno. ${ }^{97}$ Entre los factores de riesgo ambientales, que se enunciarán a continuación, los más relevantes son:

La depravación social, la desorganización comunitaria, la disponibilidad y accesibilidad de las sustancias, la percepción social del riesgo, la movilidad de la población, las normas y las leyes de la comunidad.

Es importante resaltar que las comunidades con un alto grado de Depravación Social, en la que la inseguridad es situación cotidiana, se consideran zonas de actuación prioritaria ya que el riesgo por el consumo de drogas y las conductas delictivas es en esta, aún mayor. ${ }^{98}$

De igual manera la desorganización Comunitaria hace que los procesos de socialización sean inefectivos, situación originada por la carencia de recursos y por los pocos lazos comunitarios, dejando en cierto momento, un espacio en el que la prevención se encamine a fortalecer las instituciones sociales y facilitar el "contacto" entre estas y la población, tarea que se podría pensar como una tarea difícil de ejecutar, pero que, posteriormente se tiene que entender como labores prioritarias (la generación de lazos estables, la prestación óptima de los servicios, la educación social). No obstante, los lazos que logran crear los niños cuando participan en una comunidad, se

${ }^{97}$ Los factores de riesgo ambientales y Factores de Riesgo del individuo y sus relaciones con el entorno, son aquellos que hacen reconocimiento al cuerpo en tanto a sus representaciones, a un encuentro entre imágenes y a la articulación entre la inconsciencia y a la conciencia que se genera cuando existen intercambios con los otros.

${ }^{98}$ Martínez. 1996. 
constituyen en un fuerte factor de protección tanto para las conductas drogodependientes como para las delictivas.

Al hacer referencia a la disponibilidad y accesibilidad de las sustancias es importante mencionar, igualmente que "A mayor disponibilidad de sustancias, mayor consumo. Este es un hecho incuestionable y que se ha demostrado en diversas investigaciones, razonado tanto para sustancias legales como ilegales" 99 .

La percepción social del riesgo y la Movilidad de la población son dos situaciones que se definen, desde el contexto de la información recibida, como el primer encuentro con la "realidad", ya que una vez la información llega (versiones, diálogos, comentarios, opiniones) y se moviliza (diferentes sitios, diferentes personas, cambios de residencia, cambios de Colegios) es muy difícil modificar estas primeras percepciones ${ }^{100}$, dejando al descubierto momentos de especial vulnerabilidad, razón por la cual es un importante factor a tener en cuenta a la hora de dirigir y/o realizar programas dirigidos a la prevención de drogodependencias.

Conjuntamente con los factores enunciados anteriormente, existen también aquellos en los que el individuo se relaciona con otras personas o con otros grupos; es decir, los llamados Factores de Riesgo del Individuo y sus relaciones con el entorno, los más relevantes son: la Historia familiar de Alcoholismo, las pautas educativas, las actitudes y modelos de conducta por parte de los padres, los conflictos familiares, los valores, la agresividad, la búsqueda de sensaciones, otros problemas de conducta, las actitudes hacia las drogas, el fracaso escolar y el grupo de iguales. ${ }^{101}$

La historia familiar de alcoholismo es un factor que, aunque no determine un comportamiento perturbador genéticamente cedido ${ }^{102}$, es si un aspecto que predice la fácil aparición de conductas semejantes. De igual manera las Pautas educativas $\mathrm{y} / \mathrm{o}$ las pautas de crianza son generadoras de vulnerabilidad o de protección, según sea el caso; por tanto, el permanente

\footnotetext{
${ }^{99}$ Berenzon S, Medina-Mora ME, Carreño S, Juares F, Rojas E, Villatoro J. Los factores relacionados con el uso y el abuso de sustancias psicoactivas en estudiantes de enseñanza media y media superior de la República mexicana. Salud Mental. 1996.

${ }^{100}$ Berenzon S, 1996. Op. Cit.

${ }^{101}$ Plan Nacional sobre drogas, España 1997. Op. Cit.

102 Segrin y Meneses 1996. Donde se indica que los hijos pueden no exhibir un funcionamiento psicosocial perturbado a pesar de tener un progenitor alcohólico.
} 
acompañamiento de los padres y el incentivo por mejorar en las actividades y el aprovechamiento del tiempo libre en actividades en las que el cuerpo no se vea afectado por este tipo de conductas, determinará un camino y unas pautas de vida sana, así mismo una posición diferente, determinará igualmente un comportamiento diferente.

Las actitudes y modelos de conducta por parte de los padres aparecen asociadas al uso indebido de sustancias por parte de los hijos, convirtiéndose en uno de los mejores indicadores de la valoración positiva de los niños hacia el consumo y por lo tanto aumenta sus expectativas de consumir en el futuro, convirtiéndolo definitivamente en un factor de alta vulnerabilidad. A este grupo se suman los Conflictos familiares y los valores, también incitadores de la conducta, ya que si no existe una estructura de familia sólida (lazos familiares), tampoco habrá, según Ricardo Crisorio, una construcción del cuerpo, que sea positiva, obedeciendo este a la realidad en la cual se construye. ${ }^{103}$

La agresividad, por su parte, al aparecer de manera temprana ${ }^{104}$, fortalece aún más la vulnerabilidad y generan una asociación más fuerte con el uso de las drogas.

Aunque diversos autores señalan factores semejantes a los anteriormente expuestos, los aquí consignados son los más relevantes y los que congregan y/o derivan en otros; sin embargo, los factores de riesgo pueden ser más 0 pueden incluso variar según las características etareas de la población. Por tanto, la protección se realiza cuando es tangible la ausencia de los factores de riesgo y por ende, la prevalencia de esta condición.

\footnotetext{
${ }^{103}$ Crisorio, R. 1998.

${ }^{104}$ Martínez, 1996
} 


\section{BIBLIOGRAFIA}

- Alonso, L.E. El estructuralismo genético y los estilos de vida: Consumo, Distinción y Capital Simbólico en la obra de Pierre Bourdieu, España - 2002.

- Anuario Estadístico de lbagué 2.001 - 2.003.

- Berenzon S, Medina-Mora ME, Carreño S, Juares F, Rojas E, Villatoro J. Los factores relacionados con el uso y el abuso de sustancias psicoactivas en estudiantes de enseñanza media y media superior de la República mexicana. Salud Mental. 1996.

- Cachorro G. Prácticas Corporales. Traducción de Sentidos en la Ciudad. Texto pedagógico F.A.H.C.E. - U.N.L.P. Argentina. 2009.

- Carballo C. En Educación Física, el saber no ocupa lugar (lamentablemente) - Encuentro nacional e Internacional de Investigadores en Educación Física. Uruguay. 2004. Documento elaborado como apoyo del Departamento de Educación Física. U.N.L.P. Argentina 2005.

- Carballo C. y Crespo B. - Aproximaciones al Concepto de Cuerpo Material de apoyo - Maestría en Educación Corporal - Facultad de Humanidades y Ciencias de la Educación U.N.L.P. - Argentina. 2001.

- Carusso, M. y Dussel, I - 1997 "Yo, Tu, El: ¿Quién es el Sujeto?” en cinco conceptos para pensar la educación contemporánea. Texto pedagógico de la Maestría en Educación Corporal, F.A.H.C.E U.N.L.P. - Argentina.

- Celi, Edgardo Amílcar (Arg.) - Portal de Medicina Estética - Revista de Medicina Estética y especialidades afines. http://www.medestética.com/Científica.

- Colombia, Tolima, Ibagué. Alcaldía municipal de lbagué - Secretaría de Salud Municipal de Ibagué: Diagnóstico de salud pública del municipio de Ibagué. Tolima. 2004- 2005. Ibagué, 2003.

- Colombia, Tolima, Ibagué. Alcaldía de Ibagué: Plan de desarrollo Ibagué Construyendo Futuro 2004 - 2007. Ibagué. 
- Colombia, Tolima, Ibagué. Secretaría de Salud Municipal: Plan de atención básica PAB 2004. Ibagué, 2004.

- Colombia, Tolima, Ibagué. Folleto informativo: Sí a la vida, no a las drogas, campaña juventud sin drogas. (Año 1 Vol. 1).

- Constitución Política de Colombia, 1991.

- Crisorio, R. El Problema de los Contenidos de la Educación Física. Serie pedagógica facultad de Humanidades y Ciencias de la Educación U.N.L.P. Argentina 1995.

- Crisorio, R. Constructivismo, cuerpo y lenguaje - Revista Educación Física y Ciencia, año 4, Departamento de Educación Física, Facultad de Humanidades y Ciencias de la educación, UNLP, La Plata Argentina. 1998.

- Crisorio, R. El Cuerpo y las Prácticas Corporales, revista El Monitor Publicación del Ministerio de Educación de la Nación, República Argentina. 2009.

- Encuesta Nacional sobre consumo de SPA en jóvenes de 10 a 24 años, Colombia 2001.

http://www.nuevosrumbos.org/documentos/Encuesta\%202001.pdf

- Escohotado, A. Historia General de las Drogas. Pág. 1231-1235. Ed. España, 2005.

- EY, H: Tratado de Psiquiatría. Toray-Masson. 8ª. ed., México, 1980. 459.

- Fernández Ferre ML. Gual Sole A., Cabezas Peña C. Tabaquismo, alcoholismo y otras drogodependencias en: Martín Zurro, Cano Pérez. Manual de atención Primaria. Barcelona 1995; 484 - 509.

- Ferrer Xavier., Sánchez P. José - Prevención: trampas y riesgos del Lenguaje. Instituto para el Estudio de las Adicciones. España, 2001. Enlace Web. http://www.lasdrogas.info.

- Fondo Nacional de

Estupefacientes http://www.fne.gov.co/Index.aspx?ld=12921 
- Fundación Génesis. Santa fe de Bogotá - Colombia, 2006. Enlace Web. http://www.fundagenesis.org.

- González, Alejandro - Analgésicos Narcóticos - Boletín Web de la escuela de Medicina, P. Universidad Católica de Chile 1994; 23: 159163.

- Guía sobre Drogas, Ministerio de Sanidad y Consumo, Delegación del Gobierno para el Plan Nacional sobre drogas. Gobierno de España, 2007

- Herodoto: los nueve libros de la historia, México, Editorial Porrua, 1974.

- Mamonde M. cuerpo, salud y Política. Un nudo posible - trabajo presentado en el $7^{\circ}$ Congreso argentino y $2^{\circ}$ Latinoamericano de Educación Física y Ciencias. Facultad de Humanidades y Ciencias de la Educación. U.N.L.P. Argentina 2007.

- Martínez J, García J Domingo M, Machin AJ, consumo del alcohol, tabaco y drogas en adolescentes. Atención primaria 1996.

- Massün, E. Prevención del uso indebido de Drogas. México 1991.

- Ministerio de la Protección Social. www.minproteccionsocial.gov.co/

- Muñiz, Leandro. Drogadicción. Blog enlace web - http://adiccionn1.blogspot.com Buenos Aires - Argentina 2006.

- Periódico: La Comuna 12 Editor responsable: Gustavo Carpinella Dirección: José Cubas 3249 Cap. Fed. Registro de la Propiedad Intelectual №: 801263. http://www.lacomuna12.com.ar.

- Plan Nacional Sobre Drogas, Prevención de las Drogodependencias, Secretaría General del Ministerio del Interior - España 1997.

- Resolución 01956 de 2008, por medio del cual se adoptan medidas en relación al consumo de cigarrillo y tabaco. Ministerio de la Protección Social. 
- Revista Virtual Medline plus, Servicio de la biblioteca Nacional de Medicina de EE.UU. enlace Web. Instituto Nacional de la Salud. http://www.nlm.nih.gov/medlineplus/spanish/ency/article/002258.htm

- Segrin C, Menees MM. Impacto de las habilidades de aprontamiento y de la comunicación familiar en las destrezas sociales de los hijos de alcohólicos. J Stud Alcohol 1996.

- Uribe C. La toxicología de los psicoactivos en Dirección nacional de Estupefacientes. Problemática de las drogas en Colombia. DNE Bogotá 2002. 


\section{GLOSARIO}

Abstinencia: es una renuncia voluntaria de complacer un deseo o un apetito de ciertas actividades corporales que se experimentan extensamente como placenteras.

Alcaloides: son aquellos metabolitos secundarios de las plantas sintetizados, generalmente, a partir de aminoácidos. Los alcaloides verdaderos derivan de un aminoácido, son por lo tanto nitrogenados. Poseen acción fisiológica intensa en los animales aun a bajas dosis con efectos psicoactivos.

Alterar: cambiar la esencia o función de un órgano a causa de los efectos que producen las sustancias psicoactivas.

Alucinaciones: es una percepción que no corresponde a ningún estímulo físico externo. Sin embargo, la persona siente esa percepción como real.

Alucinógenos: se le llama alucinógenos a cierto tipo de drogas que causan alteraciones profundas en la percepción de la realidad del usuario. Bajo su influencia, las personas ven imágenes, oyen sonidos y sienten sensaciones muy distintas a las propias de la vigilia. Algunos alucinógenos también producen oscilaciones emocionales rápidas e intensas.

Antidepresivos: son medicamentos para el tratamiento de las depresiones mayores.

Apreciación: Acción y efecto de apreciar, entendida como querer algo o enunciar con especial atención alguna referencia.

Aspiran: Atraen el aire, aromas o sustancias exteriores a los pulmones.

Aturdimiento: Perturbación de los sentidos por efecto de un golpe, de un ruido extraordinario o consumo de drogas.

Cannabis: es una sustancia psicoactiva tomada del cáñamo. A sus flores (o cogollo) se les llama marihuana. 
Cáñamo: es el nombre que reciben las variedades de la planta Cannabis sativa y el nombre de la fibra que se obtiene de ellas, que tiene, entre otros, usos textiles.

Etáreo: clasificación de una población por edades, grupos de personas por edades.

Conducta: es la manera con que los hombres se comportan en su vida y acciones. Por lo tanto, la palabra puede utilizarse como sinónimo de comportamiento. En este sentido, la conducta se refiere a las acciones de las personas en relación con su entorno o con su mundo de estímulos.

Conexos: Dícese de la cosa que está enlazada o relacionada con otra.

Connotación: Sentido o valor secundario que una palabra, frase o discurso adopta por asociación con un significado estricto.

Costumbre: es una práctica social arraigada. Generalmente se distingue entre costumbres que son las que cuentan con aprobación social, y las malas costumbres, que son relativamente comunes, pero no cuentan con aprobación social, y a veces leyes han sido promulgadas para tratar de modificar la conducta.

Crianza: Forma de educación y valores que se adquieren durante los primeros años de vida.

Dependencia: Necesidad de consumir sustancias psicoactivas para vivir bien.

Depresores: son sustancias químicas que ralentizan la actividad del sistema nervioso central. Los depresores son utilizados en medicina como ansiolíticos, sedantes o somníferos. También son utilizados con fines no terapéuticos como drogas ludidas o de abuso.

Desecación: Extracción o eliminación de la humedad de un terreno o cuerpo.

Desplome: Pérdida o caída, desaparición de algo.

Despreciativo: Adjetivo que expresa desprecio.

Disfunción: Alteración de una función orgánica. 
Epidemiológica: es la disciplina científica que estudia la distribución, frecuencia, determinantes, relaciones, predicciones y control de los factores relacionados con la salud y enfermedad en poblaciones humanas.

Expendedores: máquina o individuo encargado de expender droga.

Factores de riesgo: es toda circunstancia o situación que aumenta las probabilidades de una persona de contraer una enfermedad.

Fenómeno: es el aspecto que las cosas ofrecen ante nuestros sentidos; o sea el primer contacto que tenemos con las cosas, lo que denominamos experiencia.

Letalidad: Relación porcentual entre muertes y casos de una enfermedad.

Lucrativos: produce ganancia o provecho.

Mascan: Parten y desmenuzan algo con los dientes.

Mórbidos: padece enfermedad o la ocasiona.

Percepción: es un proceso nervioso superior que permite al organismo, a través de los sentidos, recibir, elaborar e interpretar la información proveniente de su entorno.

Pretensión: Ambición pretenciosa o desmedida.

Prevalencia: se define como el número de casos de una enfermedad o evento en una población y en un momento dado.

Prevención integral: Sistema que se ofrece a quienes consumen sustancias psicoactivas, la cual disminuye la oferta y demanda de drogas, para mejorar su calidad de vida en su entorno familiar, laboral, con actitud preventiva colectiva sirviendo como monitor de buenas experiencias pudiendo definir un proyecto de vida reinsertándolo en la sociedad, conyugar esfuerzos para que la persona en todas las áreas de su vida pueda tener éxito con actitudes físicas, biológicas, para garantizar su desarrollo físico, emocional y espiritual a través de programas, campañas, centros de prevención, reinserción social, granjas integrales con programación de desintoxicación biológica.

Provocan: Producir, causar. 
Psicoactivas: sustancia química de origen natural o sintético que afecta específicamente las funciones del sistema nervioso central (SNC), compuesto por el cerebro y la médula espinal, de los organismos vivos. Estas sustancias son capaces de inhibir el dolor, modificar el estado anímico o alterar las percepciones.

Se considera que una sustancia psicoactiva genera dependencia en su consumidor cuando cumple al menos tres de cuatro requisitos:

- Genera síndrome de abstinencia al dejar de consumirla.

- Llevan al consumidor a la reincidencia.

- Es utilizada con fines recreacionales, no terapéuticos.

- Tiene la capacidad de influir cambios sobre las funciones normales de la mente del consumidor.

Psicóticos: padece o manifiesta una psicosis.

Psicosis: es un término genérico utilizado en la psicología para referirse a un estado mental descrito como una pérdida de contacto con la realidad.

Reincide: Vuelve a caer o incurrir en un error, falta o delito.

Represiones: es un concepto central del psicoanálisis que designa el mecanismo o proceso psíquico del cual se sirve un sujeto para rechazar representaciones, ideas, pensamientos, recuerdos o deseos y mantenerlos en el inconsciente.

Retroalimentar: el proceso de compartir observaciones, preocupaciones y sugerencias, con la intención de recabar información, a nivel individual o colectivo, para intentar mejorar el funcionamiento de una organización o de cualquier grupo formado por seres humanos.

Síntomas: referencia subjetiva que da un enfermo por la percepción o cambio que reconoce como anómalo, o causado por un estado patológico o enfermedad.

Solanáceas: son una familia de plantas herbáceas o leñosas con las hojas alternas, simples y sin estípulas pertenecientes al orden Solanales, de las dicotiledóneas (Magnoliopsida). Las solanáceas incluyen muchos organismos 
modelo para investigar cuestiones biológicas fundamentales a nivel celular, molecular y genético, tales como el tabaco y la petunia.

Supusiera: tener como resultado o producir como consecuencia directa.

Tolerancia: ocurre cuando el organismo se adapta a una determinada cantidad (dosis) de fármaco y se da una reacción menor del organismo, lo que ocasiona que una persona necesite dosis mayores del fármaco o droga con la finalidad de que obtenga el mismo efecto inicial.

Tóxica: dícese de la sustancia que ingerida, inhalada, absorbida, aplicada, inyectada o desarrollada en el interior del organismo es capaz, por sus propiedades químicas o físicas, de provocar alteraciones órgano funcionales e incluso la muerte.

Toxicidad: es una medida usada para medir el grado tóxico o venenoso de algunos elementos.

Vulnerabilidad: se refiere a la posibilidad de ser herido o recibir alguna lesión física o moral. 


\section{ANEXOS}

Anexo 1 : $\quad$ Acuerdo 085 de 1991 - Consejo de lbagué, por medio de la cual se crea la secretaria de Salud de la ciudad.

Anexo 2 : $\quad$ Circular Externa 0018 de 2004 - Ministerio de la Protección Social, lineamientos del PAB.

Anexo 3 : Formato VESPA - Sistema de Vigilancia Epidemiológica de Sustancias Psicoactivas 


\section{Anexo 1}

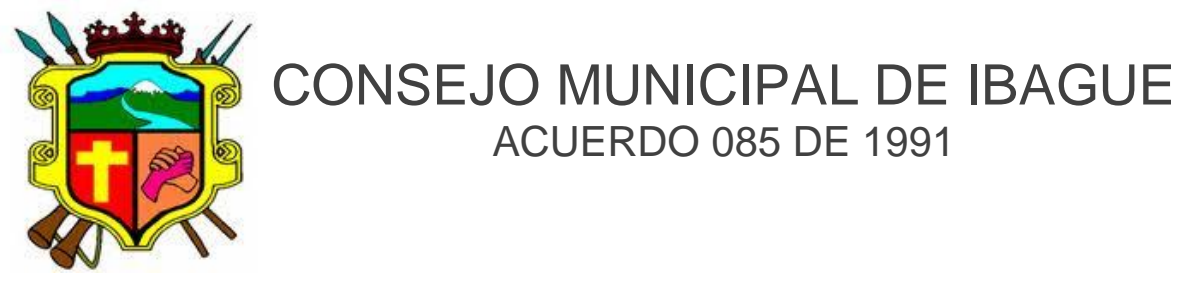

"En uso de sus facultades consagradas, en el numeral 6. Artículo 313 de la Constitución política de Colombia. ${ }^{105}$

ACUERDA

ARTICULO 1․-- Crease la SECRETARIA DE SALUD MUNICIPAL, Como una dependencia de la administración central, la cual ejercerá la dirección local del sistema de salud, la ejecución de políticas, planes y programas sectoriales, bajo la dependencia directa del despacho del alcalde.

ARTICULO 2o - La Secretaría de salud municipal, será la entidad responsable del funcionamiento del sistema de salud municipal, de conformidad con la ley 10 de 1990 y sus decretos reglamentarios y normas concordantes.

ARTICULO $3^{\circ}$ - Para el cumplimiento de su objetivo, la Secretaría de salud municipal ejercerá las siguientes funciones:

a. Coordinar y supervisar la prestación del servicio de salud en el municipio de Ibagué.

b. Programar la distribución de los recursos recaudados para el sector salud.

c. Contribuir a la formulación y adquisición de los planes, programas y proyectos del sector salud en su jurisdicción, en armonía con las políticas, planes y programas locales, departamentales y nacionales.

${ }^{105}$ Artículo 313, numeral 6: "Determinar la estructura de la administración municipal y las funciones de sus dependencias; las escalas de remuneración correspondientes a las distintas categorías de empleos; crear a iniciativa del alcalde, establecimientos públicos y empresas industriales o comerciales y autorizar la constitución de sociedades de economía mixta." 
d. Estimular la participación comunitaria, en los términos señalados por la ley.

e. Supervisar y controlar el recaudo de los recursos locales que tienen destinación específica para la salud.

f. Cumplir y hacer cumplir en el municipio, las políticas y normas trazadas por el Ministerio de salud, de acuerdo con las adecuaciones hechas por las direcciones seccional y local del sistema.

g. Desarrollar planes de formación, adiestramiento y capacitación del personal del sector salud, en coordinación con las entidades especializadas del sector o con los del sector educativo.

h. Promover la integración funcional.

i. Ejercer las funciones que expresamente le delegue el Ministerio de salud o la división seccional del sistema de salud.

j. Administrar bajo la dirección del alcalde el Fondo local de salud en coordinación con la Secretaría de hacienda, y la tesorería municipal y asignar sus recursos con atención a la cantidad, calidad y costo de los servicios programados, teniendo en cuenta el régimen tarifario.

k. Aplicar los sistemas de referencia y contra - referencia de pacientes, definidos por la dirección nacional y seccional de salud. Sin embargo, cuando los costos del servicio así lo exijan podrá autorizar la celebración de contratos entre instituciones o entidades que presten servicios de salud, para establecer sistemas especiales de referencia y contra - referencia.

I. Desconcentra el sistema local de salud, teniendo como unidad de referencia el corregimiento y la comuna.

m. Diagnosticar el estado de salud - enfermedad estableciendo los factores determinantes y elaborar el plan local de salud, efectuando su seguimiento y evaluación con la participación comunitaria que establece la ley.

n. Estimular la atención preventiva, familiar, extra hospitalaria y el control del medio ambiente. 


\title{
CONSEJO MUNICIPAL DE IBAGUE
}

\author{
ACUERDO 085 DE 1991
}

o. Controlar los factores de riesgo, referentes al estado de salud enfermedad de la población, en coordinación con las entidades del sector $y$ de los otros sectores que incidan en la salud.

p. Cumplir las normas técnicas dictadas por el Ministerio de salud (Para la construcción de obras civiles de salud.) Para la construcción de obras civiles, dotaciones básicas y mantenimiento integral de instituciones del primer nivel de atención en salud o para centros de bienestar del anciano y de acuerdo al estatuto urbano vigente (Básicas y mantenimiento integral de instituciones del primer nivel de atención en salud.

q. Cumplir y hacer cumplir las normas de orden sanitario previstas en la ley $9^{a}$ de 1979 o código sanitario nacional y su reglamentación.

r. Desarrollar labores de inspección, vigilancia y control de las instituciones que presten servicio de salud.

s. Velar por el cumplimiento de las normas sobre seguridad industrial y salud ocupacional.

t. Fijar y cobrar tasas o derechos por expedición de permisos, licencias, registros y certificaciones, de conformidad con el reglamento tarifado contemplado en la ley 10 de 1990 y el decreto 1759 de 1990.

u. Establecer en coordinación con las entidades educativas, los campos y tiempo de prácticas que deben preverse en los planes de formación de los otros sectores." 


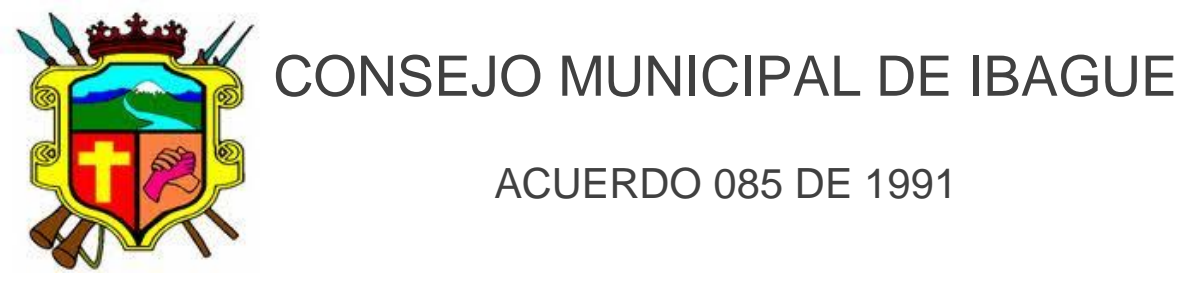

\section{SUBDIVISION DE LA SECRETARIA DE SALUD DE IBAGUE}

La Secretaría de Salud de Ibagué se distribuye de la siguiente manera:

Grupo de Salud Pública

- Área de vigilancia Epidemiológica y Políticas de Salud Pública

- Área de Participación Social

- Área de Control de Factores de Riesgo, Promoción de la Salud y prevención de la Enfermedad

Grupo de Aseguramiento

- Área de Dirección de Aseguramiento

- Área de Promoción y Garantía de la Calidad del Aseguramiento

Grupo de Desarrollo de Servicios de Salud

- Área de desarrollo de políticas, planes, programas y proyectos para la

oferta de servicios de salud

- Área de vigilancia y control de la oferta

- Área de urgencias, emergencias y desastres 
Anexo 2

Ministerio de la Protección Social República de Colombia Despacho del Ministro

Bogotá, Febrero 18 de 2004

\section{CIRCULAR EXTERNA Nº 0018}

PARA: $\quad$ GOBERNADORES, ALCALDES, DIRECTORES DEPARTAMENTALES, DISTRITALES Y MUNICIPALES DE SALUD, CONSEJOS TERRITORIALES DE SEGURIDAD SOCIAL EN SALUD.

DE:

MINISTRO DE LA PROTECCION SOCIAL

ASUNTO: LINEAMIENTOS PARA LA FORMULACIÓN Y EJECUCIÓN DE LOS

PLANES ESTRATÉGICOS Y OPERATIVOS DEL PAB 2004 - 2007 Y DE LOS RECURSOS ASIGNADOS PARA SALUD PÚBLICA.

En desarrollo de las competencias consagradás en las Leyes 100 de 1993 y 715 de 2001 y de las facultades contenidas en el Decreto 205 de 2003, el Ministerio de la Protección Social, como ente rector del Sistema General de Seguridad Social en Salud y del Sector Salud, en función de proteger la salud de la población, garantizar el logro de las metas nacionales de salud pública y focalizar la inversión de los recursos en las prioridades en salud pública, imparte las siguientes instrucciones de obligatorio cumplimiento para la formulación y ejecución de los Planes Estratégicos y Operativos del PAB $2004-2007$ y de los recursos asignados para salud pública, teniendo en cuenta las siguientes consideraciones:

Que corresponde a la Nación definir las prioridades en materia de salud pública y las acciones de obligatorio cumplimiento del Plan de Atención Básica (PAB), así como definir y aplicar sistemas de evaluación y control de gestión técnica, financiera y administrativa a las instituciones que participan en el sector y en el Sistema General de Seguridad Social en Salud.

Que es responsabilidad de los departamentos, distritos y municipios adoptar, difundir, implantar y ejecutar la política de salud pública formulada por la Nación, establecer su situación de salud y propender por su mejoramiento y formular y ejecutar los Planes de Atención Básica en su jurisdicción. 
Que el Plan de Atención Básica debe ser elaborado con la participación de la comunidad y bajo la dirección del Consejo Territorial de Seguridad Social en Salud y articularse a los Planes Sectoriales de Salud y a los Planes de Desarrollo correspondientes.

De conformidad con las anteriores consideraciones, este Despacho se permite impartir las siguientes instrucciones:

1. ACCIONES DE SALUD PUBLICA PRIORITARIAS PARA EL PAIS.- De conformidad con lo establecido en el numeral 12 del artículo 42 de la Ley 715 de 2001 se definen las siguientes prioridades de la Nación y de las entidades territoriales en materia de salud pública:

a) Reducción de enfermedades inmunoprevenibles, prevalentes de la infancia y mortalidad infantil.

b) Implementación de la Política de Salud Sexual y Reproductiva.

c) Prevención y control de enfermedades transmitidas por vectores.

d) Promoción de estilos de vida saludable para la prevención y control de las enfermedades crónicas.

e) Fortalecimiento del Plan Nacional de Alimentación y Nutrición e implementación de la Política Nacional de Seguridad Alimentaria y Nutricional.

f) Reducción del impacto en salud de la violencia e implementación de las Políticas de Salud Mental y de Reducción del Consumo de Sustancias Psicoactivas.

2. ACCIONES DE ESTRICTO CUMPLIMIENTO DE LOS PLANES DE ATENCION BÁsICA.- Para el logro de los objetivos propuestos en las prioridades de salud pública definidas para el país, es de estricto cumplimiento incorporar en los Planes de Atención Básica departamentales, distritales y municipales las acciones, metas e indicadores descritas en el anexo técnico que forma parte integral de la presente circular.

3. ADMINISTRACION DE LOS RECURSOS DE SALUD PUBLICA.- LoS recurSOS asignados para salud pública, se deben manejar en una subcuenta presupuestal de los fondos departamentales, distritales o municipales de salud, denominada "Subcuenta de Salud Pública". Estos incluyen:

a) Los recursos asignados para el componente de salud pública del Sistema General de Participaciones.

b) Las transferencias de la Nación para los programas de control de vectores, lepra y tuberculosis.

c) Los recursos provenientes del Fondo de Solidaridad y Garantía que eventualmente se asignen a la entidad territorial para la financiación o cofinanciación de las acciones de salud pública. 
Ministerio de la Protección Social

República de Colombia

Despacho del Ministro

literdy 0 cea

d) En el caso de los departamentos y del Distrito Capital de Bogotá, los recursos que se generen por la venta de los servicios de los Laboratorios de Salud Pública y demás recursos que se asignen por la entidad territorial para la prestación de dichos servicios.

e) Los recursos propios de las entidades territoriales que se destinen a la financiación o cofinanciación de las acciones de salud pública.

f) Los recursos y aportes que a cualquier título se asignen o reciba directamente la entidad territorial para la financiación o cofinanciación de acciones de salud pública.

g) Los rendimientos financieros, los recursos del balance y demás ingresos que se generen a favor de la subcuenta.

Los recursos que en cumplimiento de lo dispuesto en el artículo 46 de la Ley 715 de 2001, el Acuerdo 229 del CNSSS y la Resolución 968 de 2002, se descuenten del valor de la Unidad de Pago por Capitación del Régimen Subsidiado para financiar las acciones de promoción y prevención del POS a cargo de las entidades territoriales, se administrarán en la Subcuenta de Subsidios a la Demanda del Fondo de Salud de la entidad territorial que haya acreditado los requisitos establecidos para el efecto.

4. RECURSOS DE SALUD PÚBLICA NO EJECUTADOS A 31 DE DICIEMBRE.- LOS saldos presupuestales no comprometidos de las vigencias anteriores, los recursos que se liberen por la liquidación de los convenios o contratos, y los rendimientos financieros que se hayan generado durante estas vigencias, deberán incorporarse al presupuesto de la vigencia siguiente en la subcuenta de salud pública del Fondo de Salud de la entidad territorial y programarse y ejecutarse de conformidad con lo previsto en la presente circular.

5. DESTINACION DE LOS RECURSOS DE SALUD PUBLICA DEL SGP Y LAS TRANSFERENCIAS NACIONALES.- Las transferencias nacionales para el control de las enfermedades transmitidas por vectores y el control de la tuberculosis y la lepra, son de destinación específica para el desarrollo de las actividades de prevención y control de dichas enfermedades. De igual manera, los recursos del componente de salud pública del Sistema General de Participaciones deberán aplicarse exclusivamente para la financiación de las acciones de estricto cumplimiento definidas para las prioridades de la Nación en salud pública en la presente circular y en el cumplimiento de las competencias asignadas en el numeral 3 de los artículos 43 y 44 y lo pertinente del artículo 45 de la Ley 715 de 2001.

6. CONCEPTOS DE GASTO DE LOS RECURSOS DE SALUD PUBLICA DEL SGP Y LAS TRANSFERENCIAS NACIONALES.- Con los recursos de que trata el numeral anterior, se podrán financiar los gastos necesarios para el cumplimiento de las funciones técnicas y operativas exclusivas de salud pública, que entre otros conceptos de gasto, incluye: contratación de talento humano, contratación de servicios, 


\author{
Ministerio de la Protección Social \\ República de Colombia \\ Despacho del Ministro
}

litendy 0 den

adquisición de equipos, adquisición de software, adquisición de insumos críticos y de reactivos para el laboratorio de salud pública, viáticos y gastos de viaje, capacitación y desarrollo del talento humano de planta, combustibles y lubricantes, mantenimiento, adquisición de papelería y útiles de escritorio, fletes y gastos de transporte.

El talento humano de las Direcciones Territoriales de Salud dedicado exclusivamente al desarrollo de las acciones de salud pública definidas en la presente circular, independientemente de su forma de vinculación, se podrá financiar con recursos de salud pública del Sistema General de Participaciones y las transferencias nacionales según corresponda.

El talento humano que desarrolla funciones de carácter directivo o administrativo, incluyendo los coordinadores territoriales del PAB o de salud pública, deberán financiarse con los recursos de funcionamiento de la respectiva entidad territorial, incluidos los que se destinen en aplicación de los artículos 59 y 60 de la Ley 715 de 2001 y los recursos de libre destinación del componente de propósito general del Sistema General de Participaciones previstos en el Artículo 78 de la citada Ley.

En todo caso, es responsabilidad del ente de dirección de salud territorial garantizar la capacidad técnica e idoneidad del talento humano que prestará servicios de salud pública, cualquiera que sea su modalidad de vinculación y nivel de formación.

Bajo ninguna circunstancia serán objeto de financiación con cargo a estos recursos, los siguientes conceptos de gasto:

a) El pasivo prestacional e indemnizaciones por liquidación o supresión de cargos.

b) El talento humano que desarrolla actividades de promoción y prevención del POS de los regímenes subsidiado y contributivo.

c) Actividades de diagnóstico, tratamiento y rehabilitación, referencia y contrarreferencia de la población afiliada a los regímenes contributivo y subsidiado, regímenes especiales y población vinculada, salvo las excepciones previstas en el anexo técnico de la presente circular y eventualmente los biológicos del PAI y medicamentos para el tratamiento de la lepra, tuberculosis, leishmaniasis y enfermedad de chagas, cuando estos no puedan ser suministrados por la Nación y los que en caso de emergencia sanitaria autorice el Ministerio de la Protección Social.

d) Adquisición de dispositivos y equipos biomédicos para población discapacitada tales como prótesis, órtesis, aparatos y ayudas ortopédicas.

e) Elaboración e impresión de objetos promocionales o de carácter suntuoso, que no generan impacto en salud pública, tales como: Calendarios, Petos, Camisetas, Gorras, Botones, Prendedores, Lapiceros, entre otros.

7. CONTRATACIÓN DE LAS ACTIVIDADES DE SALUD PÚBLICA.- De acuerdo con lo dispuesto en el artículo 46 de la Ley 715 de 2001, las acciones de salud pública 


\author{
Ministerio de la Protección Social \\ República de Colombia \\ Despacho del Ministro
}

litercd i c ces

previstas en la presente circular que no puedan ser realizadas directamente por la Dirección de Salud Territorial, se contratarán prioritariamente con las IPS públicas, vinculadas a la entidad territorial, de acuerdo con su capacidad técnica y operativa, siempre y cuando éstas cumplan las condiciones del Sistema Único de Garantía de Calidad. Para los efectos aquí previstos, el término prioritariamente debe entenderse en el sentido de que, en igualdad de condiciones de calidad, se preferirá contratar a las IPS públicas respecto de las privadas. En todo caso se deberán celebrar contratos que se regirán por la normatividad vigente en materia de contratación de entidades públicas.

8. ORGANIZACION INSTITUCIONAL PARA EL CUMPLIMIENTO DE LAS COMPETENCIAS EN SALUD PUBLICA. De conformidad con lo dispuesto en el artículo 55 de la Ley 715 de 2001, los Alcaldes y Gobernadores deberán adecuar y orientar su estructura administrativa, técnica y de gestión, con el propósito de garantizar el óptimo cumplimiento de sus competencias en salud pública y mejorar la eficiencia de su gestión en función de los recursos asignados, infraestructura y talento humano disponible.

En el caso de los departamentos y distritos, en este proceso se deberá definir con claridad la(s) repartición(es) que adelantará(n) las competencias que les correspondan en materia de gestión de la salud pública (asesoría, asistencia técnica, monitoreo y evaluación de las acciones de salud pública del PAB y del POS), vigilancia en salud pública, laboratorio de salud pública, inspección, vigilancia y control de factores de riesgo del ambiente, medicamentos y sustancias químicas potencialmente tóxicas, control de vectores y zoonosis y acciones complementarias de promoción y prevención.

Mientras las entidades territoriales realizan los ajustes requeridos en su estructura orgánica para el desarrollo de las competencias de vigilancia y control de los factores de riesgo del ambiente, de conformidad con lo dispuesto en el numeral cuarto del capítulo VI de la Sentencia de la Honorable Corte Constitucional No C-617 de 2002, los departamentos podrán celebrar contratos para el desarrollo de dichas funciones, siempre y cuando estos se realicen con otras entidades del Estado, se fijen los derechos y obligaciones de las entidades delegante y delegataria y la delegación sea de carácter temporal.

9. FORMULACION DEL PLAN ESTRATÉGICO DEL PAB 2004 - 2007 Y DE LOS PLANES OPERATIVOS ANUALES DEL PAB. Es responsabilidad de los alcaldes de los municipios y distritos y de los gobernadores formular el Plan Estratégico del PAB para las vigencias $2004-2007$, en el que se definan los objetivos para el periodo y los resultados esperados para cada año en el logro de las metas en salud pública definidas por la Nación y el cumplimiento de las competencias establecidas en la Ley 715 de 2001.

Hoja 5 de 7 
Ministerio de la Protección Social

República de Colombia

Despacho del Ministro

likercd; [ D tes

Para el desarrollo del Plan Estratégico, anualmente se deberá formular un Plan Operativo que discrimine las actividades que se desarrollarán para el logro de los resultados esperados en el año, en función de los recursos disponibles en cada vigencia en el respectivo nivel territorial.

La formulación de estos Planes deberá sujetarse a las actividades de estricto cumplimiento definidas para cada nivel territorial en el Anexo Técnico de la presente Circular y presentarse en los formatos establecidos para el efecto en el mismo.

10. APROBACIÓN DE LOS PLANES ESTRATÉGICO Y OPERATIVOS DEL PAB. En cumplimiento de lo establecido en el Artículo 46 de la Ley 715 de 2001, corresponde a los Consejos Territoriales de Seguridad Social en Salud, dirigir la elaboración del Plan de Atención Básica en su jurisdicción. En consecuencia, el Plan estratégico del PAB de los departamentos, distritos y municipios deberá presentarse al Consejo Territorial de Seguridad Social en Salud respectivo, para la revisión y aval correspondiente, a más tardar el 30 de marzo de 2004, para su incorporación al Plan de Desarrollo Territorial. Igual trámite se adelantará cada año con el Plan Operativo Anual antes de finalizar el primer trimestre de la vigencia correspondiente.

Para el cumplimiento de lo anterior, las direcciones departamentales de salud deberán brindar asistencia técnica y realizar monitoreo sobre la conformación y operación de los Consejos Municipales de Seguridad Social en Salud, así como para la concertación, formulación y presentación de los Planes estratégico y operativos del $\mathrm{PAB}$ a este cuerpo colegiado.

Para su ejecución, los Planes de Atención Básica municipales no requieren concepto previo de viabilización por parte del departamento, ni los departamentales y distritales aprobación previa por parte de la Nación.

11. CONCERTACION DEL PLAN DE ATENCION BASICA CON GRUPOS ETNICOS: Cuando en la entidad territorial existan grupos étnicos legalmente reconocidos, la formulación del PAB debe incluir los procesos de consulta y concertación que establece la normatividad vigente, orientada a la adecuación etnocultural de las acciones a realizar.

12. EVALUACIÓN DEL PLAN DE ATENCIÓN BÁsICA. Para efectos de realizar el seguimiento y control, los departamentos y distritos deberán presentar a la Dirección General de Salud Pública del Ministerio de la Protección Social, antes del 30 de abril de la vigencia correspondiente los siguientes documentos:

a) Plan estratégico del PAB 2004 - 2007 (Sólo en la vigencia 2004)

b) Plan Anual Operativo del PAB de la vigencia correspondiente.

c) Certificados de aprobación de cada uno de los Planes emitidos por el CTSSS.

Hoja 6 de 7 
Anexo 3

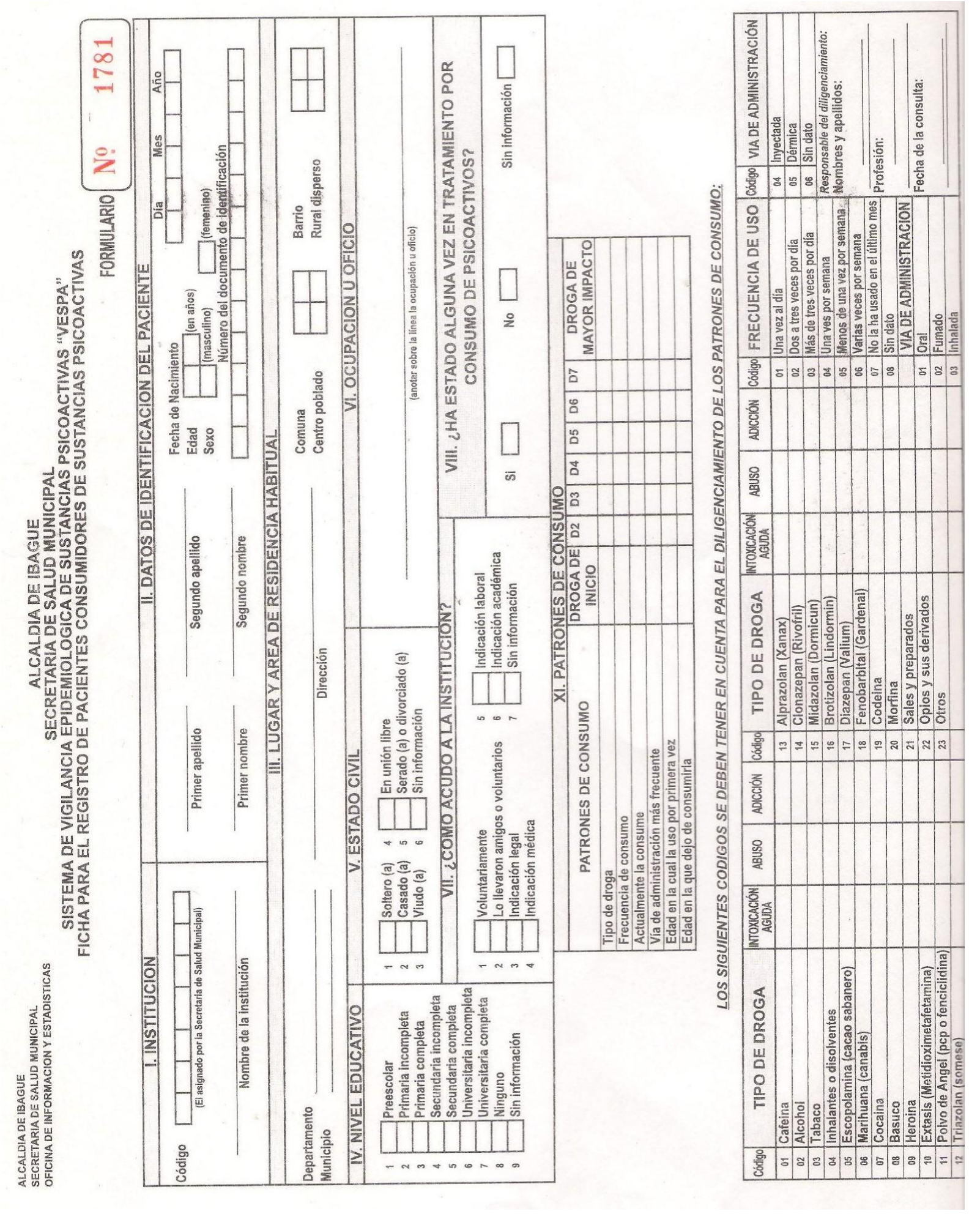

Formato del VESPA. 